\title{
Intersecting the Academic Gender Gap: \\ The Education of Lesbian, Gay and Bisexual America
}

\author{
Joel Mittleman \\ University of Notre Dame \\ Forthcoming in: \\ American Sociological Review
}

\section{Acknowledgments:}

This research benefited from the guidance and thoughtful feedback of the $A S R$ editors and three anonymous reviewers as well as Jennifer Jennings, Sanyu Mojola, Danya Lagos, Simone IspaLanda, Abigail Ocobock, Erin Metz McDonnell, Marta Tienda, Sara McLanahan and seminar participants in Notre Dame's Center for Research on Educational Opportunity. The analyses reported here would not be possible without the generations of researchers, activists and public servants who made LGBTQ lives visible in population research.

\section{Funding:}

The research reported here began at the Princeton University Office of Population Research, with the support from The Eunice Kennedy Shriver National Institute of Child Health \& Human Development of the National Institutes of Health under Award Number P2CHD047879.

\section{Key Words:}

Education, Gender and Sexuality, Stratification, LGBTQ Studies

\section{Correspondence:}

Joel Mittleman, University of Notre Department of Sociology, 4081 Jenkins Nanovic Hall, Notre Dame, IN 46556. Phone: 574-631-6463. Email: jmittlem@nd.edu 


\section{ABSTRACT}

Although gender is central to contemporary accounts of educational stratification, sexuality has been largely invisible as a population-level axis of academic inequality. Taking advantage of major recent data expansions, the current study establishes sexuality as a core dimension of educational stratification in America. First, I analyze lesbian, gay and bisexual (LGB) adults' college completion rates: overall, by race/ethnicity and by birth cohort. Then, using new data from the High School Longitudinal Survey of 2009, I analyze LGB students' performance on a full range of achievement and attainment measures. Across analyses, I reveal two demographic facts. First, women's rising academic advantages are largely confined to straight women: although lesbian women historically outpaced straight women, in contemporary cohorts, lesbian and bisexual women face significant academic disadvantages. Second, boys' well-documented underperformance obscures one group with remarkably high levels of school success: gay boys. Given these facts, I propose that marginalization from hegemonic gender norms has importantbut asymmetric — impacts on men and women's academic success. To illustrate this point, I apply what I call a "gender predictive" approach, using supervised machine learning methods to uncover patterns of inequality otherwise obscured by the binary sex/gender measures typically available in population research. 
The "rise of women" in education is among the central demographic transformations of the last half century. For every birth cohort since 1960, women have increasingly outpaced men in educational attainment (DiPrete and Buchmann 2013). Men still dominate popular perceptions of brilliance (Musto 2019) and maintain majorities in certain persistently segregated fields (Leslie et al. 2015). Overall, though, the "new gender gap" in education is defined primarily with reference to "boys' notorious underperformance" (Legewie and DiPrete 2012:463). From kindergarten classrooms (DiPrete and Jennings 2012) through programs of doctoral study (England, Levine and Mishel 2020), men now lag behind women on most measures of school success. This "problem with boys" has attracted the attention of scholars, policymakers and the popular press.

In explaining these patterns, sociologists have emphasized the social dynamics of gender over and above the purported dictates of sex. The gender gap, sociologists show, is not an immutable fact of biology; it is a contingent product of students' social positions and social contexts. To illustrate this fact, stratification research has uncovered the considerable heterogeneity in men and women's academic outcomes, analyzing variation across birth cohorts (DiPrete and Buchmann 2013), family resources (Buchmann and DiPrete 2006), race/ethnicity (Hsin 2018) and school context (Legewie and DiPrete 2012).

Within this body of research, one central axis of inequality has gone largely unobserved: Sexuality. For decades, sexuality has been invisible in the demographic surveys and administrative data sources used to analyze population-level patterns of academic performance (Wimberly 2015). One important exception is the Add Health study, which enabled a generation of research on lesbian, gay and bisexual (LGB) students' achievement and attainment (e.g., Pearson, Muller and Wilkinson 2007; Mollborn and Everett 2015). Still, that research came to 
inconsistent conclusions and captured the experience of just one cohort: a cohort that left high school about twenty-five years ago.

The relative invisibility of sexuality in educational stratification research is consequential because sexuality intersects gender in a uniquely fundamental way. "Heterosexuality," as Meadow (2018:53) puts it, "underwrites much of what we think of as gender." Inherent in what it means to "do gender" is the mandate to "do heterosexuality" (Schilt and Westbrook 2009). This is especially true for school-aged boys, for whom the fear of becoming a "fag" is a central concern (Pascoe 2007). In this way, LGB ${ }^{1}$ students, generally—and LGB boys, in particularprovide a unique opportunity to reexamine the impact of gender on school success. If existing research has documented the consequences of hegemonic gender norms, then LGB students offer a chance to uncover how gender shapes school success from "the perspective of the margins" (Compton, Meadow and Schilt 2018:17).

Fortunately, it has recently become possible to study America's LGB populations in important new ways. Taking advantage of major recent expansions in sexual identity data, the current study incorporates LGB students into contemporary understandings of educational stratification. In so doing, I advance a new, more fully intersectional account of the gender gap in education. Across datasets and outcomes, I find consistent evidence that sexuality is a highly consequential axis of academic inequality, albeit in ways that vary sharply by sex. As a whole, my results reveal two core demographic facts. First, "the rise of women" should be understood more precisely as the rise of straight women. Second, "the problem with boys" obscures one group with rather remarkable levels of academic success: gay boys. 


\section{THE GENDER GAP IN EDUCATION}

The Rise of Women Amid an Asymmetric Gender Revolution

By one measure, girls have always outperformed boys in the classroom. For as long as we have had data on it, girls have earned better grades from their teachers (DiPrete and Buchmann 2013). What changed over the $20^{\text {th }}$ century, therefore, was not so much women's academic performance, but rather the societal constraints and incentives governing women's academic investments. Until relatively recently, patriarchal laws and norms required women to choose between higher education, on the one hand, and marriage and family, on the other (Goldin, Katz and Kuziemko 2006; DiPrete and Buchmann 2013). At the same time, limited access to contraceptive technology meant that women's educational careers were often cut short by fertility (Bailey and Lindo 2017). As a result of these mutually reinforcing forces, for most of the $20^{\text {th }}$ century, never married women earned college degrees at substantially higher rates than their married peers (Isen and Stevenson 2010). As these external constraints eased, women's "latent advantage in academic performance" expressed itself in rapidly rising educational attainment (DiPrete and Buchmann 2013:201).

In contrast to women's swift gains across cohorts, men's educational attainment has remained remarkably flat for decades. Strikingly, men born after 1980 are just slightly more likely to have a BA than those born before 1950 (DiPrete and Buchmann 2013). This stalling out is particularly surprising because it occurred during a period when the economic incentives for college completion grew ever stronger (Goldin and Katz 2008).

From a rational choice perspective, men's human capital investments are difficult to explain. From a gender perspective, however, men's academic stagnation is directly in line with the broader rigidity observed among men over the last half century. The "gender revolution" was 
asymmetric: allowing certain profound changes for women, but involving far fewer changes by men (England 2010). Women gained access to previously male-exclusive educational and professional opportunities, but men's educational and occupational choices remained largely unchanged (Charles and Bradley 2009). Women's wage labor became an increasingly essential component of household income, but men's domestic labor failed to compensate accordingly (Hochschild and Machung 1989). More fundamentally, femininity expanded to allow certain activities and attributes historically restricted to men, but masculinity has remained stubbornly narrow and anxiously focused on repudiating effeminacy.

\section{Masculinities in the Classroom}

It is this pressure to enact a certain kind of masculinity that is at the heart of sociological accounts of boys' academic underperformance. A long tradition of ethnographic research shows how boys' adolescent peer groups denigrate academic effort and valorize school-related rebellion (Coleman 1961; Willis 1981; MacLeod 1987; Morris 2012). ${ }^{2}$ As Morris (2012:70) shows in his ethnography of working-class American high schools, boys who work hard and play by school rules are mocked as "gay" by their peers (Morris 2012:70). Similarly, in her study of British secondary schools, Epstein (1998) finds that boys who appear committed to schoolwork get called "queer" by classmates (DiPrete and Buchmann 2013:168).

Masculinities research suggests that the choice of insult in these studies is not incidental. “To call someone gay or fag," one boy explained to Pascoe (2007:55), "is like the lowest thing you can call someone." Connell (1995:78) formalizes this boy's intuition, arguing that "gayness...is the repository of whatever is symbolically expelled from hegemonic masculinity." Therefore, in labeling academically committed boys "gay," peers are drawing a distinctly sharp boundary: casting open investment in school outside the bounds of acceptably masculine 
practice. Being seen as naturally "brilliant" doesn't necessarily threaten boys' masculinity (Musto 2019), especially if they successfully display an air of "contrived carelessness" (Morris 2012). However, at least in certain contexts, visibly working hard in school is feminized; being a real man and being a conscientious student are incompatible.

\section{Femininity Premiums and "Bad Girl" Penalties}

Currently, it is boys' failure to adapt to the knowledge economy that is puzzling. Historically, though, it was girls' academic success that struck sociologists as an intriguing anomaly (Mickelson 1989). Why did girls academically outperform boys even in cohorts when women's achievement was unlikely to yield an economic payoff? At least part of the answer, sociologists proposed, lies in girls' gender socialization and the gendered interpretation of behavior by teachers (e.g., Mickelson 1989; Entwisle, Alexander and Olson 2007). "Girls," in this account, "are raised to conform to the expectations dictated by adults and authorities, including following the academic 'rules"” (Riegel-Crumb, Kyte and Morton 2018:135).

In this tradition, a central component of female students' success in the classroom lies in their adhering to the "good girl" role. This requires, at a minimum, being modestly feminine in dress, soft-spoken in speech and deferential in behavior. More recent research has underscored the raced and classed dimensions of the "good girl" role, clarifying the extent to which these expectations reflect White, middle-class standards of femininity (e.g., Morris 2007; Jones 2010; Ispa-Landa 2013). In this way, favorable treatment by teachers is an early example of what Hamilton et al. (2019) call "femininity premiums:" the benefits that intersectionally accrue to women for successfully enacting hegemonic femininities.

What unifies the various dictates of being a "good girl" is the fundamental mandate that women should remain distanced from and deferential to masculinity (Schippers 2007; Manne 
2017). Just as the specter of effeminacy polices the borders of masculinity among boys, the "bad girl" penalty punishes girls who stray too far from the constraints imposed by femininity. Pascoe's (2007) research illustrates this fact. Of all the teenage girls who "dressed, talked and carried themselves in many ways 'like guys'...none were strangers to the disciplinary system" $(115,154)$.

\section{GENDER, SEXUALITY AND SCHOOL SUCCESS}

\section{The Interconnectedness of Gender and Sexuality}

In sketching out sociological explanations for the academic gender gap, we see that gender operates at multiple levels across distinct historical contexts. At the macro-historical

level, women's educational attainment was long constrained by a patriarchal system organized around male breadwinners. In the contemporary period, gendered academic patterns persist, at least in part, because of dynamics enforced at the interactional level: through the pressure to normatively "do gender" in ways rewarded by peers and teachers. Incorporating sexuality into the study of educational stratification throws both of these explanations into sharper relief.

At the macro-historical level, it was not simply a patriarchal system that long constrained women's education; it was a heteropatriarchal system. When previous accounts of women's rising educational attainments describe the changing dynamics of $20^{\text {th }}$ century marriage markets (Goldin, Katz and Kuziemko 2006; DiPrete and Buchmann 2013), they leave unacknowledged that what they're actually describing are straight marriages: Marriage wasn't extended to all women until the $21^{s t}$ century. As such, for LGB women, the dynamics governing the "rise of women" may have been quite different.

At the interactional level, the pressure to normatively "do gender" draws much of its disciplinary power from homophobia, especially among boys (Connell 1995; Pascoe 2007). 
Although previous accounts of boys' underachievement attest to the pervasiveness of homophobia in boys' peer cultures (Epstein 1998; Morris 2012), they are unable to access the perspectives of those most directly targeted by such cultures: LGB boys themselves. For LGB boys, the pressure to prove one's manhood through academic disengagement could feel particularly strong, but it also might feel liberatingly absent.

In all these ways, making sexuality visible provides an opportunity to more fully refine existing explanations for the academic gender gap. However, I argue that studying LGB students also encourages new ways of measuring gender and conceptualizing its impact on school success. Because it is not just at the level of institutions and ideology where gender and sexuality intertwine. Across the life course and along a range of measures, sexuality also consistently stratifies how gender is enacted in everyday life.

Beginning in early childhood, "gender and sexuality evolve in an intricate relationship to one another" (Meadow 2018:42). As such, a large literature finds that nonconforming gendertyped behavior —on such measures as preferred playmates, toys and activities-is a common, though certainly not universal, feature of gay/lesbian childhoods (e.g., Rieger et al. 2008; Li, Kung and Hine 2017). These early play preferences also manifest later in life in terms of occupational aspirations (Lippa 2000) and realized occupational destinations (Tilcsik, Anteby and Knight 2015), with multiple studies finding that "gay men and lesbians are more likely to cross gender boundaries in the professions" (Baumle, Compton and Poston 2009:168). Although these kinds of gendered preferences and behaviors are fluid over time and across contexts, what this research shows is that —at given snapshots of time - gay and lesbian populations are, on average, significantly more gender atypical than straight populations. 
Alongside these patterns of preferences and behaviors, sexuality also stratifies more direct, embodied measures of gender expression. For instance, between 2017 and 2019, ten cities across America asked representative samples of high school students the question: "A person's appearance, style, dress, or the way they walk or talk may affect how people describe them. How do you think other people at school would describe you?” and provided seven response options, ranging from "very feminine” through "very masculine." Figure 1 presents teens' average responses, separately by sex and sexual identity; Online Figure 1 displays the full distribution of results.

\section{[ Figure 1 About Here ]}

Within both sex-based groups in Figure 1, the same pattern emerges: gay/lesbian teens report significantly more nonconforming gender expression than bisexual teens, who, in turn, report more nonconforming expression than straight teens. The full distribution of responses, shown in Online Figure 1, underscores these patterns. Among both sexes, straight teens hew closely to the "very" and "mostly" masculine/feminine categories. By contrast, bisexual—and, especially, gay and lesbian - teens are more fully represented throughout the masculine-feminine spectrum. Although only 3\% of straight-identified girls report feeling seen as somewhat-to-very masculine, $7 \%$ of bisexual and $32 \%$ of lesbian girls report feeling seen along the masculine spectrum. Among boys, $26 \%$ of bisexual and $45 \%$ of gay boys report feeling seen along the feminine spectrum compared to only $9 \%$ of straight boys.

Emerging across these multiple measures - the styles that feel natural or foreign, the friends and interests that excite or repel, the way one sounds (Lagos 2019) or holds their bodyis the sense that $\mathrm{L} / \mathrm{G} / \mathrm{B}$ and straight populations gravitate, on average, toward different locations 
within a spectrum of gendered possibilities. Historically, sociologists have had few tools to make these distinct locations visible. Instead, when describing population-level patterns of academic inequality, research has largely relied on surveys that include only "starkly dichotomous" measures that conflate gender and sex (Westbrook and Saperstein 2015:535). In such studies, "masculinity" and "femininity" come to be seen only as a property of male- or female-assigned bodies, rather than as "a subjectivity that is enduring, stable and divorced from the body" (Meadow 2018:52). LGB youth underscore the limitations of such an approach, encouraging new measurement methods that allow a more continuous spectrum of masculinity and femininity to be untethered from binary sex.

\section{LGB Students in America's Schools}

Schools are famously inhospitable spaces for LGB youth. A longstanding research tradition has examined the social and psychological aspects of LGB students' school experiences, documenting bullying (e.g., Toomey and Russell 2016), discriminatory policies and practices (e.g., Kosciw et al. 2018), and the heavy toll that unsafe school contexts take on LGB students' mental health (e.g., Russell and Fish 2016). Given these facts, some have concluded that schools are "the most homophobic of all social institutions" (Aragon et al. 2014:2).

Within this literature, however, LGB students' core academic outcomes have been largely unobservable. Given the psychosocial strains that LGB students face, one might expect that they would struggle academically as well. However, given the sharp gender-typing of academic performance, there are also many reasons why the academic outcomes of LGB boys could be very different from those of LGB girls.

For LGB boys, precisely those aspects of gender that are socially costly could also be academically beneficial. If locally dominant norms of masculinity denigrate academic 
investment, then being alienated from those norms — and excluded from the peer groups that promote them—could be tremendously beneficial. Similarly, in contexts where teachers criminalize boys' masculinities from an early age (e.g., Ferguson 2000; Rios 2011), those with less normatively masculine gender enactments might endure peer sanctions but actually avoid the more formalized sanctions imposed by school officials (Mittleman 2018).

For LGB girls, to the extent that students construct academic engagement as feminine, an internally felt aversion to "girliness" may encourage some to view school skeptically. This internal feeling could find external reinforcement in how LGB girls are treated by school officials. To the extent that teachers see LGB girls as enacting masculinity, this could make them prime targets for the "bad girl" penalty identified by previous research. This risk could be especially high for Black girls, who are already stereotyped as masculine by white authority figures (Jones 2010; Ispa-Landa 2013). In this way, LGB identities could be doubly disadvantaging for girls: both socially risky and academically costly.

\section{Existing Evidence and the Invisibility of Sexuality in Population Data}

Research into these kinds of possibilities has long been hampered by severe data limitations. For decades, researchers had to fight even for the acknowledgement that there was an LGB population (Gates 2012). Although that fight may seem won, the majority of America's demographic surveys still do not include information on sexual orientation (National Academies of Sciences, Engineering, and Medicine 2020). A recent review found that, of over 100 ongoing federal surveys, only 11 assessed sexual orientation (Velte 2020). Researchers studying gay and lesbian adults have used the same-sex partnerships revealed in the household rosters of core demographic surveys like the American Community Survey and the decennial census (e.g., Gates and Ost 2004; Baumle, Compton and Poston 2009). However, partnership data reveal only 
a selective subset of the gay and lesbian population while at the same time mislabeling bisexuals in both same-sex and other-sex partnerships. Moreover, given the sharp stratification of cohabitation patterns by educational attainment (e.g., McLanahan 2004), partnership data are particularly ill-suited for studying educational outcomes.

Even as data on LGB populations are generally sparse, data on LGB students have been even more uncommon. In a context where six states still have so-called "No Promo Homo" laws forbidding the acknowledgement of homosexuality in public schools (GLSEN 2018), research on student sexuality has faced steep opposition (Wimberly and Battle 2015). Measures of student sexual orientation have become increasingly available in health surveys - such as those administered through the CDC's Youth Risk Behavior Surveillance system-but these surveys include few questions, if any, about academics.

Given these limitations, most population-based research on LGB students' academic outcomes has relied on just one study: Add Health. Tracking a cohort of middle and high school students from 1994 on through adulthood, Add Health enabled a generation of research on LGB achievement and attainment. This research supports the intuition that LGB boys and girls face divergent academic experiences, but it came to conflicting conclusions about the direction of these effects.

In an early study, Pearson, Muller and Wilkinson (2007) used a same-sex attraction measure reported at baseline and found that same-sex attracted boys, but not girls, left high school with lower GPA's, lower rates of advanced course taking and higher rates of course failure. Notably, however, later Add Health research came to directly reversed conclusions. Using a sexual identity measure reported in adulthood, Mollborn and Everett (2015) found that men identifying as "mostly gay" or "entirely gay" actually graduated high school with 
significantly higher GPA's than straight men and went on to enroll in college at much higher rates. Other studies further parse LGB students' outcomes by school urbanicity and culture (Wilkinson and Pearson 2009) as well as by the timing and consistency of reported sexuality (Walsemann et al. 2014; Pearson and Wilkinson 2017). All told, it is difficult to draw consistent conclusions from this pioneering body of work. Moreover, the Add Health data capture only one birth cohort: a cohort whose experiences may have been very different both from those born long before them as well as those born more recently.

Research examining the educational attainment of LGB adults comes to similarly mixed conclusions. Demographic profiles that identify gay and lesbian adults using partnership data consistently note that same-sex households have higher rates of educational attainment than other-sex households (Black et al. 2000; Gates and Ost 2004; Black, Sanders and Taylor 2007). However, the limitations of partnership data make it difficult to interpret these findings. Therefore, it is notable that Gates' (2014:7) review of four population-based surveys with direct measures of sexual identity concluded that "findings regarding educational attainment did not show a completely consistent pattern across surveys."

Some of the inconsistencies of existing research are surely due to the fact that, as a comparatively small population, L/G/B respondents yield only limited sample sizes in nationally representative surveys. Such limited samples not only generate unstable estimates, they also prevent analyses of how sexuality further intersects with other aspects of identity and context. For instance, generations of intersectional scholarship have highlighted the distinct experiences of Black lesbian women (Combahee River Collective 1983; Collins 2004; Moore 2011), a group obscured in analyses that combine all lesbian women together. Similarly, LGB Americans' 
academic outcomes are likely to vary substantially by birth cohort, both because of the rapid progress in LGBTQ rights and because of the sweeping rise of women more broadly.

\section{SUMMARY AND CURRENT CONTRIBUTIONS}

Taken together, existing research is marked by conflicting findings and critical limitations. Fortunately, new data makes it possible to more comprehensively incorporate LGB students into contemporary accounts of educational stratification. During President Obama's second term, there was a coordinated effort across the federal research apparatus to expand the collection of sexual orientation measures (Federal Interagency Working Group 2016). As a result, sexual identity measures were added to three of America's largest, longest-running nationally representative household surveys: The National Health Interview Survey (NHIS), the National Survey on Drug Use and Health (NSDUH) and the National Crime Victimization Survey (NCVS). At the same time, the National Center for Educational Statistics (NCES) received approval to ask about students' sexual identity in the latest wave of its High School Longitudinal Survey of 2009 (HSLS). The most recent in NCES' longstanding cohort series, HSLS is the first such study to ever assess student sexuality. Taking advantage of these new data, the current study makes three primary empirical contributions.

First, I analyze how sexuality stratifies bachelor's degree (BA) attainment among American adults, attending to variation by sex, race/ethnicity and birth cohort. Using every available wave of the NHIS $(N=197,277)$, NSDUH $(N=149,189)$ and NCVS $(N=141,567)$, these analyses reconstruct "the rise of women" across $20^{\text {th }}$ century birth cohorts while also revealing BA attainment rates among $\mathrm{L} / \mathrm{G} / \mathrm{B}$ women and men.

Second, I complement these population-level analyses with a more granular examination of contemporary L/G/B students' experiences during and after high school. Drawing on 
restricted-use transcript and survey data from the $\operatorname{HSLS}(N \approx 15,270),{ }^{3} \mathrm{I}$ examine how sexuality stratifies a comprehensive set of academic performance measures as well as multiple indicators of discrimination and minority stress (Meyer 2003).

Finally, I test whether L/G/B women and men's disparate academic outcomes reflect their distinct positions within a spectrum of masculinity/femininity. To do this, I extend existing "gender diagnosticity" techniques (e.g., Lippa and Connelly 1990; Yavorsky and Buchmann 2019) to take advantage of advances in supervised machine learning algorithms. I propose that this approach—what I call a "gender predictive" approach—could have application across a range of empirical contexts as a valuable tool for flexibly summarizing gendered inequalities along a continuous distribution rather than collapsing them into a single, binary difference.

\section{DATA AND METHODS:}

\section{Data:}

Adult Population: To document the educational attainment of LGB adults, I draw on three federally-sponsored household surveys: the NHIS, the NSDUH, and the NCVS. Each of these studies have long been key parts of the federal research apparatus, conducted annually since 1957, 1971, and 1972, respectively. Unlike other federally-sponsored surveys used to study LGB populations (e.g., BRFSS, NHANES and NSFG), the NHIS, NSDUH and NCVS are representative of the entire civilian, noninstitutionalized adult population of the United States, not just adults in specific states or specific age ranges. For each survey, I use every wave that included a sexual identity measure: seven waves for NHIS (2013-2019), five waves for NSDUH (2015-2019), and three waves for NCVS (2017-2019). 
High School Cohort: The fifth and most recent high school cohort study sponsored by NCES, the HSLS follows a sample of public and private school students who were in $9^{\text {th }}$ grade in 2009. From this study, I analyze three waves of student surveys: a baseline survey in 2009, a follow up survey from spring 2012 (when most students were in $11^{\text {th }}$ grade), and a postsecondary survey, administered from March 2016 to January 2017. To analyze students' course-taking and achievement, I also draw on students' official transcripts provided by their high schools and postsecondary institutions.

\section{Measures:}

Dependent Variables

I examine three broad domains of outcomes: educational attainment, achievement and academic orientation, and discrimination/minority stress. ${ }^{4}$

Educational Attainment: In studying the adult population, I document three levels of educational attainment: at least a high school diploma, at least a bachelor's degree and a professional/ doctoral degree (JD, MD, $\mathrm{PhD})$. Of these, my primary outcome of interest is a binary measure of whether the respondent reports having earned a four-year college degree or higher ("BA attainment"). In the HSLS, students following an on-time, direct progression from high school through college would have been in their junior year of college at the time of the latest survey. Therefore, my primary HSLS attainment measure is an indicator of whether students reported that they were currently enrolled at a four-year institution pursuing a bachelor's degree ("BA enrollment"). I also report whether HSLS students report having earned a high school diploma and whether they report ever "dropping out" of high school (defined as withdrawing for more than 4 consecutive weeks, other than for vacation or illness). 
Achievement and Academic Orientation: The HSLS transcript and survey data allow me to complement these binary attainment measures with rich measures of achievement and academic orientation. From students' official transcripts, I analyze three outcomes: high school GPA, postsecondary GPA and high school curricular intensity. Both GPA measures were computed by NCES on a continuous four-point scale. Among those who pursued further education after high school, the post-secondary GPA measure reflects their cumulative performance across all courses in which they earned credits by 2017 . To construct a high school curricular intensity scale, I adopt Austin's (2019) approach, which uses four transcript variables: the student's highest math class, total science credits, total English credits and whether they took an AP class.

To assess students' broader academic orientation during high school, I use student survey data to construct three measures: An academic behaviors scale, an academic attitudes scale and a friends' academic orientation scale. The behaviors scale includes four items on rule following (e.g., "how often do you go to class late") and three items on the amount of time spent on homework. The attitudes scale includes items five items on students' beliefs about the importance of high school for later life success (e.g., "high school is often a waste of time"). Finally, the friends scale includes four items on how many of the students' "close friends" "get good grades," "have ever dropped out of high school," "have taken college admissions tests" and "plan to attend a 4-year college."

To construct all of these scales, I conducted polychoric factor analyses to account for the non-continuous nature of the underlying variables. In each case, the first principal component effectively summarized the measures: only the first principal components had eigenvalues over 1 and each explained at least $50 \%$ of the underlying variation. Therefore, I extracted the first 
principal component from each factor analysis and standardized them to a mean of zero and standard deviation of one.

Discrimination and Minority Stress: Finally, to situate HSLS students' academic outcomes within their broader school experiences, I also analyze three measures of discrimination and minority stress. First, I analyze whether, as $9^{\text {th }}$ graders, they disagreed with the statement "I feel safe in this school." Then, from the postsecondary survey, I analyze whether students reported that "discrimination or unfair treatment based on a personal characteristic has limited [my] educational opportunities" as well as whether they ever had "serious difficulty concentrating, remembering, or making decisions [because of] an emotional or mental health issue."

\section{The Complexity of Operationalizing Sexuality in Population Research}

From a certain queer perspective, attempting to silo individuals into discrete, stable "sexual orientations" is epistemically fraught, at best, and entirely misguided, at worst (Compton, Meadow and Schilt 2018). Even firmly within a positivist framework, however, empirical complexities abound. Sexuality is multifaceted: constituted by attractions, behaviors and identifications that may not align (e.g., Silva 2019; Mishel 2019). Sexuality is concealable and may be underreported on surveys (Coffman, Coffman and Ericson 2017). Finally, sexuality is fluid and sexual identification may evolve across the life course (e.g., Diamond 2008; Moore 2011). Demographic research on LGB populations often elides these complexities, relying on point-in-time sexual identity measures that fail to capture to the multidimensionality of sexuality itself. Although this study faces some of the same limitations, I work to address each of these complexities — multifacetedness, underreporting and fluidity—in a few key ways. 
For my primary analyses, I use sexual identity measures reported at a single point in time. Across all surveys, the exact question wordings were nearly identical, asking variations of "Which of the following best represents how you think of yourself?" All surveys included the following response options: "Lesbian or Gay," "Straight, that is, not lesbian or gay," "Bisexual," "I don't know the answer," and "Refused." To clarify the presentation of results, I focus only on comparisons between lesbian, gay, bisexual and straight respondents; complete regression results including the other groups are included in the Online Supplement.

Given the potential limitations of these point-in-time sexual identity measures, I take three steps to address the concerns above. First, to address multifacetedness of sexuality, I replicate my results using a sexual attraction measure included in the NSDUH. Second, to address the possible underreporting of sexuality, I replicate my results not just across surveys but also across survey administration modes, comparing results from face-to-face interviews (as in the NHIS and NCVS) with results from privately completed self-administered questionnaires (as in the NSDUH). Although LGB identities may still be underreported on private, selfadministered questionnaires, previous research shows that such techniques yield higher rates of reported LGB identification (Williams Institute 2009). Finally, to address concerns about the fluidity of sexuality, I conduct sensitivity tests exploring the possibility that college itself may reshape students' perceived possibilities for sexual identification. To do this, I draw on a nationally representative study of recent college graduates, the 2016-17 Baccalaureate and Beyond Longitudinal Study (B\&B:16/17)

\section{Analytic Approach:}

For all outcomes, I present two forms of evidence. First, I present purely descriptive statistics, separately by sex and sexual identity. Then, to assess whether these descriptive results 
could reflect selective patterns of LGB identity reporting across demographic groups, I also present regression-adjusted results. Across all models, the key coefficients of interest are the two- and three-way interactions between L/G/B identity, sex, and other aspects of identity (e.g., race/ethnicity, birth cohort). All descriptive statistics and regression analyses are weighted to reflect complex sampling procedures. To facilitate comparisons across models and simplify the interpretation of two- and three-way interaction effects, I present all regression results in terms of average adjusted predictions and average marginal effects (Breen, Karlson and Holm 2018). Complete regression results are included in the Online Supplement.

\section{Analytic Samples:}

Adult Samples: I replicate my primary results across three samples of American adults. To allow time for respondents to complete a four-year degree and to be consistent with Census Bureau reporting standards, I restrict these samples to respondents aged 25 or older. Given low levels of missingness on all variables, I use listwise deletion to reach analytic samples of 197,277 for the NHIS, 149,189 for the NSDUH, and 141,567 for the NCVS.

HSLS Sample: Of the $\sim 21,440$ students included in the HSLS baseline sample, $\sim 17,340$ participated in the most recent survey wave. Of these, about $\sim 1,470$ respondents only completed an abbreviated version of the survey, which did not include the sexual orientation measure. From that initial sample of $\sim 15,870$, I reach my final analytic sample of $\sim 15,270$ by excluding those without information on post-secondary enrollment $(N \approx 70)$ and those who did not answer the sexual identity question $(N \approx 530) .{ }^{5}$ Given these multiple exclusions and the relatively high level of attrition, it is important to note that the analytic sample is no longer strictly generalizable to a 
well-defined population. Instead, it should be understood only as a geographically diverse, population-based cohort of American high school students.

After sample restrictions, remaining levels of missing data were relatively low: about 5\% for high school transcript data and $9 \%$ for student survey data. To address missing data, I implemented multiple imputation by chained equations, producing five imputed datasets. All covariates used in this study were included in the imputation equations. Analyses conducted using only unimputed complete cases produced substantively identical results.

Sample Descriptions: Table 1 summarizes the data sources. Across all household surveys, estimates for the size of the gay and lesbian population are rather consistent. Notably, this consistency is not just across data sources, but also across data collection techniques. Estimates for the size of bisexual population are less consistent across surveys and appear to be potentially sensitive to the mode of survey administration, with the NSDUH yielding a bisexual sample roughly three times larger than the others.

\section{[ Table 1 About Here ]}

Within the HSLS sample, reported rates of gay and lesbian identity are somewhat higher than in the adult population at large. The more striking difference, however, is the substantial increase in bisexuality among women. In the HSLS sample, about $7 \%$ of women but only about $2 \%$ of men identify as bisexual. In Online Figure 2, I show that this pattern—of sharply rising bisexuality among younger cohorts of women, but not men (England, Mishel and Caudillo 2016) - is replicated across the NHIS, NSDUH and NCVS. By contrast, reported rates of gay and lesbian identity increased slightly over the first three birth cohorts, but have been stable from the 1960-69 birth cohort onward. These contrasting cohort patterns - the relative stability of 
gay/lesbian identification but sharp rise in bisexual identification—have important implications for the interpretation of cohort trends in BA attainment, a point to which I return below.

\section{RESULTS}

\section{Study 1: Educational Attainment Among American Adults}

\section{Descriptive Statistics}

Table 2 presents descriptive statistics on the educational attainment of American adults, separately by sex and sexual identity. Compared to straight adults of the same sex, gay men and lesbian women both report consistent advantages at every level of educational attainment. Gay men's successes especially stand out. In every dataset and across every level of educational attainment, gay men surpass all other groups. For example, the data indicate that about $6 \%$ of gay men in America have a JD, $\mathrm{MD}$ or $\mathrm{PhD}$, making them roughly $50 \%$ more likely to have an advanced professional degree than straight men. Bisexual-straight disparities, among both men and women, are generally smaller, less consistent in sign and rarely statistically significant.

\section{[ Table 2 About Here ]}

\section{Regression-Adjusted BA Attainment Rates}

To explore these descriptive results more fully, I estimate logistic regressions of BA attainment controlling for: race/ethnicity (constrained, due to sample sizes, to White, Black, Hispanic, Asian and Other), birth cohort (before 1950, 1950-59, 1960-69, 1970-79 and after $1980)^{6}$ and a measure of nativity (directly reported in NHIS and NCVS; proxied in NSDUH by whether the survey was completed in a language other than English). Figure 2 presents the

results of these regressions in terms of the average adjusted prediction from the two-way interaction of sex-by-sexual identity. 
[ Figure 2 About Here ]

Figure 2 underscores the consistency of results across datasets. In every survey, gay men's BA attainment levels are replicated nearly to the point estimate: $51.9 \%, 50.9 \%$ and $52.6 \%$ of gay men in the NHIS, NSDUH and NCVS, respectively, are estimated to have earned at least a BA. These are strikingly high levels of educational attainment. One way to contextualize the magnitude of gay men's BA attainment rates is to compare them internationally. As of 2019, America ranked $9^{\text {th }}$ in the world in terms of the percentage of adults who earned the equivalent of a BA or higher (National Center for Educational Statistics 2021: Table 603.30). However, if America's gay men were considered on their own, they would have, by far, the highest college completion rate in the world: easily surpassing the current leader, Luxemburg, at $46.6 \%$.

Lesbian women also significantly surpass most other groups of American adults, with an estimated $43.2 \%, 40.2 \%$ and $45.1 \%$ of lesbians in the NHIS, NSDUH, and NCVS, respectively, earning at least a BA. These, too, are high levels of college completion by both American and international standards. Bisexual-straight disparities remain small and are generally not significantly different from zero. Among men, bisexuals appear to slightly outperform straight men, though none of these differences reach statistical significance. Among women, bisexuals consistently face slight disadvantages. These disadvantages are particularly pronounced in the NSDUH, which is the dataset with the highest rate of reported bisexual identification.

\section{Moderation by Race/Ethnicity}

By combining all racial/ethnic groups, the overall population averages reported above may mask significant heterogeneity within the gay, lesbian and bisexual populations. To test this possibility, I re-estimate the models above, allowing the sex-specific effect of sexuality to vary 
by race/ethnicity. For ease of interpretation, Figure 3 presents this three-way interaction - sexby-sexuality-by-race/ethnicity — in terms of average marginal effects, summarizing the estimated disparities rather than presenting the full set of levels.

\section{[ Figure 3 About Here ]}

The results in Figure 3 reveal that, in every dataset, gay men's sizable BA advantage extends across the four largest racial/ethnic groups. Among White (non-Hispanic) men, Black men, Hispanic men and Asian men, gay men consistently surpass straight men by double digit margins. Gay men's academic advantages are perhaps especially striking among Asians, given the already high levels of academic success in the Asian population (Hsin and Xie 2014).

By contrast, lesbian women's overall BA advantage appears to be concentrated almost entirely among White lesbians. Although there is variation across datasets among Hispanic, Asian and "Other" women, all datasets are consistent in showing that Black lesbians have clearly been excluded from the educational advantages that historically accrued to White lesbians. Results for bisexuals are less precisely estimated and suggest few consistent disparities across racial/ethnic groups.

\section{Moderation by Birth Cohort}

In the final models for the adult population, I allow the sex-specific effect of sexuality to vary by birth cohort, estimating the three-way interaction of sex-by-sexuality-by-birth cohort. I present two sets of results. First, in Figure 4, I present the full range of birth cohorts, focusing on the gay, lesbian and straight populations. I present cohort-specific results for bisexuals in Online Figure 3, excluding them from Figure 4 because the concentration of bisexual identification among younger women yields insufficient sample sizes in earlier cohorts. Given this fact, I also 
present Figure 5, which focuses on those born after 1980 and includes results for bisexuals. To begin to describe the HSLS results alongside the adult surveys, Figure 5 also includes the observed BA enrollment rates of the HSLS cohort.

\section{[ Figure 4 About Here ]}

Focusing only on the straight population, the results in Figure 4 mirror the "rise of women" documented in previous research. Straight women's outcomes rise monotonically across cohorts, increasingly surpassing straight men from the 1960's birth cohort onward. By making sexuality visible, however, Figure 4 reveals that the straight experience reflects just one specific trajectory of population-level educational attainment. From the perspective of the gay and lesbian population, the history of the college gender gap looks quite different.

Across all birth cohorts, in every dataset, gay men maintain a large and statistically significant BA advantage: particularly over straight men, but also over straight women. By contrast, all datasets show that lesbian women in earlier birth cohorts had a sizable BA advantage over straight women, but this advantage has declined over time. This diminishing advantage reflects straight women's rising attainments, but also, more curiously, lesbian women's declining $\mathrm{BA}$ rates in recent cohorts.

\section{[ Figure 5 About Here ]}

Focusing just on contemporary cohorts, the results in Figure 5 illustrate a well-replicated pattern across datasets, including into the HSLS cohort. Among both men and women, bisexuals consistently report the lowest BA attainment/enrollment rates of all sexual identities, though it is only among women that these disadvantages reach statistical significance. Lesbian women's 
overall BA advantage, documented in Figure 2, is entirely absent in recent cohorts. Instead, in three of the four datasets, lesbian women have lower BA rates than straight women, though none of these disadvantages reaches statistical significance. Finally, across all datasets, gay men continue to surpass all other groups.

Summary of Study 1:

Bringing together three large, nationally representative household surveys, Study 1 establishes a number of well-replicated demographic facts. First, I find that - across datasets, racial/ethnic groups and birth cohorts_-gay men report remarkably high levels of educational attainment, surpassing not just straight men, but also straight women. Second, I find that lesbian women have an advantage over straight women, but this population average masks significant heterogeneity by race/ethnicity and birth cohort. On closer inspection, lesbian women's overall advantage appears to be almost entirely concentrated among older cohorts of White lesbian women. Third, at the population level, both bisexual men and women are roughly at parity with their straight counterparts. However, in recent cohorts - among whom reported bisexual identification is highest — bisexual men and, especially, women are disadvantaged compared to straight men and women. The HSLS data offer an opportunity to test whether the patterns documented in Study 1 persist into a more recent cohort and whether they extend across a broader set of school-related outcomes.

\section{Study 2: The Academic Experiences and Outcomes of the HSLS Cohort} Descriptive Statistics

As above, I first present descriptive statistics on the HSLS sample's outcomes, separately by sex and sexual identity. Table 3 presents these results. Across academic outcomes, the pattern 
of results largely reflects those documented in the post-1980 birth cohort above. Among boys, gay boys continue to outperform straight boys, whereas bisexuals are slightly disadvantaged on most outcomes. Among girls, both lesbian and bisexual girls are broadly disadvantaged, with bisexuals generally experiencing the worst outcomes. These patterns persist not just in the selfreported outcomes on surveys, but also in students' official transcripts, both in high school and among those who completed any postsecondary coursework $(N \approx 9,920)$. Notably, however, the patterns for academic outcomes shift with respect to the three measures of discrimination and minority stress. Despite their clear divides in academic performance, L/G/B boys and girls all report worse outcomes than straight students in terms of feeling unsafe in school, facing discrimination, and experiencing mental health challenges.

\section{[ Table 3 About Here ]}

\section{Regression-Adjusted Estimates}

To examine these descriptive results more fully, I estimate a series of survey-weighted ordinary least squares regression models controlling for students' race/ethnicity (White, Black, Hispanic, Asian, Native American and Other), native English speaking and a composite measure of socioeconomic status, constructed by NCES using both parents' education, income and occupation. To control for unmeasured aspects of students' school and local contexts, I include school fixed effects in all models. To facilitate the presentation of a wide range outcomes, Figure 6 presents the two-way interaction of sex-by-sexuality in terms of average marginal effects, focusing on the estimated disparities between L/G/B and straight women and men.

[ Figure 6 About Here ] 
Figure 6 reveals a number of important facts. First, these results demonstrate the breadth of gay boys' academic advantages. Compared to observably similar straight boys from the same high school, gay boys: earn substantially better grades in more advanced courses, drawing on more committed work habits while endorsing more pro-school school attitudes and connecting with more academically oriented close friends (all differences $\mathrm{p}<0.001$ ). Accordingly, gay boys' ultimate BA enrollment rates are about 18 percentage points higher than the straight boys from their high schools. As in the adult population, the magnitude of these advantages is striking. For instance, in the HSLS data, gay boy's 18 percentage point BA enrollment advantage is more than double the size of the overall female-vs.-male enrollment advantage ( 8 percentage points).

Second, compared to observably similar straight girls from the same high school, lesbian girls are broadly disadvantaged, though not all disparities reach statistical significance.

Compared to straight girls, lesbians receive worse grades $(\mathrm{p}=0.07)$ and appear to be much more alienated from culture of their schools, reporting less pro-school attitudes $(\mathrm{p}<0.05)$ and fewer academically oriented friends $(\mathrm{p}=0.07)$. Most troublingly, lesbian girls report "dropping out" of high school at substantially higher rates: an estimated $26 \%$ of lesbian girls report having dropped out at least once, surpassing straight girls by 11 percentage points $(\mathrm{p}<0.05)$.

Third, unlike the clear divide between gay boys and lesbian girls, both bisexual boys and girls are generally disadvantaged compared to their straight schoolmates. These disadvantages are particularly pronounced for bisexual girls, who report statistically significant disadvantages for every single academic outcome considered. For bisexual boys, the pattern of results is more complex. For several outcomes from high school, bisexual boys are almost at parity with straight boys. Nevertheless, something seems to be intervening in bisexual boys' lives that prevents them from translating high school performance into postsecondary enrollment. Compared to 
observably similar straight boys from the same high school, bisexual boys were about 10 percentage points less likely $(\mathrm{p}<0.01)$ to be enrolled for a BA at the time of the postsecondary survey.

Finally, Figure 6 underscores the dramatic divide between academic and non-academic outcomes for LGB students. Although not every disparity reaches statistical significance, each group of L/G/B students reports enduring higher levels of discrimination and minority stress than those reported by their straight schoolmates. The results in Figure 6 are especially notable for gay boys, given their high levels of academic success. These results show that gay boys' academic advantage is a domain-specific one and should not be interpreted as implying that their social experience of high school is any easier than that documented by previous research (e.g., Pascoe 2007; Toomey and Russell 2016).

\section{Summary of Study 2:}

Using the first NCES cohort study to ever assess student sexual orientation, Study 2 illustrates that sexuality is a consequential axis of academic inequality among contemporary American high schoolers. In most regards, the HSLS results extend and reinforce the patterns documented in Study 1. Among boys, the academic successes of gay men documented in Study 1 persist into a more recent cohort and extend across a wide range of academic outcomes. In high school, bisexual boys mostly performed similarly to their straight schoolmates, but, after high school, they went on to enroll in college at significantly lower rates. Among girls, I find that both lesbians and bisexuals are broadly disadvantaged across academic outcomes. Finally, despite their very different academic outcomes, I find that all groups of L/G/B students report elevated rates of discrimination and minority stress. 


\section{Sensitivity Analyses: Can Results Be Explained by Selective Reporting of LGB Identities?}

Together, these two studies above provide strong evidence that sexual identity consequentially stratifies academic outcomes. Before providing a substantive interpretation of these results, I address an alternate concern: Could they reflect something about who is reporting an LGB identity rather than something about sexuality itself? I address two forms of this concern, presenting full analyses in the Online Supplement but briefly describing the core results here.

First, I note that —alongside sexual attraction and sexual behavior-sexual identity is just one dimension of sexuality (e.g., Mishel 2019). Moreover, sexual identity labels may not have the same meaning and resonance across populations (e.g., Silva 2019). Therefore, perhaps my results simply reflect the differential salience of a "gay," "lesbian" or "bisexual" identity label among different groups. To address this concern, in the Online Supplement, I replicate my Study 1 analyses using a five-option sexual attraction measure included in the NSDUH. Results using this attraction measure of sexuality closely replicate the identity results presented above: not just overall, but also by race/ethnicity and birth cohort.

The second form of the concern about selective reporting that I address is a more traditional concern about selection bias. Given gay men's striking educational advantages, one might worry that there is some unmeasured selection process relating gay identification and college completion. One could imagine, for instance, that successfully reaching higher education affords gay men a certain freedom that makes them more willing to report their sexual identity. Or, more fundamentally, perhaps the college experience actually reshapes men's sense of sexual possibility, impacting their underlying identity itself and not just their willingness to report that identity. In either case, I could be "selecting on the dependent variable" of academic success. 
I address this concern in two ways. First, I stratify the HSLS sample by BA enrollment, reanalyzing gay boys' academic outcomes within two distinct groups: those who did make it to college by the latest survey and those who did not. If gay men's apparent successes in high school were driven only by the differential "coming out" of those who made it to college, then conditioning on college enrollment would neutralize these effects. Second, I draw on an entirely separate dataset constituted only by recent college graduates: the 2016/17 Baccalaureate and Beyond Longitudinal Study (B\&B:16/17). Within this nationally representative sample of students who completed bachelor's degrees in 2015-2016 ( $N \approx 19,490)$, I analyze students' college GPAs (as reported on their official transcripts) alongside their sexual identities (as reported in the B\&B:16/17 baseline survey). As shown in the Online Supplement, I find thatacross all of these analyses — gay men maintain statistically significant, substantively large academic advantages. In the B\&B:16/17, for example, gay men's college GPA advantage over straight men is 0.15 points $(\mathrm{p}<0.001)$ : more than double the magnitude of the GPA advantage associated with having at least one college-educated parent ( 0.06 points).

Together, these sensitivity analyses do not exhaust the tests one might consider. Still, I argue that they are sufficient to establish that it is unlikely that this study's results are simply an artifact of imperfect and/or selectively reported measures of sexuality. Instead, I believe the body

of evidence presented here reflects something real about the lived experience of gender and sexuality in the United States. I turn to this argument now.

\section{EXPLAINING LGB OUTCOMES: A “GENDER PREDICTIVE” APPROACH}

\section{Describing the Approach}

The current study demonstrates that sexuality does not stand alone as a single and separate source of academic advantage or disadvantage. Instead, sexuality shapes school success 
primarily in its intersection with gender, particularly between gay boys and lesbian girls. These results are consistent with the possibility put forward above: that, for boys, a felt distance from masculinity may be academically beneficial, but, for girls, alienation from femininity could be academically risky.

How might one test this possibility? Within psychology, the development and analysis of "masculinity" and "femininity" scales has a long history (e.g., Terman and Miles 1936; Bem 1974). Sociologists, however, have been rightfully skeptical of such approaches, noting that they rely on inventories of contextually-specific gender stereotypes (Magliozzi, Saperstein and Westbrook 2016) and that they treat as individual attributes what are actually the unequal results of collective processes (Connell 1987).

A more promising alternative, first proposed Lippa and Connelly (1990), is the "gender diagnosticity" approach. Rather than imposing pre-specified scales thought to distinguish men from women, the gender diagnostic approach uses existing survey items that, empirically, $d o$ show large male/female differences. The goal is appealingly modest: to identify items that "differentiate men and women in a particular population...mak[ing] no assumptions as to why specific behaviors serve to probabilistically predict an individual's gender in such populations" (Lippa and Connelly 1990:1053). Given its attention to contingent social contexts and its agnosticism with respect to the ultimate causes of male-female differences, the gender diagnostic approach provides a sociologically-informed way to repurpose existing survey items to generate continuous measures of gender typicality.

Following Cleveland, Udry and Chantala's (2001) demonstration of this approach in the Add Health student survey data, a number of Add Health studies have examined gender typicality defined in this way (e.g., Ueno and McWilliams 2010; Fleming, Harris and Halpern 
2017). Notably, Yavorsky and Buchmann (2019) demonstrate the promise of this approach for studies of educational stratification. Using 12 items in the Add Health Wave I survey that showed large sex differences, Yavorksy and Buchmann (2019) estimate a logistic regression to assign each respondent a probability of being a male. Over and above binary sex, they find that this probability consequentially stratifies students' GPAs.

Although they do not necessarily frame their approach as such, all of these studies treat gender typicality as a prediction task: Given some vector of inputs, $\boldsymbol{X}$, they estimate a function, $f(X)$, to generate predictions, $\widehat{Y}$, of each respondents' binary sex. Understanding gender diagnosticity in this way makes it clear that this approach naturally lends itself to the rapidly growing toolkit afforded by supervised machine learning (SML) algorithms: a set of tools designed specifically to optimize predictions. A full overview of SML is beyond the scope of this discussion (for a sociologically-focused introduction, see Molina and Garip 2019). However, the key relevant difference between SML and classical statistical approaches is SML's emphasis on optimizing out-of-sample predictions. By partitioning a single dataset into training and testing data, and iteratively tuning model parameters using the testing data, SML enables a more flexible, data-driven approach to model selection.

Unlike current gender diagnosticity approaches - which rely on manual comparisons of survey items and select only a small number of variables based on statistical significance cutoffs - SML provides a principled way to easily automate the variable selection process and, ultimately, to draw on a much larger set of variables (including, potentially, their higher order transformations and complex interactions). With reference to the setup above, SML allows a wider range of function classes, $f(X)$, to automatically analyze the entire input vector, $\boldsymbol{X}$, and generate potentially much more accurate predictions, $\hat{Y}$. 
As with gender diagnosticity approaches more broadly, this approach—what I call a "gender predictive" approach—is not without limitations. Still, for quantitative studies of gender inequality, I propose that a gender predictive approach provides an easily implemented and broadly applicable way to repurpose existing survey data so that continuous distributions of gendered outcomes can be presented alongside binary male/female differences.

\section{Applying the Approach}

To illustrate this approach, I predict whether HSLS students reported that their assigned sex was male using their full set of responses to the $9^{\text {th }}$ and $11^{\text {th }}$ grade surveys. ${ }^{7}$ If the goal is simply to generate predictions given a vector of survey responses, then any number of SML approaches could be applied. In this context, I turn to Least Absolute Shrinkage and Selection Operator (lasso) logistic regressions. Perhaps the most well-established SML method among social scientists (Bucca and Urbina 2019), lasso regressions offer two key advantages over more complex SML approaches (such as neural nets or classification trees). First, lasso regressions still provide regression coefficients for all selected predictors, providing a face-validity test that is not possible with more complex, black-box approaches. Second, lasso regressions are easily implemented in all statistical software programs and provide a natural extension of the regression methods already used in sociological research. Part of a class of functions called penalized regressions, lasso regressions balance overfitting and underfitting by iteratively drawing on a large number of variables while shrinking their coefficients toward zero (for a more complete overview, see Bucca and Urbina 2019).

Of the roughly 7,000 answer choices available across 759 questions, the lasso selected a total of 1,132 distinct answer choices to include in the model. In Table 4, I present the ten answer 
choices that the lasso identified as most predictive of student sex in the HSLS; Online Table 1 presents the top fifty answer choices.

\section{[Table 4 About Here]}

Although the specific coefficient values produced by penalized regressions should be interpreted with caution (Molina and Garip 2019), the general rank-ordering here provides an illustrative face validity check. As a summary of American masculinity, it seems not unreasonable to say that adolescent boys: do play videogames, do not talk to their friends about their personal problems and do imagine themselves as future professional athletes.

Next, in Figure 7, I plot students' average predicted probability of being male, separately by sex and L/G/B identity; in Online Figure 4, I present the full distribution of these predicted probabilities. As expected, these results show that $\mathrm{L} / \mathrm{G} / \mathrm{B}$ respondents were, in fact, more gender atypical in their survey responses than their straight peers. Indeed, the patterns in Figure 7 are strikingly similar to those reported on the direct measure of gender expression summarized in Figure 1, above. Just as in Figure 1, gay/lesbian respondents are more atypical than bisexuals and, of all groups, gay boys deviate the most, on average, from their straight peers.

[Figure 7 About Here]

How does gender atypicality shape students' outcomes? To answer this question, Figure 8 presents kernel-weighted local polynomial regressions of two key outcomes—high school GPA and reported discrimination — plotted against a measure of gender atypicality. Following Yavorsky and Buchmann (2019), I define atypicality, for women, as the predicted probability of being male and, for men, as one minus this predicted probability. Consistent with the framework 
outlined above, these results show that, for academic performance, gender atypicality is beneficial for boys but costly for girls. However, this effect is domain-specific: as a risk factor for discrimination, gender atypicality is risky for both boys and girls.

[Figure 8 About Here]

So far, these results demonstrate two key facts. First, that gender atypicality asymmetrically shapes boys' and girls' academic performance. Second, that bisexual—and, especially, gay and lesbian—-students are more gender atypical than their straight peers. As a final step, I directly explore whether L/G/B students' gender atypicality helps explain their high school GPA's. To do this, I re-estimate the main HSLS regression models, separately by sex, with and without controls for gender atypicality. Table 5 presents these results.

\section{[ Table 5 About Here ]}

The results in Table 5 show that —over and above binary sex, sexual identity, race/ethnicity, nativity and parent socioeconomic status - gender atypicality is a highly significant $(\mathrm{p}<0.001)$ predictor of students' high school GPAs. Moreover, for gay boys and lesbian girls, gender atypicality goes a fair way in explaining their academic (dis)advantages. Controlling for gender atypicality reduces the magnitude of gay boys' GPA advantage by about $28 \%$ and lesbian girls' GPA disadvantage by about $14 \%$. Nevertheless, both gay boys and lesbian girls still maintain statistically significant, substantively large (dis)advantages even after controlling for gender atypicality. By contrast, controlling for gender atypicality leaves bisexuals' GPA disadvantages almost entirely unchanged. I more fully explore the implications of these results in the discussion below. 


\section{DISCUSSION}

In her ethnography, Dude You're A Fag: Masculinity and Sexuality in High School, Pascoe (2007) tells the story of Ricky. One of only three out gay boys at River High, Ricky's sexuality and expansive gender expression marked him as a target for crushing "abuse at the hands of negligent adults, cruel teenagers and indifferent school administrators" (65). Ricky's isolation and victimization stands in stark contrast to the experiences of girls like Rebeca and Jessie. Two of several out lesbians at River High, these girls discovered that "gender and sexual non-normativity for girls can actually increase their social status" (120).

The current study supports the ongoing relevance of Pascoe's portrait of the social dynamics of American high schools. I find, for example, that gay boys report feeling unsafe in school at about twice the rate of straight boys, but lesbian girls are just slightly more likely than straight girls to report feeling unsafe. However, by analyzing these social dynamics alongside academic outcomes, the current study shows that this portrait is also incomplete in important ways. For contemporary lesbian girls, I find that a comparatively easy social experience masks rather serious vulnerabilities in terms of academic success. At the same time, I show that gay boys' well-documented victimization should now always be understood alongside their remarkable academic resilience.

In every dataset, across all birth cohorts, among White, Black, Hispanic and Asian men, and along full range of outcomes, I find that gay men achieve strikingly high levels of academic success. Some of contemporary gay men's success appears to be explained by their distance from the kind of masculinity reported by their peers. Most of gay boys' advantages, however, are left unexplained by this measure. Moreover, attributing gay men's success only to their avoiding 
the problems of masculinity doesn't address the fact that, on many measures, gay men surpass not only straight men, but also straight women. What explains this dynamic?

I propose that gay boys' felt distance from hegemonic masculinity doesn't just allow them to avoid the academic costs of masculinity, it also encourages them to pursue especially high levels of academic success. From an early age, gay boys face compounding status threats. Persistent cultural sexism leaves all boys' masculinity “exquisitely fragile” (Meadow 2018:21). Enduring heterosexism leaves all boys' heterosexuality “especially precarious” (Mize and Manago 2018:315). Growing up, gay boys discover themselves on the wrong side of both of these intersecting divides. In academics, they may find one incredibly adaptative way of responding to these status threats.

Academic performance offers an accessible domain of competitive self-mastery. Whereas the rules of masculinity may feel obscure or unattainable, the rules of school can feel discrete and manageable. Whereas the approval of a parent may be uncertain, the praise of a teacher can be regularly earned with the right amount of effort. And when other avenues for "being a man" are cut off, pursuing the kinds of prestigious careers made possible through meticulously high achievement offers a way to shore up one's standing as a man. In these ways, my results provide population-level support for what Pachankis and Hatzenbuehler (2013:177) call the "Best Little Boy in the World" hypothesis: the idea that gay boys "learn to deflect attention away from their concealed stigma through overcompensation in achievement-related domains."

In contrast to gay men's consistent advantages, I find that lesbian women's academic outcomes varied substantially by birth cohort and race/ethnicity. Within the entire population of adult women in America, lesbian women have significantly higher levels of BA attainment than straight women. On closer examination, though, this overall advantage is concentrated entirely 
among women from earlier birth cohorts. Similarly, when I examined lesbian women separately by race/ethnicity, it revealed that the BA advantages that historically accrued to lesbian women were concentrated among White lesbians. Although larger sample sizes are needed to estimate the full four-way interaction of sex-by-sexuality-by-race/ethnicity-by-birth cohort, it would seem that lesbian women's overall BA advantage is driven primarily by older cohorts of White lesbian women. What accounts for these patterns?

I propose that lesbian women's changing educational attainments offer a certain "outsider within" perspective (Collins 1986) on the broader "gender revolution" of $20^{\text {th }}$ century. For much of the $20^{\text {th }}$ century, heteropatriarchal laws and norms required women to limit their educations in deference to the constraints of early marriage, childrearing and economic dependence on a male provider. Lesbian women's marginalization from this gender regime would have provided many reasons to pursue higher education. Refusing to be reliant on a man for income, lesbian women could have sought out college degrees to increase their earning potential. Facing pressure to "settle down" into a straight marriage, higher education may have offered a recognizable path for forestalling the marital timeline imposed by others. Less likely to have their educational careers cut short by unintended fertility, lesbian women may have persisted in college when others were made to stop. Even so, not all lesbian women would have had the resources and freedom needed to actually capitalize on these shared reasons for higher education. Therefore, I propose that, when an earlier gender regime pushed lesbian women to pursue more education than straight women, it was the most advantaged lesbian women—disproportionately White lesbians — that best capitalized on those pressures.

In contemporary cohorts, the gender regime governing women's education has changed profoundly: "a historic reversal" has occurred (England and Bearak 2012). Today, many of the 
external forces constraining women's college completion have dissipated. Instead, the rapid "rise of women" has promoted the normative expectation that girls should pursue at least a college degree. In the current moment, then, a skepticism toward the strictures and expectations of femininity may undercut academic investments among lesbian women. My analysis of gender atypicality and lesbian women's academic performance provides some support for this idea: lesbian women's distance from the kind of femininity reported by straight girls helps explain some — though not much — of their large GPA disadvantage. What might explain the rest?

I propose that, in contemporary cohorts, lesbian women's academic achievement is suppressed by unequal treatment by school authorities. That is, I suspect that lesbiansespecially those who enact "masculine" styles of speech, dress and behavior-disproportionately face the kinds of "bad girl" penalties identified by previous research. Indeed, the HSLS data provide new evidence of lesbian girls' substantial overrepresentation in exclusionary school discipline. Consistent with prior research (Mittleman 2018), Online Figure 5 shows that lesbian girls are more than twice as likely $(\mathrm{p}<0.05)$ to report having been suspended or expelled in the six months prior to their $11^{\text {th }}$ grade survey. Moreover, these higher rates of discipline are concentrated entirely among lesbians of color: among White girls, there is no difference in discipline rates between lesbians and their straight schoolmates. The apparent specificity of these sanctions is consistent with the idea that hegemonic femininity is not just a gendered ideal, but a racialized ideal as well (e.g., Collins 2004; Hamilton et al. 2019). To the extent that students of color are already scrutinized for failing to conform to a White "good girl" norm, any further deviations from feminine gender expression among lesbian students of color may be met with especially harsh penalties. 
Bisexual men and women sit somewhat uneasily in this framework. Among all American adults, I find that bisexual men and women have earned college degrees at essentially the same rate as straight men and women. However, for recent cohorts of women —among whom bisexual identification is, by far, the highest—bisexuals are disadvantaged across the full range of academic outcomes. These disadvantages are generally smaller for bisexual men. However, in the HSLS cohort, bisexual boys report substantially lower rates of BA enrollment than their straight schoolmates. How are we to explain these disadvantages?

To begin, I note that these patterns of bisexual academic disadvantage are directly in line with research on other life domains, such as labor market earnings (Mize 2016) and physical and mental health (Feinstein and Dyar 2019). In these areas, as in my results, bisexuals face considerable disadvantages, not just compared to the straight population but compared to gay and lesbian populations as well. These disadvantages are often attributed to the especially high levels of stigma, discrimination and minority stress that bisexuals face (Mize 2016; Feinstein and Dyar 2019). The same dynamics may be at work here as well.

However, my results highlight one important complexity: the question of why bisexual women's disadvantages largely follow lesbian women's, but bisexual men's outcomes diverge so sharply from gay men's. It is not obvious how to interpret this result. One possibility suggested by my results and in line with prior research (e.g., $\mathrm{Li}$, Kung and Hine 2017) is that bisexual boys are, on average, far more gender typical than gay boys. As such, bisexual boys may derive fewer of the academic benefits of gender atypicality even as they still face a heavy toll of stigma and discrimination. For the bisexual population, then, identity-specific stressors may shape academic outcomes in a way that's largely independent of the crosscutting pressures of gender. 
Still, the data assembled here provides reason to exercise a certain humility when interpreting the academic performance of the bisexual population. There are complex questions about how to account for the bisexual population's outcomes at time when bisexual identification is, itself, expanding in a very specific way: rapidly among young women, but not among men (England, Mishel and Caudillo 2016). The actively shifting and socially structured dynamics of bisexual identification complicate easy explanations for this population's patterns. Future research, particularly qualitative research, should more fully investigate the mechanisms by which bisexual women and men are disadvantaged in America's schools.

\section{Limitations and Implications for Future Research}

These conclusions come with limitations that suggest several directions for future research. The most significant of these limitations is that, although I have analyzed $L G B$ populations, Transgender and Queer populations remain beyond the scope of this paper. Relying on binary sex measures, my analyses continue to be populated by "men" and "women," "boys" and "girls." Wilkinson, Shifrer and Pearson (2021) provide important evidence on the academic outcomes of gender diverse youth in the HSLS and future work should continue to break down the gender binary that prevails in studies of educational stratification.

Another important limitation of the current study is that, while I have information on respondents' sexual identities, I know nothing about how those identities have manifested in respondents' lives. For instance, I do not know whether respondents are "out" in their daily lives or the age at which they came out. I do not know whether their sexuality was met with stigma or support in their families, schools and communities. All of these kinds of variations surely shape students' academic experiences, but not in any one obvious direction. It could be, for example, that gay boys in more stigmatizing environments may feel a greater drive for academic 
performance, such that those who are able to come out earlier in life actually underperform those who are forced to remain closeted.

The unavailability of these kinds of measures reveals the extent to which demographic research on LGBTQ populations is, in many ways, still in its infancy. All of this study's analyses were only possible because public servants recently included sexual identity measures in a few key parts of the federal research apparatus. During the Obama administration, plans were also finalized to include sexual identity and gender identity measures in a much larger, much more consequential demographic survey: the 2018 American Community Survey. The size and breadth of those data would have profoundly expanded the possibilities for LGBTQ demographic research. Under Trump, these plans were canceled abruptly and without justification (Wang 2018). This erasure of LGBTQ Americans not only impacts governments' budget decisions and researchers' opportunities. It also makes a fundamental statement about who we recognize and which lives we value: it structures a "recognition gap" of the kind Lamont (2018) compels us to close.

\section{CONCLUSION}

The question of how gender shapes academic performance has animated sociological research for decades. In the wake of the Covid-19 pandemic, this old question has taken on new meaning. Although the pandemic suppressed college enrollment among both men and women, the decline for men was seven times as steep (National Student Clearinghouse Research Center 2021). Given the benefits of higher education, finding ways to promote masculinities more compatible with educational attainment is an increasingly urgent social problem.

As questions of gender and school success continue to shape American life in the years to come, this study provides new reasons for sociologists to heed a lesson long taught by queer 
theorists: that any analysis of gender is incomplete without an analysis of sexuality. By making the margins of the academic gender order visible, LGB students allow us to see the spectrum of academic performance in a new light. Incorporating sexuality into the study of educational stratification, we find the persistent penalties for women who defy the dictates of hegemonic femininity and the tremendous possibilities for men outside the confines of hegemonic masculinity. 


\section{ENDNOTES:}

1. Although straight, lesbian, gay and bisexual clearly do not capture the full range of sexual identities, I focus on these groups because they are consistently available across surveys and, given the identity options presented, constitute the largest sexual identity groups in America.

2. This valorization of defiance is likely not unrelated to the fact that teaching is, and has been, a largely female profession. In $76 \%$ of American classrooms, boys are not just defying teachers: they are defying the authority of women.

3. Consistent with NCES standards for reporting on restricted use data, I round all HSLS sample sizes to the nearest 10 .

4. Complete replication code is available from the author.

5. This high degree of missingness is due, in large part, to the fact $\sim 420$ stopped the survey before reaching the sexual identity question, which was among the final questions. As a sensitivity test, I retained and recoded as "gay/lesbian" the $\sim 110$ respondents who specifically skipped the that the sexual identity question: all results were substantively unchanged.

6. In every dataset, I estimate respondents' birth year using their reported age last birthday and the survey year. For the NSDUH, age is available only in intervals (24/5, 26-9, 30-4, 35-49, $50-64,65+)$. To estimate age within these intervals, I randomly assign respondents across the interval such that the resulting age distribution matches the average of the NHIS and NCVS age distributions.

7. To maximize the sample used to fit the model, I include all students who ever participated in the HSLS, not just those in the analytic sample. Results using only the analytic sample were substantively identical. 


\section{REFERENCES}

Aragon, Steven R., V. Paul Poteat, Dorothy L. Espelage and Brian W. Koenig. 2014. "The influence of peer victimization on educational outcomes for LGBTQ and non-LGBTQ high school students." Journal of Lesbian, Gay, Bisexual, Transgender Youth 11(1): 1-19.

Austin, Megan. 2019. "Measuring High School Curricular Intensity over Three Decades." Sociology of Education 93(1):65-90

Bailey, Martha J. and Jason M. Lindo. "Access and Use of Contraception and Its Effects On Women's Outcomes in the U.S.” NBER Working Paper No. 23465.

Baumle, Amanda K., D'Lane R. Compton and Dudley L. Poston Jr. 2009. Same-Sex Partners: The Social Demography of Sexual Orientation. Albany, NY: State University of New York Press.

Bem, Sandra L. 1974. "The Measurement of Psychological Androgyny." Journal of Consulting and Clinical Psychology 42(2):155-62

Black, Dan, Gary Gates, Seth Sanders and Lowell Taylor. 2000. "Demographics of the gay and lesbian population in the United States: Evidence from available systematic data sources." Demography 37:139-154.

Black, Dan A., Seth G. Sanders and Lowell J. Taylor. 2007. "The Economics of Lesbian and Gay Families." Journal of Economic Perspectives 21(2): 53-70.

Breen, Richard, Kristian Bernt Karlson, and Anders Holm. 2018. "Interpreting and Understanding Logits, Probits, and Other Nonlinear Probability Models." Annual Review of Sociology 44:39-54.

Bucca, Mauricio and Daniela R. Urbina. 2019. "Lasso Regularization for Selection of Log-linear Models: An Application to Educational Assortative Mating." Sociological Methods \& Research Online First:1-38.

Buchmann, Claudia and Thomas A. DiPrete. 2006. "The Growing Female Advantage in College Completion: The Role of Family Background and Academic Achievement." American Sociological Review 71(4):515-541.

Charles, Maria and Karen Bradley. 2009. "Indulging Our Gendered Selves? Sex Segregation by Field of Study in 44 Countries." American Journal of Sociology 114(4):924-976.

Cleveland, H. Harrington, J. Richard Udry and Kim Chantala. 2001. "Environmental and Genetic Influences on Sex-Typed Behaviors and Attitudes of Male and Female Adolescents." Personality and Social Psychology Bulletin 27(12):1587-1598. 
Coffman, Katherine B. Lucas C. Coffman and Keith M. Marzilli Ericson. 2017. "The Size of the LGBT Population and the Magnitude of Antigay Sentiment Are Substantially Underestimated." Management Science 63(10): 3147-3529.

Coleman, James S. 1961. The Adolescent Society. Glencoe, IL: Free Press.

Collins, Patricia Hill. 1986. "Learning from the outsider within: The sociological significance of Black feminist thought.” Social Problems 33(6): S14-S31.

Collins, Patricia Hill. 2004. Black Sexual Politics: African Americans, Gender and the New Racism. New York: Routledge.

Combahee River Collective. 1983. "The Combahee River Collective Statement.” Pp. 272-82 in Home Girls: A Black Feminist Anthology, edited by B. Smith. New York: Kitchen Table: Women of Color Press.

Compton, D’Lane R., Tey Meadow and Kristen Schilt, eds. 2018. “Introduction: Queer Work in a Straight Discipline.” Pp. 1-36 in Other, Please Specify: Queer Methods in Sociology. Oakland, CA: University of California Press.

Connell, R.W. 1987. Gender and power: Society, the person and sexual politics. Stanford University Press.

Connell, R.W. 1995. Masculinities. Cambridge: Polity Press.

Diamond, Lisa A. 2008. Sexual fluidity: Understanding women's love and desire. Cambridge, MA: Harvard University Press.

DiPrete, Thomas A. and Claudia Buchmann. 2013. The Rise of Women: The Growing Gender Gap in Education and What it Means for American Schools. New York: Russell Sage Foundation.

DiPrete, Thomas A. and Jennifer L. Jennings. 2012. "Social and behavioral skills and the gender gap in early educational achievement." Social Science Research 41(1):1-15.

England, Paula. 2010. "The Gender Revolution: Uneven and Stalled." Gender \& Society 24(2):149-166.

England, Paula and Jonathan Bearak. 2012. Women's Education and Their Likelihood of Marriage: A Historic Reversal. Council on Contemporary Families.

England, Paula, Andrew Levine and Emma Mishel. 2020. "Progress toward gender equality in the United States has slowed or stalled.” PNAS 117(13):6990-6997. 
England, Paula, Emma Mishel and Mónica L. Caudillo. 2016. "Increases in Sex with Same-Sex Partners and Bisexual Identity Across Cohorts of Women (but Not Men)." Sociological Science 3: 951-970.

Entwisle, Doris R., Karl L. Alexander, Linda S. Olson. 2007. "Early Schooling: The Handicap of Being Poor and Male." Sociology of Education 80(2):114-138.

Federal Interagency Working Group on Improving Measurement of Sexual Orientation and Gender Identity in Federal Surveys. 2016. Current Measures of Sexual Orientation and Gender Identity in Federal Surveys. Washington, DC: Author. Retrieved July 272021

(https://nces.ed.gov/FCSM/pdf/current_measures_20160812.pdf)

Ferguson, Ann Annette. 2000. Bad Boys: Public Schools in the Making of Black Masculinity. Ann Arbor, MI: University of Michigan Press.

Fleming, Paul J., Kathleen Mullan Harris and Carolyn Tucker Halpern. 2017. "Description and Evaluation of a Measurement Technique for Assessment of Performing Gender." Sex Roles 76(11):731-746.

Gates, Gary J. 2012. "LGBT Identity: A Demographer 's Perspective.” Loyola of Los Angeles Law Review 45(3): 693-714.

Gates, Gary J. 2014. LGB/T Demographics: Comparisons among population-based surveys. Williams Institute, UCLA School of Law.

Gates, Gary J. and Jason Ost. 2004. The Gay and Lesbian Atlas. Washington, DC: The Urban Institute Press.

GLSEN. (2018). Laws Prohibiting "Promotion of Homosexuality” in Schools: Impacts and Implications (Research Brief). New York: GLSEN.

Goldin, Claudia, Lawrence F. Katz and Ilyana Kuziemko. 2006. "The Homecoming of American College Women: The Reversal of the College Gender Gap." Journal of Economic Perspectives 20(4):133-156.

Goldin, Claudia and Lawrence F. Katz. 2008. The Race Between Education and Technology. Cambridge: Harvard University Press.

Hamilton, Laura T., Elizabeth A. Armstrong, J. Lotus Seeley and Elizabeth M. Armstrong. 2019. "Hegemonic Femininities and Intersectional Domination." Sociological Theory 37(4):315-341.

Hochschild, Arlie Russell and Anne Machung. 1989. The Second Shift: Working Parents and the Revolution at Home. New York: Viking Penguin.

Hsin, Amy. 2018. "Hegemonic Gender Norms and the Gender Gap in Achievement: The Case of Asian Americans." Sociological Science 5: 752- 774. 
Hsin, Amy and Yu Xie. 2014. "Explaining Asian Americans' academic advantage over whites." PNAS 111(23):8416-8421.

Isen, Adam and Betsey Stevenson. 2010. "Women's Education And Family Behavior: Trends In Marriage, Divorce And Fertility.” NBER Working Paper No. 15725.

Ispa-Landa, Simone. 2013. "Gender, Race, and Justifications for Group Exclusion: Urban Black Students Bussed to Affluent Suburban Schools." Sociology of Education 86(3): 218-233.

Jones, Nikki. 2010. Between Good and Ghetto: African American Girls and Inner-City Violence. Rutgers University Press.

Kosciw, Joseph G., Emily A. Greytak, Adrian D. Zongrone, Caitlin M. Clark and Nhan L. Truong. 2018. The 2017 National School Climate Survey: The experiences of lesbian, gay, bisexual, transgender, and queer youth in our nation's schools. New York: GLSEN.

Lamont, Michèle. 2018. "Addressing Recognition Gaps: Destigmatization and the Reduction of Inequality." American Sociological Review 83(3):419-444.

Lagos, Danya. 2019. "Hearing Gender: Voice-Based Gender Classification Processes and Transgender Health Inequality.” American Sociological Review 84(5):801-827.

Legewie, Joscha and Thomas A. DiPrete. 2012. "School Context and the Gender Gap in Educational Achievement." American Sociological Review 77(3):463-485.

Leslie, Sarah-Jane, Andrei Cimpian, Meredith Meyer, and Edward Freeland. 2015. "Expectations of Brilliance Underlie Gender Distributions across Academic Disciplines." Science 347(6219): 262-65.

Li, Gu, Karson T.F. Kung and Melissa Hines. 2017. "Childhood gender-typed behavior and adolescent sexual orientation: a longitudinal population-based study." Developmental Psychology 53(4):764-777.

Lippa, Richard. 2000. "Gender-Related Traits in Gay Men, Lesbian Women, and Heterosexual Men and Women: The Virtual Identity of Homosexual-Heterosexual Diagnosticity and Gender Diagnosticity." Journal of Personality 68:899-926.

Lippa, Richard and Sharon Connelly. 1990. "Gender diagnosticity: A new Bayesian approach to gender-related individual differences." Journal of Personality and Social Psychology 59(5):1051-1065.

MacLeod, Jay. 1987. Ain't No Makin'It: Leveled Aspirations in a Low-Income Neighborhood. Westview Press. 
Magliozzi, Devon, Aliya Saperstein and Laurel Westbrook. 2016. "Scaling Up: Representing Gender Diversity in Survey Research.” Socius: Sociological Research for a Dynamic World Volume 2: 1-11.

Manne, Kate. 2017. Down Girl: The Logic of Misogyny. New York: Oxford University Press.

McLanahan, Sara. 2004. "Diverging destinies: How children are faring under the second demographic transition." Demography 41:607-627.

Meadow, Tey. Trans Kids: Being Gendered in the $21^{\text {st }}$ Century. Oakland, CA: University of California Press.

Meyer, Ilan H. 2003. "Prejudice, social stress, and mental health in lesbian, gay, and bisexual populations: Conceptual issues and research evidence." Psychological Bulletin 129(5): 674 697.

Mickelson, Roslyn Arlin. 1989. "Why Does Jane Read and Write so Well? The Anomaly of Women's Achievement." Sociology of Education 62(1):47-63.

Mittleman, Joel. 2018. "Sexual Orientation and School Discipline: New Evidence From a Population-Based Sample.” Educational Researcher 47(3): 181-190.

Mishel, Emma. 2019. "Intersections between Sexual Identity, Sexual Attraction, and Sexual Behavior among a Nationally Representative Sample of American Men and Women." Journal of Official Statistics 35(4):859-884.

Mize, Trenton D. 2016. "Sexual Orientation in the Labor Market." American Sociological Review 81(6):1132-1160.

Mize, Trenton D. and Bianca Manago. 2018. "Precarious Sexuality: How Men and Women Are Differentially Categorized for Similar Sexual Behavior.” American Sociological Review 83(2):305-330.

Molina, Mario and Filiz Garip. 2019. "Machine Learning for Sociology.” Annual Review of Sociology. 45:27-45.

Mollborn, Stefanie and Bethany Everett. 2015. "Understanding the Educational Attainment of Sexual Minority Women and Men." Research in Social Stratification and Mobility 41:40-55.

Moore, Mignon. 2011. Invisible Families: Gay Identities, Relationships, and Motherhood among Black Women. Berkeley: University of California Press.

Morris, Edward W. 2007. “'Ladies' or 'Loudies'?: Perceptions and Experiences of Black Girls in Classrooms." Youth \& Society 38(4): 490-515. 
Morris, Edward W. 2012. Learning the Hard Way: Masculinity, Place, and the Gender Gap in Education. New Brunswick, NJ: Rutgers University Press.

Musto, Michela. 2019. "Brilliant or Bad: The Gendered Social Construction of Exceptionalism in Early Adolescence.” American Sociological Review 84(3):369-393.

National Academies of Sciences, Engineering, and Medicine. 2020. Understanding the WellBeing of LGBTQI+ Populations. Washington, DC: The National Academies Press.

National Center for Educational Statistics. 2021. "Table 603.30. Percentage of the population 25 to 64 years old who attained a postsecondary degree, by highest degree attained, age group, and country: 2019." In Digest of Educational Statistics:2019. Retrieved July 272021

(https://nces.ed.gov/programs/digest/d20/tables/dt20_603.30.asp).

National Student Clearinghouse Research Center. 2021. "Current Term Enrollment Estimates: Fall 2020.” Retrieved October 132021 (https://nscresearchcenter.org/wpcontent/uploads/CTEE_Report_Fall_2020.pdf)

Pachankis, John E. and Mark L. Hatzenbuehler. 2013. "The Social Development of Contingent Self-Worth in Sexual Minority Young Men: An Empirical Investigation of the "Best Little Boy in the World" Hypothesis." Basic and Applied Social Psychology 35(2):176-190.

Pascoe, C.J. 2007. Dude, You're a Fag: Masculinity and Sexuality in High School. Oakland, CA: University of California Press.

Pearson, Jennifer, Chandra Muller and Lindsey Wilkinson. 2007. "Adolescent Same-Sex Attraction and Academic Outcomes: The Role of School Attachment and Engagement." Social Problems 54(4):523-542.

Pearson, Jennifer and Lindsey Wilkinson. 2017. "Same-Sex Sexuality and Educational Attainment: The Pathway to College." Journal of Homosexuality 26: 1-39.

Riegel-Crumb, Catherine, Sarah Blanchard Kyte and Karisma Morton. 2018. "Gender and Racial/Ethnic Differences in Educational Outcomes: Examining Patterns, Explanations and New Directions for Research.” Pp. 131-153. Handbook of the Sociology of Education in the $21^{\text {st }}$ Century, edited by B. Schneider. Springer.

Rieger, Gerulf, Joan A W Linsenmeier, Lorenz Gygax and J Michael Bailey. 2008. "Sexual orientation and childhood gender nonconformity: evidence from home videos." Developmental Psychology 44(1):46-58.

Rios, Victor M. 2012. Punished: Policing the Lives of Black and Latino Boys. New York: NYU Press.

Russell, Stephen T. and Jessica N. Fish. 2016. "Mental Health in Lesbian, Gay, Bisexual, and Transgender (LGBT) Youth.” Annual Review of Clinical Psychology 12:465-487. 
Schilt, Kristen and Laurel Westbrook. 2009. "Doing Gender, Doing Heteronormativity: 'Gender Normals,' Transgender People, and the Social Maintenance of Heterosexuality." Gender and Society 23(4):440-464.

Schippers, Mimi. 2007. "Recovering the Feminine Other: Masculinity, Femininity and Gender Hegemony." Theory and Society 36(1):85-102.

Silva, Tony J. 2019. "Straight Identity and Same-Sex Desire: Conservatism, Homophobia, and Straight Culture.” Social Forces 97(3): 1067-1094.

Terman, Lewis Madison, and Catharine Cox Miles. 1936. Sex and Personality. New York: McGraw-Hill.

Toomey, Russell B. and Stephen T. Russell. 2016. "The Role of Sexual Orientation in SchoolBased Victimization: A Meta-Analysis.” Youth \& Society 48(2): 176-201.

Ueno, Koji, and Summer McWilliams. 2010. "Gender-Typed Behaviors and School Adjustment." Sex Roles 63:580-91.

Velte, Kyle C. 2020. “Straightwashing the Census.” Boston College Law Review 61(1):69-127.

Walsemann, Katrina M., Lisa L. Lindley, Danielle Gentile and Shehan V. Welihindha. 2014. "Educational Attainment by Life Course Sexual Attraction: Prevalence and Correlates in a Nationally Representative Sample of Young Adults." Population Research and Policy Review 33: 579-602.

Wang, Hansi Lo. 2018. “Trump Officials 'Did Not Want' Census Survey To Ask About Sexual Orientation." NPR. Retrieved Sep. 15, 2020.

(https://www.npr.org/2018/09/20/649752485/trump-officials-did-not-want-census-survey-to-askabout-sexual-orientation)

Westbrook, Laurel and Aliya Saperstein. 2015. "New Categories Are Not Enough: Rethinking the Measurement of Sex and Gender in Social Surveys." Gender and Society 29(4):534-560.

Wimberly, George L. 2015. "Use of Large-Scale Data Sets and LGBTQ Education.” Pp. 175-218 in LGBTQ Issues in Education: Advancing a Research Agenda, edited by G.L. Wimberly.

Washington, DC: American Educational Research Association.

Wimberly, George L. and Juan Battle. 2015. "Challenges to Doing Research on LGBTQ Issues in Education and Important Research Needs." Pp. 219-236 in LGBTQ Issues in Education: Advancing a Research Agenda, edited by George L. Wimberly. Washington, DC: American Education Research Association.

Wilkinson, Lindsey and Jennifer Pearson. 2009. "School Culture and the Well-Being of SameSex-Attracted Youth." Gender \& Society 23(4): 542 - 568. 
Wilkinson, Lindsey, Dara Shifrer and Jennifer Pearson. 2021."Educational Outcomes Of Gender-Diverse Youth: A National Population-Based Study." Gender \& Society 35(5):806-837.

Williams Institute. 2009. Best Practices for Asking Questions about Sexual Orientation on Surveys. Los Angeles: Author. Retrieved July 272021 (https://williamsinstitute.law.ucla.edu/wpcontent/uploads/Best-Practices-SO-Surveys-Nov-2009.pdf)

Willis, Paul. 1981. Learning to Labour: How Working Class Kids Get Working Class Jobs. New York: Columbia University Press.

Yavorsky, Jill E. and Claudia Buchmann. 2019. "Gender Typicality and Academic Achievement among American High School Students.” Sociological Science 6: 661-683. 


\section{TABLES AND FIGURES}

Figure 1: Average Reported Gender Expression Among American High School Students: Selected Cities, 2017/19
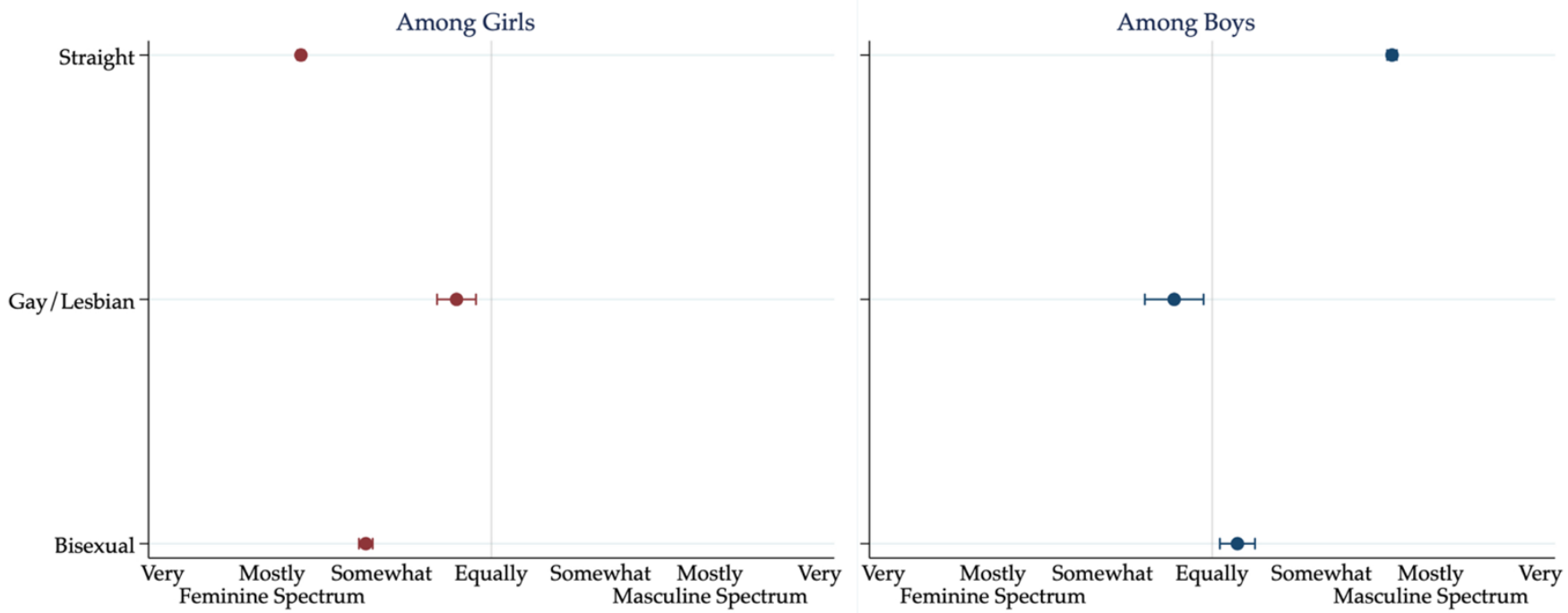

Note: Data from 2017 and/or 2019 Youth Risk Behavior Surveillance System surveys in Chicago, Los Angeles, New York City, San Diego, San Francisco, Oakland CA, Philadelphia, Seattle, Broward County FL and Duval County FL. $N=38,183$. Data are weighted to reflect complex sampling procedures and are representative of students in public high schools in sampled cities. 
Table 1: Summary of Data Sources

\begin{tabular}{|c|c|c|c|c|c|c|}
\hline \multirow{2}{*}{ Survey Name } & \multirow{2}{*}{ Years Available } & \multirow{2}{*}{ Sample Size } & \multicolumn{4}{|c|}{ Percent Reporting $L / G / B$ Identities } \\
\hline & & & Gay & Lesbian & Bi Men & Bi Women \\
\hline \multicolumn{7}{|c|}{ Nationally Representative Household Surveys } \\
\hline $\begin{array}{l}\text { National Health Interview } \\
\text { Survey }\end{array}$ & 2013-2019 & 197,277 & $\begin{array}{c}1.9 \% \\
{[1.8,2.1]}\end{array}$ & $\begin{array}{c}1.3 \% \\
{[1.2,1.4]}\end{array}$ & $\begin{array}{c}0.5 \% \\
{[0.4,0.6]}\end{array}$ & $\begin{array}{c}1.2 \% \\
{[1.1,1.3]}\end{array}$ \\
\hline $\begin{array}{l}\text { National Survey of Drug } \\
\text { Use and Health }\end{array}$ & $2015-2019$ & 149,189 & $\begin{array}{c}2.1 \% \\
{[1.9,2.3]}\end{array}$ & $\begin{array}{c}1.5 \% \\
{[1.4,1.6]}\end{array}$ & $\begin{array}{c}1.5 \% \\
{[1.4,1.6]}\end{array}$ & $\begin{array}{c}3.0 \% \\
{[2.9,3.2]}\end{array}$ \\
\hline $\begin{array}{l}\text { National Crime } \\
\text { Victimization Survey }\end{array}$ & $2017-2019$ & 141,567 & $\begin{array}{c}1.7 \% \\
{[1.5,1.8]}\end{array}$ & $\begin{array}{c}1.3 \% \\
{[1.2,1.3]}\end{array}$ & $\begin{array}{c}0.3 \% \\
{[0.2,0.3]}\end{array}$ & $\begin{array}{c}0.8 \% \\
{[0.7,0.9]}\end{array}$ \\
\hline \multicolumn{7}{|c|}{ School-Based Cohort Study } \\
\hline $\begin{array}{l}\text { High School Longitudinal } \\
\text { Study of } 2009\end{array}$ & $\begin{array}{c}\text { One cohort } \\
\text { surveyed in } \\
2009,2011,2016\end{array}$ & $\sim 15,270$ & $\begin{array}{c}2.2 \% \\
{[1.8,2.6]}\end{array}$ & $\begin{array}{c}2.6 \% \\
{[1.8,3.3]}\end{array}$ & $\begin{array}{l}2.2 \% \\
{[1.8,2.7]}\end{array}$ & $\begin{array}{c}7.2 \% \\
{[6.3,8.1]}\end{array}$ \\
\hline
\end{tabular}

Note: All estimates are weighted to reflect complex sampling procedures. National household surveys are representative of the civilian, non-

institutionalized adult $(25+)$ population of the United States. $95 \%$ confidence intervals in brackets. In keeping with the National Center for Education

Statistics' restricted data reporting requirements, High School Longitudinal Study sample size is rounded to nearest 10. 
Table 2: Educational Attainment by Sex and Sexual Identity: American Adults, 25+

\begin{tabular}{|c|c|c|c|c|c|c|}
\hline & Straight & $\begin{array}{l}\text { Men } \\
\text { Gay }\end{array}$ & Bisexual & Straight & $\begin{array}{l}\text { Women } \\
\text { Lesbian } \\
\end{array}$ & Bisexual \\
\hline \multicolumn{7}{|c|}{ National Health Interview Survey } \\
\hline $\begin{array}{l}\text { High School Diploma } \\
\text { or Greater }\end{array}$ & $\begin{array}{c}87.0 \\
{[86.5,87.4]}\end{array}$ & $\begin{array}{c}95.6 * * * \\
{[94.5,96.7]}\end{array}$ & $\begin{array}{c}93.6 * * * \\
{[90.7,96.5]}\end{array}$ & $\begin{array}{c}87.4 \\
{[87.0,87.8]}\end{array}$ & $\begin{array}{c}92.7^{* * *} \\
{[91.0,94.4]}\end{array}$ & $\begin{array}{c}88.2 \\
{[85.6,90.8]}\end{array}$ \\
\hline $\begin{array}{l}\text { Bachelor's Degree } \\
\text { or Greater }\end{array}$ & $\begin{array}{c}33.9 \\
{[33.3,34.6]}\end{array}$ & $\begin{array}{c}52.7^{* * *} \\
{[49.7,55.6]}\end{array}$ & $\begin{array}{c}38.1 \\
{[32.7,43.5]}\end{array}$ & $\begin{array}{c}33.6 \\
{[33.0,34.2]}\end{array}$ & $\begin{array}{c}44.0 * * * \\
{[40.5,47.5]}\end{array}$ & $\begin{array}{c}35.4 \\
{[31.8,39.1]}\end{array}$ \\
\hline $\begin{array}{l}\text { Professional Degree: } \\
\text { JD/MD/PhD }\end{array}$ & $\begin{array}{c}4.0 \\
{[3.8,4.2]}\end{array}$ & $\begin{array}{c}6.2 * * \\
{[4.7,7.6]}\end{array}$ & $\begin{array}{c}3.5 \\
{[1.8,5.3]}\end{array}$ & $\begin{array}{c}2.6 \\
{[2.4,2.7]}\end{array}$ & $\begin{array}{c}3.7^{*} \\
{[2.6,4.8]}\end{array}$ & $\begin{array}{c}2.6 \\
{[1.4,3.8]} \\
\end{array}$ \\
\hline \multicolumn{7}{|c|}{ National Survey of Drug Use and Health } \\
\hline $\begin{array}{l}\text { High School Diploma } \\
\text { or Greater }\end{array}$ & $\begin{array}{c}87.4 \\
{[87.0,87.8]}\end{array}$ & $\begin{array}{c}94.5^{* * *} \\
{[93.1,95.9]}\end{array}$ & $\begin{array}{c}90.2 \\
{[87.1,93.4]}\end{array}$ & $\begin{array}{c}88.7 \\
{[88.3,89.1]}\end{array}$ & $\begin{array}{c}90.8 \\
{[88.5,93.2]}\end{array}$ & $\begin{array}{c}89.1 \\
{[87.6,90.6]}\end{array}$ \\
\hline $\begin{array}{l}\text { Bachelor's Degree } \\
\text { or Greater }\end{array}$ & $\begin{array}{c}34.3 \\
{[33.7,34.9]}\end{array}$ & $\begin{array}{c}52.0 * * * \\
{[48.3,55.7]}\end{array}$ & $\begin{array}{c}37.9 * \\
{[34.4,41.5]}\end{array}$ & $\begin{array}{c}34.7 \\
{[34.0,35.3]}\end{array}$ & $\begin{array}{c}41.1 * * * \\
{[37.6,44.6]}\end{array}$ & $\begin{array}{c}31.0 * * \\
{[28.5,33.6]}\end{array}$ \\
\hline \multicolumn{7}{|c|}{ National Crime Victimization Survey } \\
\hline $\begin{array}{l}\text { High School Diploma } \\
\text { or Greater }\end{array}$ & $\begin{array}{c}88.7 \\
{[88.4,89.0]}\end{array}$ & $\begin{array}{c}95.8 * * * \\
{[94.4,97.2]}\end{array}$ & $\begin{array}{c}92.4 \\
{[88.3,96.6]}\end{array}$ & $\begin{array}{c}88.5 \\
{[88.2,88.8]}\end{array}$ & $\begin{array}{c}94.2 * * * \\
{[92.5,96.0]}\end{array}$ & $\begin{array}{c}89.5 \\
{[86.3,92.7]}\end{array}$ \\
\hline $\begin{array}{l}\text { Bachelor's Degree } \\
\text { or Greater }\end{array}$ & $\begin{array}{c}37.4 \\
{[37.0,37.8]}\end{array}$ & $\begin{array}{c}54.1 * * * \\
{[50.7,57.5]}\end{array}$ & $\begin{array}{c}39.6 \\
{[31.4,47.8]}\end{array}$ & $\begin{array}{c}35.0 \\
{[34.6,35.4]}\end{array}$ & $\begin{array}{c}47.3 * * * \\
{[43.5,51.0]}\end{array}$ & $\begin{array}{c}35.4 \\
{[30.8,40.0]}\end{array}$ \\
\hline $\begin{array}{l}\text { Professional Degree: } \\
\mathrm{JD} / \mathrm{MD} / \mathrm{PhD}\end{array}$ & $\begin{array}{c}4.2 \\
{[4.1,4.4]}\end{array}$ & $\begin{array}{c}5.8 \\
{[4.2,7.4]}\end{array}$ & $\begin{array}{c}3.6 \\
{[1.0,6.2]}\end{array}$ & $\begin{array}{c}3.0 \\
{[2.8,3.1]}\end{array}$ & $\begin{array}{c}5.0 * \\
{[3.4,6.6]}\end{array}$ & $\begin{array}{c}4.5 \\
{[2.5,6.5]}\end{array}$ \\
\hline
\end{tabular}

Note: $* * * \mathrm{p}<0.001, * * \mathrm{p}<0.01, * \mathrm{p}<0.05$ (two-tailed $t$-tests comparing gay and straight and bisexual and straight outcomes, separately for men and women). 95\% confidence intervals in brackets. All estimates are weighted to reflect complex sampling procedures are representative of the civilian, non-institutionalized adult $(25+)$ population of the United States. 
Figure 2: Bachelor's Degree Attainment by Sex and Sexuality, American Adults 25+
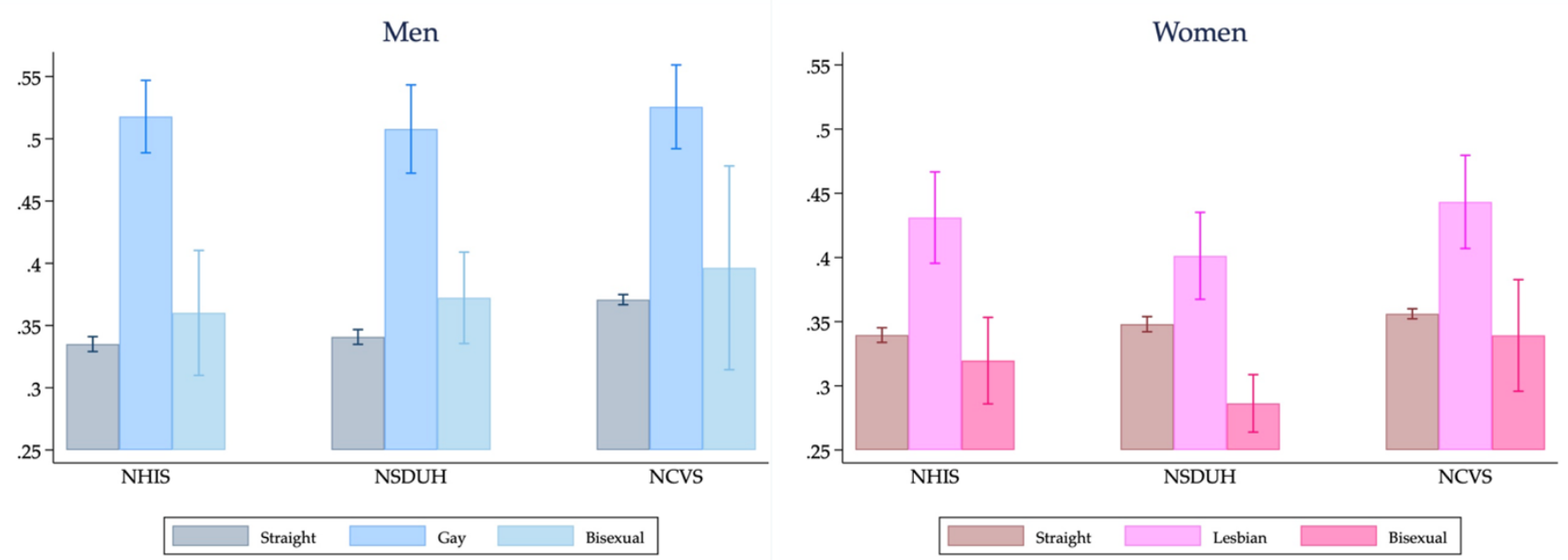

Note: Estimates are the average adjusted predictions calculated from the two-way interaction of sexual identity-by-sex in a survey-weighted logistic regression. Regression models also controlled for: birth cohort, race/ethnicity and nativity. Complete regression results presented in online supplement. NHIS=National Health Interview Survey $(N=197,277)$; NSDUH=National Study of Drug Use and Health $(N=149,189)$; NCVS=National Crime Victimization Survey $(N=141,567)$. 
Figure 3: Differences in Bachelor's Degree Attainment, by Sex, Sexuality and Race/Ethnicity, American Adults 25+
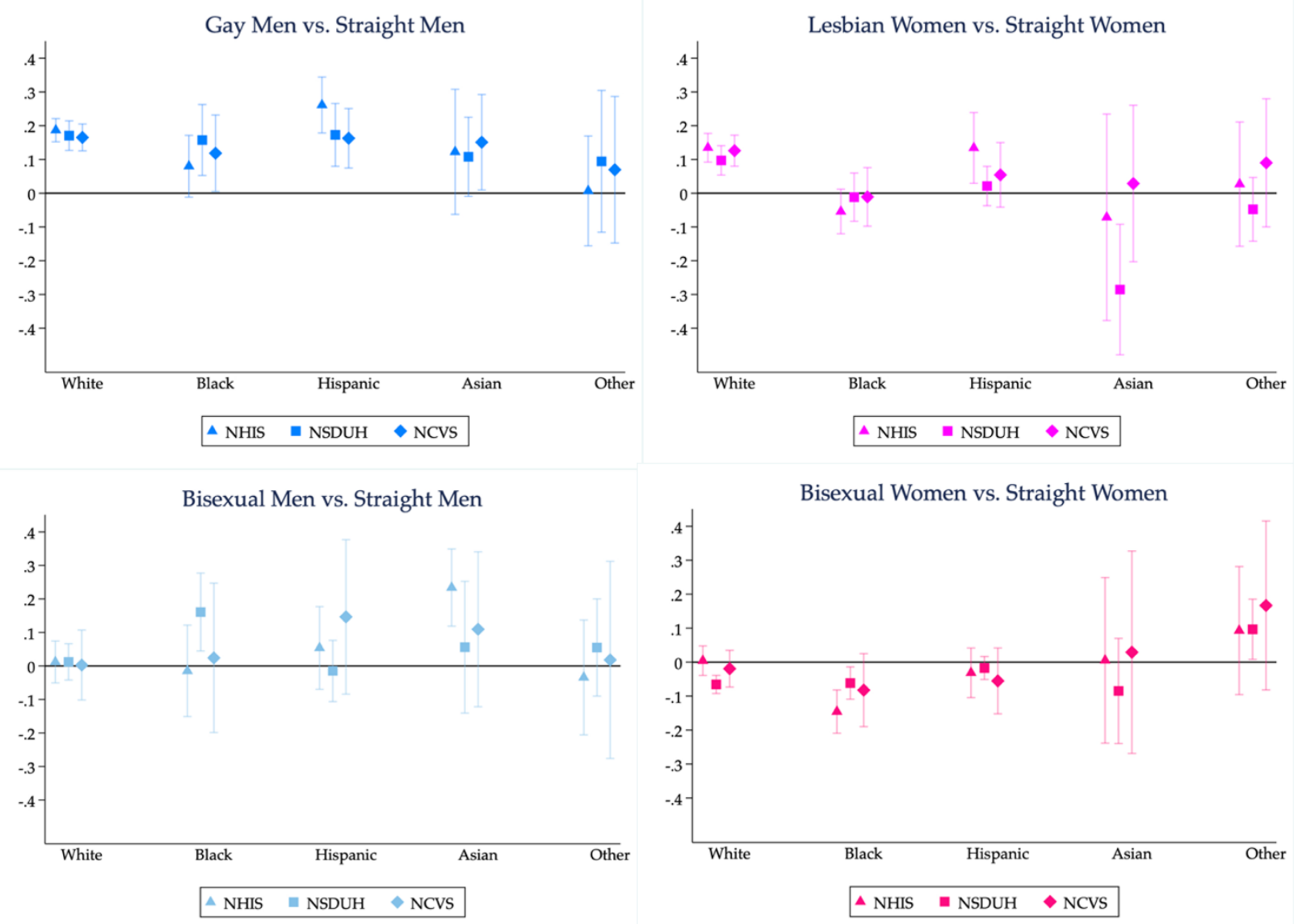

Note: Estimates are the average marginal effect sexual identity, calculated from the three-way interaction of sexual identity-bysex-by-race/ethnicity in a survey-weighted logistic regression. Regression models also controlled for: birth cohort and nativity. Complete regression results presented in online supplement. NHIS=National Health Interview Survey $(N=197,277)$;

NSDUH=National Study of Drug Use and Health $(N=149,189)$; NCVS=National Crime Victimization Survey $(N=141,567)$. 
Figure 4: Reconstructing the "Rise of Women:" Bachelor's Degree Attainment by Sex, Sexuality and Birth Cohort
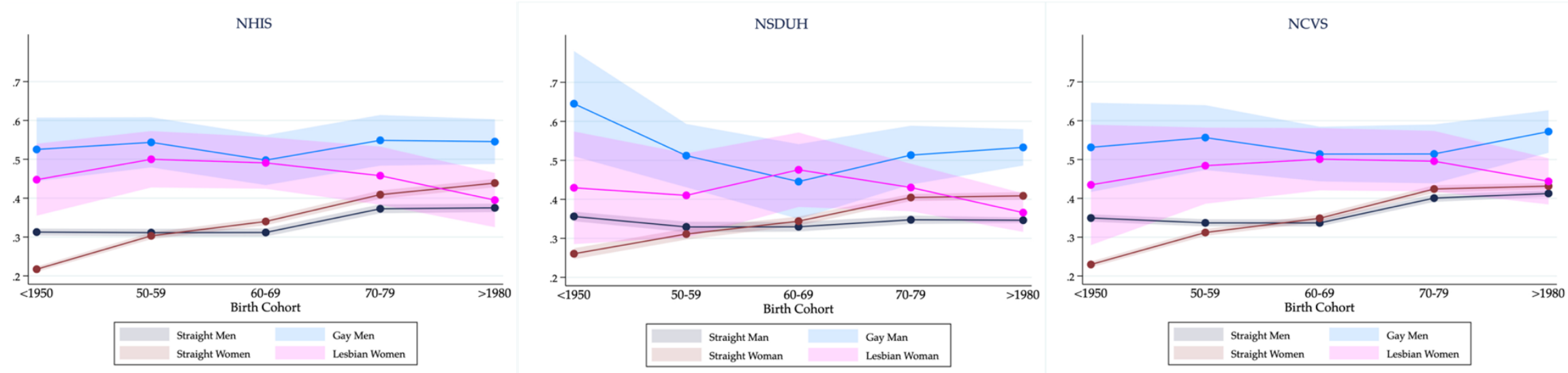

Note: Estimates are the average adjusted predictions calculated from the three-way interaction of sexual identity-by-sex-by-birth cohort in a survey-weighted logistic regression. Regression models also controlled for: race/ethnicity and nativity. Complete regression results presented in online supplement. NHIS=National Health Interview Survey $(N=197,277)$; NSDUH=National Study of Drug Use and Health $(N=149,189)$; NCVS=National Crime Victimization Survey $(N=141,567)$. 
Figure 5: Bachelor's Degree Attainment or Enrollment, by Sex and Sexuality, Among Contemporary Cohorts
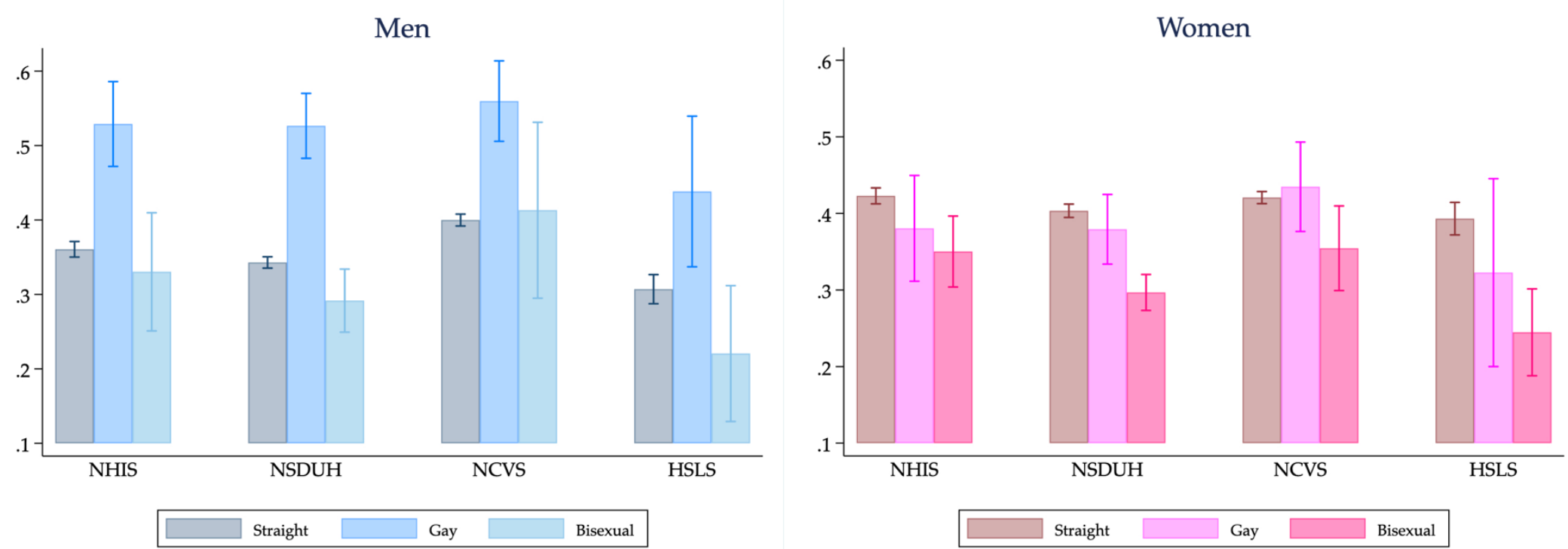

Note: NHIS, NSDUH and NCVS samples are restricted to those born after 1980. NHIS, NHSDUH and NCVS estimates are the average adjusted predictions calculated from the two-way interaction of sexual identity-by-sex in a survey-weighted logistic regression, controlling for race/ethnicity and nativity. HSLS estimates are surveyweighted group means. Complete regression results presented in online supplement. NHIS=National Health Interview Survey $(N=40,709)$; NSDUH=National Study of Drug Use and Health $(N=62,577)$; NCVS=National Crime Victimization Survey $(N=36,066)$; HSLS=High School Longitudinal Study of 2009 $(N \approx 15,270)$. 
Table 3: Academic Performance and Orientation, High School Longitudinal Study of 2009

\begin{tabular}{|c|c|c|c|c|c|c|}
\hline & \multicolumn{3}{|c|}{ Male } & \multicolumn{3}{|c|}{ Female } \\
\hline & Straight & Gay & Bisexual & Straight & Gay & Bisexual \\
\hline \multicolumn{7}{|c|}{ Educational Attainment } \\
\hline High School Diploma ${ }^{1}$ & $\begin{array}{c}89.39 \\
{[87.96,90.81]}\end{array}$ & $\begin{array}{c}90.28 \\
{[83.02,97.55]}\end{array}$ & $\begin{array}{c}87.33 \\
{[85.34,89.32]}\end{array}$ & $\begin{array}{c}92.85 \\
{[91.8,93.9]}\end{array}$ & $\begin{array}{c}85.76 \\
{[82.36,89.16]}\end{array}$ & $\begin{array}{c}85.38^{* *} \\
{[82.28,88.48]}\end{array}$ \\
\hline Ever "Dropped Out" High School ${ }^{1}$ & $\begin{array}{c}18.5 \\
{[16.68,20.32]}\end{array}$ & $\begin{array}{c}11.45^{*} \\
{[.17,22.72]}\end{array}$ & $\begin{array}{c}22.9 \\
{[17.92,27.87]}\end{array}$ & $\begin{array}{c}14.71 \\
{[13.22,16.2]}\end{array}$ & $\begin{array}{c}28.15^{*} \\
{[17.36,38.94]}\end{array}$ & $\begin{array}{c}28.31 * * * \\
{[20.83,35.78]}\end{array}$ \\
\hline Enrolled for BA in $2016^{1}$ & $\begin{array}{c}31.08 \\
{[29.1,33.05]}\end{array}$ & $\begin{array}{c}44.02 * \\
{[30.22,57.81]}\end{array}$ & $\begin{array}{c}22.25^{\wedge} \\
{[10.46,34.03]}\end{array}$ & $\begin{array}{c}39.31 \\
{[37.12,41.5]}\end{array}$ & $\begin{array}{c}32.46 \\
{[21.05,43.87]}\end{array}$ & $\begin{array}{c}24.66^{* * *} \\
{[18.16,31.16]}\end{array}$ \\
\hline \multicolumn{7}{|c|}{ Transcript Outcomes: Achievement and Course-Taking } \\
\hline High school GPA ${ }^{2}$ & $\begin{array}{c}2.53 \\
{[2.49,2.57]}\end{array}$ & $\begin{array}{c}2.85^{* * *} \\
{[2.58,3.12]}\end{array}$ & $\begin{array}{c}2.47 \\
{[2.3,2.64]}\end{array}$ & $\begin{array}{c}2.82 \\
{[2.77,2.86]}\end{array}$ & $\begin{array}{c}2.44^{*} \\
{[2.27,2.62]}\end{array}$ & $\begin{array}{c}2.53 * * * \\
{[2.41,2.65]}\end{array}$ \\
\hline Post-Secondary GPA ${ }^{3}$ & $\begin{array}{c}2.51 \\
{[2.46,2.56]}\end{array}$ & $\begin{array}{c}2.94 * * * \\
{[2.78,3.1]}\end{array}$ & $\begin{array}{c}2.28 \\
{[2.14,2.42]}\end{array}$ & $\begin{array}{c}2.77 \\
{[2.72,2.82]}\end{array}$ & $\begin{array}{c}2.61 \\
{[2.42,2.79]}\end{array}$ & $\begin{array}{c}2.58^{\wedge} \\
{[2.29,2.88]}\end{array}$ \\
\hline Curricular Intensity Scale ${ }^{2}$ & $\begin{array}{c}-.32 \\
{[-.37,-.27]} \\
\end{array}$ & $\begin{array}{c}.10 * * * \\
{[-.19, .39]}\end{array}$ & $\begin{array}{c}-.34 \\
{[-.58,-.1]}\end{array}$ & $\begin{array}{c}-.08 \\
{[-.13,-.02]}\end{array}$ & $\begin{array}{c}-.32 \\
{[-.56,-.08]}\end{array}$ & $\begin{array}{c}-.28 * * \\
{[-.44,-.13]}\end{array}$ \\
\hline \multicolumn{7}{|c|}{ Attitudes and Behaviors (Z-Scores) } \\
\hline Academic Behaviors Scale ${ }^{4}$ & $\begin{array}{c}-.26 \\
{[-.31,-.2]}\end{array}$ & $\begin{array}{c}.03 * \\
{[-.2, .25]}\end{array}$ & $\begin{array}{c}-.22 \\
{[-.44, .01]}\end{array}$ & $\begin{array}{c}.08 \\
{[.03, .13]}\end{array}$ & $\begin{array}{c}-.09 \\
{[-.39, .21]}\end{array}$ & $\begin{array}{c}-.15^{* * *} \\
{[-.29,-.01]}\end{array}$ \\
\hline Academic Attitudes Scale ${ }^{5}$ & $\begin{array}{c}-.19 \\
{[-.23,-.14]}\end{array}$ & $\begin{array}{c}.16^{* * *} \\
{[-.12, .44]}\end{array}$ & $\begin{array}{c}-.33 \\
{[-.67,0]}\end{array}$ & $\begin{array}{c}.04 \\
{[0, .08]}\end{array}$ & $\begin{array}{c}-.28^{\wedge} \\
{[-.61, .05]}\end{array}$ & $\begin{array}{c}-.27 * * * \\
{[-.44,-.11]}\end{array}$ \\
\hline Friends' Academic Orientation Scale ${ }^{5}$ & $\begin{array}{c}-.29 \\
{[-.34,-.24]}\end{array}$ & $\begin{array}{c}.11 * * * \\
{[-.16, .38]} \\
\end{array}$ & $\begin{array}{c}-.19 \\
{[-.46, .09]}\end{array}$ & $\begin{array}{c}-.06 \\
{[-.11,-.01]}\end{array}$ & $\begin{array}{c}-.37^{\wedge} \\
{[-.67,-.07]}\end{array}$ & $\begin{array}{c}-.38 * * * \\
{[-.52,-.23]}\end{array}$ \\
\hline
\end{tabular}


Table 3: Academic Performance and Orientation: High School Longitudinal Study of 2009

\begin{tabular}{|c|c|c|c|c|c|c|}
\hline & \multicolumn{3}{|c|}{ Male } & \multicolumn{3}{|c|}{ Female } \\
\hline & Straight & Gay & Bisexual & Straight & Gay & Bisexual \\
\hline \multicolumn{7}{|c|}{ Discrimination and Minority Stress } \\
\hline Disagree: "I feel safe at this school"4 & $\begin{array}{c}10.69 \\
{[9.32,12.07]}\end{array}$ & $\begin{array}{c}19.12^{\wedge} \\
{[7.94,30.31]}\end{array}$ & $\begin{array}{c}18.04^{\wedge} \\
{[9.16,26.92]}\end{array}$ & $\begin{array}{c}8.25 \\
{[6.97,9.53]}\end{array}$ & $\begin{array}{c}9.53 \\
{[2.2,16.86]}\end{array}$ & $\begin{array}{c}18.12^{\wedge} \\
{[12.81,23.43]}\end{array}$ \\
\hline $\begin{array}{l}\text { "Discrimination...has limited [my] } \\
\text { educational opportunities"1 }\end{array}$ & $\begin{array}{c}12.67 \\
{[11.04,14.3]}\end{array}$ & $\begin{array}{c}22.54 * \\
{[12.47,32.61]}\end{array}$ & $\begin{array}{c}19.68 \\
{[8.44,30.93]}\end{array}$ & $\begin{array}{c}11.72 \\
{[10.24,13.2]}\end{array}$ & $\begin{array}{c}16.75 \\
{[4.02,29.48]}\end{array}$ & $\begin{array}{c}16.53^{\wedge} \\
{[10.73,22.33]}\end{array}$ \\
\hline $\begin{array}{l}\text { Had "serious difficulty concentrating } \\
\ldots \text { [because of] mental health issue."1 }\end{array}$ & $\begin{array}{c}9.91 \\
{[8.59,11.23]} \\
\end{array}$ & $\begin{array}{c}19.01 * \\
{[7.44,30.59]}\end{array}$ & $\begin{array}{c}31.4 * * * \\
{[19.81,43]} \\
\end{array}$ & $\begin{array}{c}13.15 \\
{[11.57,14.74]} \\
\end{array}$ & $\begin{array}{c}26.47 * * \\
{[14.42,38.52]} \\
\end{array}$ & $\begin{array}{c}30.14 * * * \\
{[24.45,35.83]} \\
\end{array}$ \\
\hline
\end{tabular}


Figure 6: L/G/B vs. Straight Disparities: High School Longitudinal Study of 2009
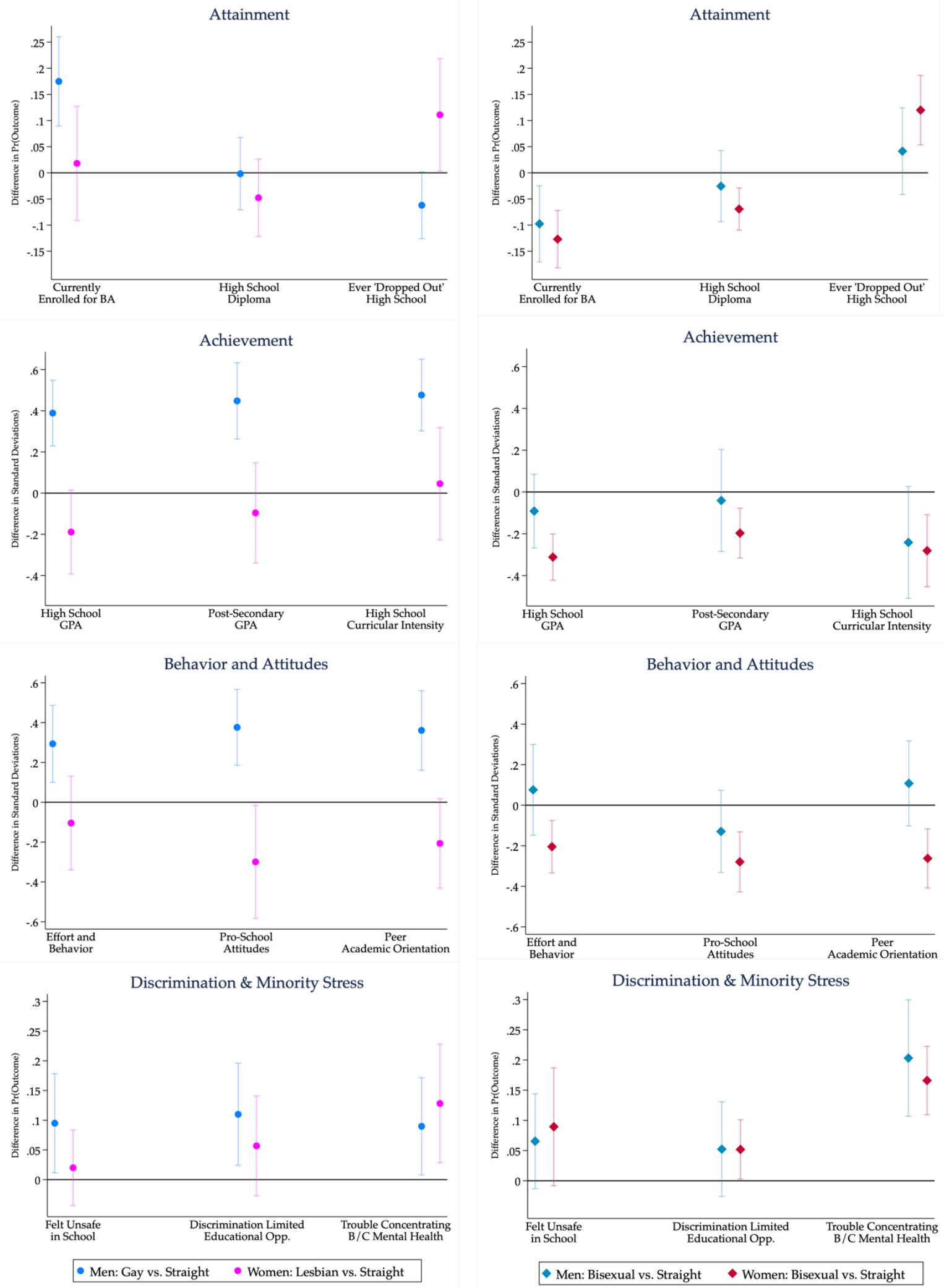

Note: Presented estimates are the average marginal effect of an L/G/B identity, calculated from the two-way interaction of sexual identity-by-sex in a survey-weighted fixed effects regression, controlling for students' race/ethnicity, native English speaking, parents' socioeconomic status and sample high school fixed effects. Complete regression results presented in online supplement. 
Table 4: Gender Predictability: Top 10 Answer Choices Most Predictive of Being Male in HSLS

\begin{tabular}{|c|c|c|}
\hline Question & Answer Choice & Odds Ratio \\
\hline During a typical weekday during the school year how many hours do you spend playing video games? & Less than 1 hour & 0.51 \\
\hline $\begin{array}{l}\text { Since the beginning of the last school year (2008-2009), which of the following people have you talked } \\
\text { with about personal problems? }\end{array}$ & Your friends: No & 1.46 \\
\hline As things stand now, what is the job or occupation that you expect or plan to have at age $30 ?^{*}$ & Registered Nurse & 0.70 \\
\hline As things stand now, what is the job or occupation that you expect or plan to have at age $30 ?$ & Registered Nurse & 0.74 \\
\hline $\begin{array}{l}\text { Since the beginning of the last school year (2008-2009), which of the following people have you talked } \\
\text { with about personal problems? }\end{array}$ & $\begin{array}{l}\text { Your mother or female } \\
\text { guardian: Yes }\end{array}$ & 0.76 \\
\hline $\begin{array}{l}\text { Since the beginning of the last school year (2008-2009), which of the following people have you talked } \\
\text { with about personal problems? }\end{array}$ & $\begin{array}{l}\text { Your father or } \\
\text { male guardian: Yes }\end{array}$ & 1.31 \\
\hline As things stand now, what is the job or occupation that you expect or plan to have at age $30 ?$ & $\begin{array}{l}\text { Athletes and } \\
\text { sports competitors }\end{array}$ & 1.31 \\
\hline $\begin{array}{l}\text { During a typical weekday during the school year how many hours do you spend chatting or surfing } \\
\text { online? }\end{array}$ & Less than 1 hour & 1.29 \\
\hline During a typical weekday during the school year how many hours do you spend playing video games? & Missing & 0.78 \\
\hline In general, how would you compare males and females in English or language arts?* & Females are much better & 0.80 \\
\hline
\end{tabular}

Notes: Results from lasso logistic regression predicting reported sex being male. Lasso estimated using 10-fold cross validation and a final, selected lambda of 0.00287. Lasso selected 1,132 non-zero coefficients with an out-of-sample deviance ratio of 0.48 . Occupational aspirations were reported in open-ended question, recoded by NCES staff using six-digit O-NET codes. * Indicates responses on $11^{\text {th }}$ grade survey; otherwise, responses are from $9^{\text {th }}$ grade survey. Italicized items highlight answer choices negatively associated with reported male. Top 50 most predictive answer choices presented in Online Table 1. 
Figure 7: Gender Predictability: Estimated Gender Typicality by Sex and Sexuality in HSLS

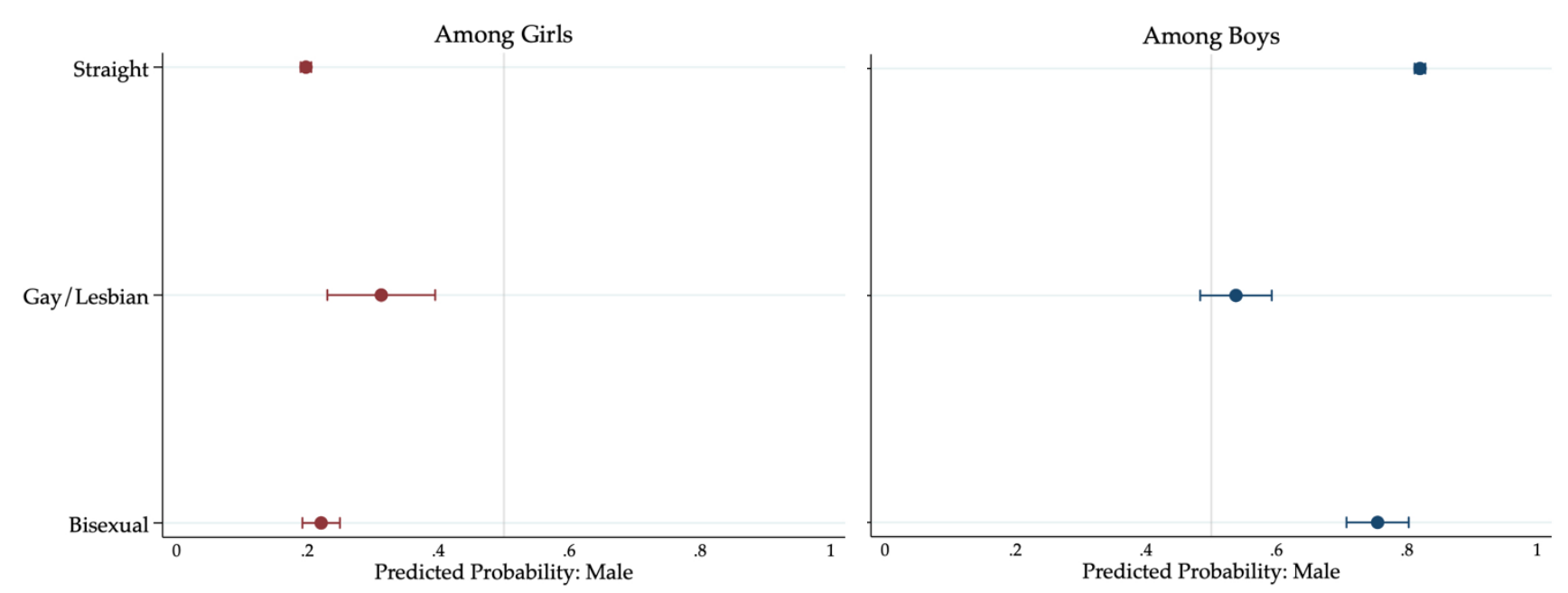

Note: Results are the survey-weighted average and $95 \%$ confidence interval of the predicted probability of being male, estimated using lasso logistic regression described in Table 4. 
Figure 8: Plotting Selected Outcomes by Predicted Gender Atypicality: HSLS
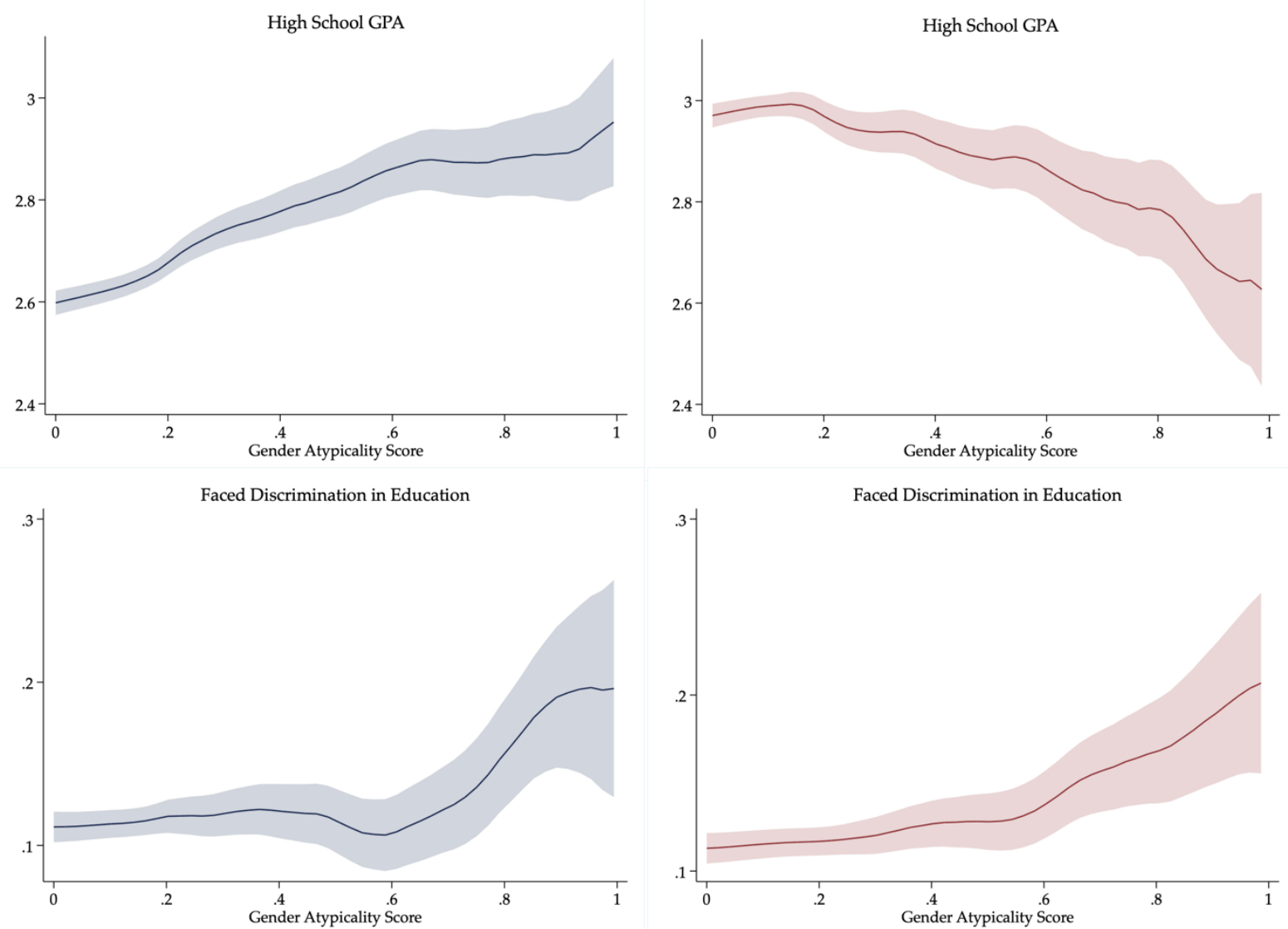

Note: Results reflect kernel-weighted local polynomial regressions, separately for men (on left; $N \approx 7,390$ ) and women (on right; $N \approx 7,890$ ). $95 \%$ confidence intervals shaded around estimates. Gender atypicality calculated, for women, as the lasso-generated predicted probability of being male and, for men, as one minus this predicted probability. 
Table 5: Gender Atypicality and L/G/B Students' High School GPA

\begin{tabular}{l|cc|cc}
\hline \multicolumn{3}{c}{ Males } & \multicolumn{2}{c}{ Females } \\
\hline Gay/Lesbian (Ref: Straight) & $0.36^{* * *}$ & $0.26^{* *}$ & $-0.21^{*}$ & $-0.18^{*}$ \\
& $(0.08)$ & $(0.08)$ & $(0.10)$ & $(0.09)$ \\
Bisexual & -0.05 & -0.07 & $-0.26^{* * *}$ & $-0.25^{* * *}$ \\
& $(0.08)$ & $(0.08)$ & $(0.05)$ & $(0.05)$ \\
Gender Atypicality & & $0.35^{* * *}$ & & $-0.28^{* * *}$ \\
& & $(0.07)$ & & $(0.07)$ \\
Constant & & & & $3.15^{* * *}$ \\
& $2.89^{* * *}$ & $2.86^{* * *}$ & $3.10^{* * *}$ & $(0.04)$ \\
\hline
\end{tabular}

Notes: $* * * \mathrm{p}<0.001, * * \mathrm{p}<0.01,{ }^{*} \mathrm{p}<0.05$. Survey-weighted fixed effects regression, controlling for students' race/ethnicity, native English speaking, parents' socioeconomic status and sample high school fixed effects. Male $(N \approx 7,390)$; Female $(N \approx$ $7,890)$. 
ADDITIONAL MATERIALS INTENDED FOR ONLINE SUPPLEMENT

1) Additional Figures and Tables Mentioned in the Text

2) Sensitivity Analyses

3) Complete Regression Results for all Figures in the Text 
Online Figure 1: Full Distribution of Reported Gender Expression Among American High School Students: Selected Cities, 2017/19
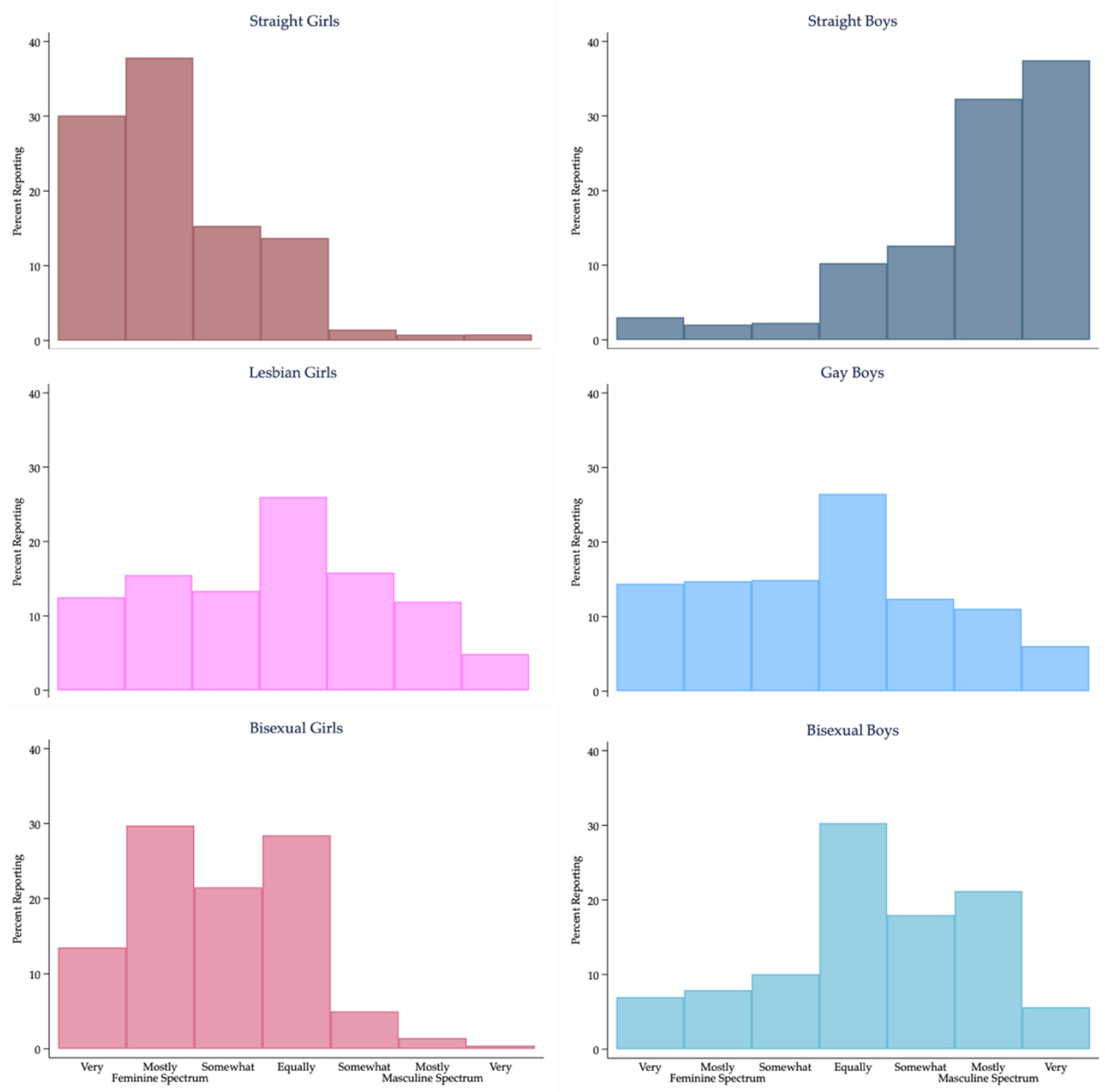

Note: Data from 2017 and/or 2019 Youth Risk Behavior Surveillance System surveys in Chicago, Los Angeles, New York City, San Diego, San Francisco, Oakland CA, Philadelphia, Seattle, Broward County FL and Duval County FL. $N=38,183$. 
Online Figure 2: Lesbian, Gay and Bisexual Identification by Birth Cohort and Dataset
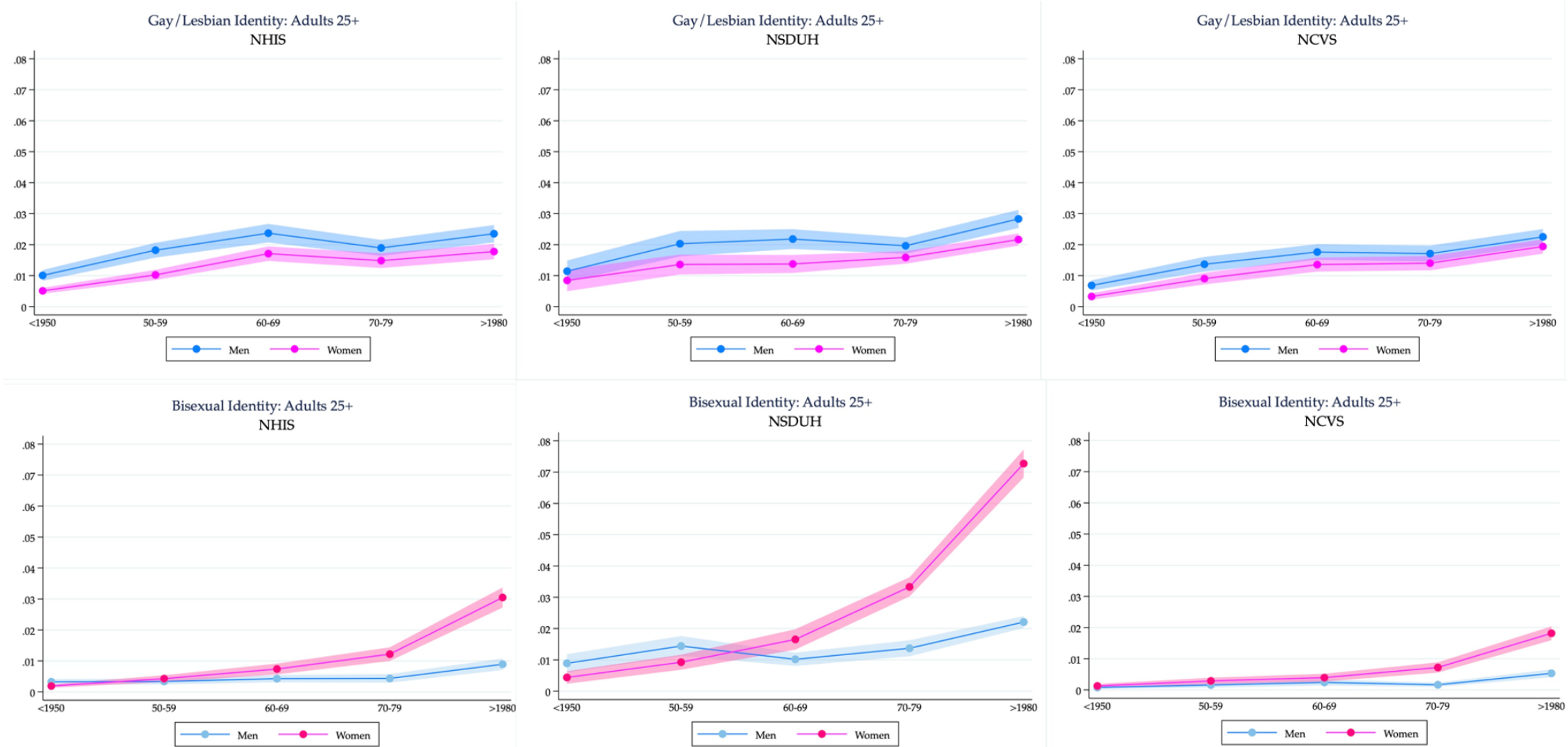

Note: Survey-weighted estimates reflect complex sampling procedures and are representative of the civilian, non-institutionalized adult (25+) population of the United States. NHIS=National Health Interview Survey $(N=197,277)$; NSDUH=National Study of Drug Use and Health $(N=149,189)$; NCVS=National Crime Victimization Survey $(N=141,567)$. 
Online Figure 3: Bisexual and Straight Bachelor's Degree Attainment by Sex and Birth Cohort
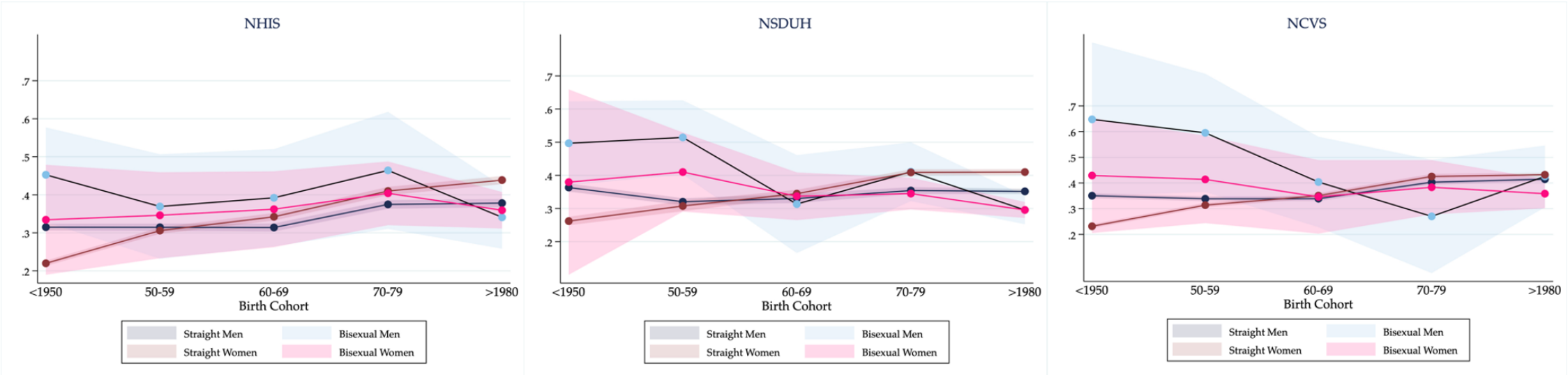

Note: Estimates are the average adjusted predictions calculated from the three-way interaction of sexual identity-by-sex-by-birth cohort in a survey-weighted logistic regression. Regression models also controlled for: race/ethnicity and nativity. NHIS=National Health Interview Survey $(N=197,277)$; NSDUH=National Study of Drug Use and Health $(N=149,189)$; NCVS=National Crime Victimization Survey $(N=141,567)$. 
Online Figure 4: Predicted Probability of Being Male by Sex and Sexuality: HSLS
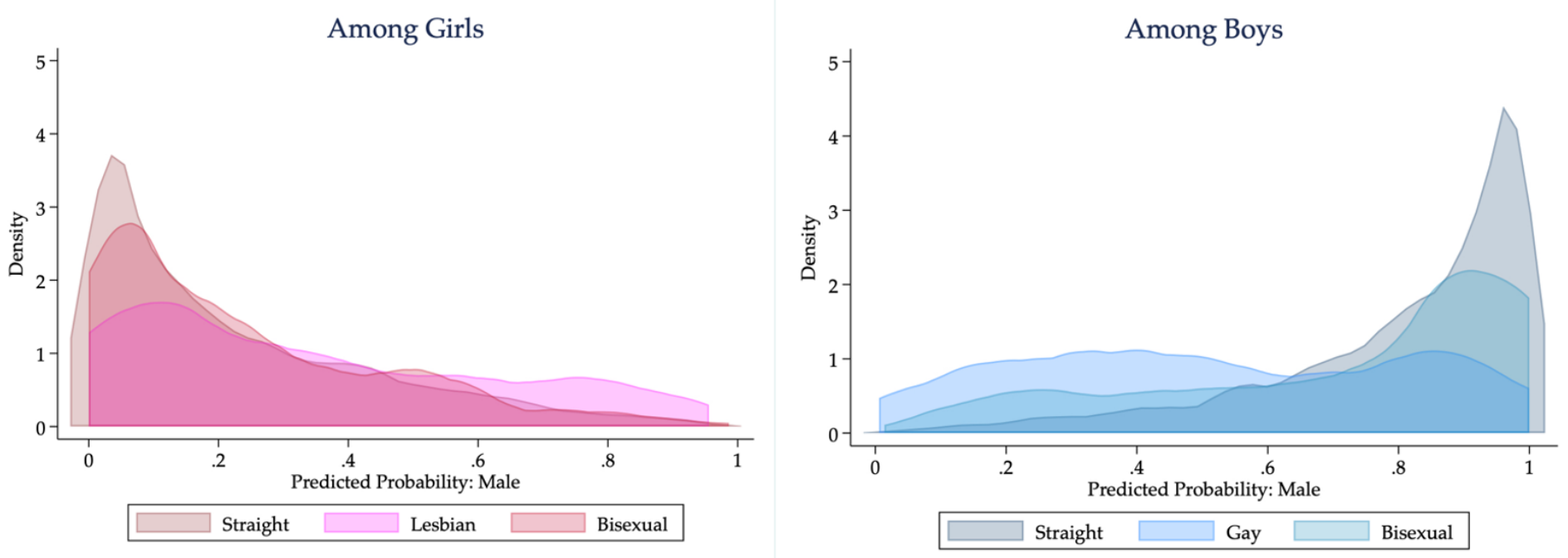

Note: Figures show the kernel density distribution of the predicted probability of being male, estimated using the lasso logistic regression described in Table 4. 
Online Figure 5: Recent Exclusionary Discipline by Sex and Sexuality: HSLS
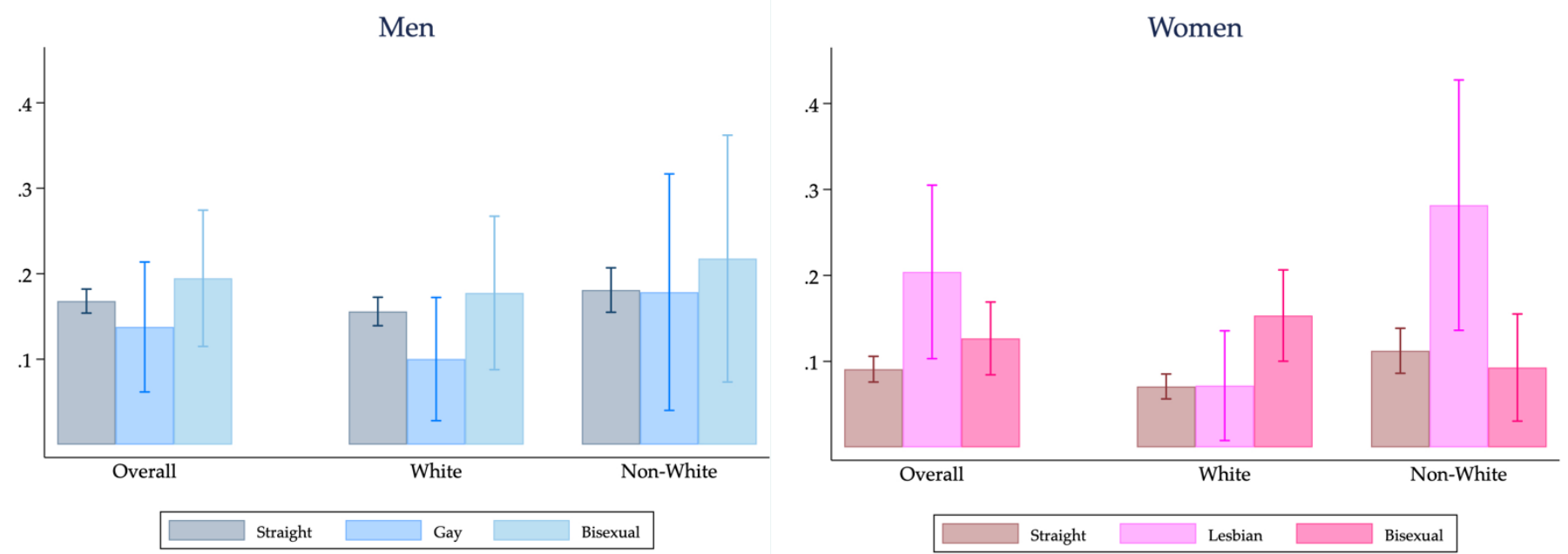

Note: Presented estimates are the average adjusted predictions calculated from the two-way interaction of sexual identity-by-sex in a survey-weighted fixed effects regression, controlling for students' race/ethnicity, native English speaking, parents' socioeconomic status and sample high school fixed effects. 
Appendix Table 1: Gender Predictability: Top 50 Answer Choices Most Predictive of Being Male in HSLS

\begin{tabular}{|c|c|c|}
\hline Question & Answer Choice & Odds Ratio \\
\hline $\begin{array}{l}\text { During a typical weekday during the school year how many hours do you spend playing } \\
\text { video games? }\end{array}$ & Less than 1 hour & 0.51 \\
\hline $\begin{array}{l}\text { Since the beginning of the last school year (2008-2009), which of the following people } \\
\text { have you talked with about personal problems? }\end{array}$ & Your friends: No & 1.46 \\
\hline $\begin{array}{l}\text { As things stand now, what is the job or occupation that you expect or plan to have at age } \\
30 ?^{*}\end{array}$ & Registered Nurse & 0.7 \\
\hline $\begin{array}{l}\text { As things stand now, what is the job or occupation that you expect or plan to have at age } \\
30 ?\end{array}$ & Registered Nurse & 0.74 \\
\hline $\begin{array}{l}\text { Since the beginning of the last school year (2008-2009), which of the following people } \\
\text { have you talked with about personal problems? }\end{array}$ & Your mother or female guardian: Yes & 0.76 \\
\hline $\begin{array}{l}\text { Since the beginning of the last school year (2008-2009), which of the following people } \\
\text { have you talked with about personal problems? }\end{array}$ & Your father or male guardian: Yes & 1.31 \\
\hline $\begin{array}{l}\text { As things stand now, what is the job or occupation that you expect or plan to have at age } \\
30 \text { ? }\end{array}$ & Athletes and sports competitors & 1.31 \\
\hline $\begin{array}{l}\text { During a typical weekday during the school year how many hours do you spend chatting or } \\
\text { surfing online? }\end{array}$ & Less than 1 hour & 1.29 \\
\hline $\begin{array}{l}\text { During a typical weekday during the school year how many hours do you spend playing } \\
\text { video games? }\end{array}$ & Missing & 0.78 \\
\hline In general, how would you compare males and females in English or language arts? ${ }^{*}$ & Females are much better & 0.8 \\
\hline How often do you go to class without pencil or paper? & Never & 0.81 \\
\hline $\begin{array}{l}\text { As things stand now, what is the job or occupation that you expect or plan to have at age } \\
30 ?^{*}\end{array}$ & Hairdresser, hairstylist, cosmetologist & 0.81 \\
\hline Not including lunch or study periods, what is your favorite school subject? & Physical education or gym & 1.23 \\
\hline $\begin{array}{l}\text { As things stand now, what is the job or occupation that you expect or plan to have at age } \\
30 ?\end{array}$ & Hairdresser, hairstylist, cosmetologist & 0.83 \\
\hline
\end{tabular}

(Continued on next page) 
Appendix Table 1: Gender Predictability: Top 50 Answer Choices Most Predictive of Being Male in HSLS

\begin{tabular}{|c|c|c|}
\hline Question & Answer Choice & Odds Ratio \\
\hline $\begin{array}{l}\text { How many of your close friends plan to have a full-time job instead of continuing their } \\
\text { education?* }\end{array}$ & None of them & 0.84 \\
\hline $\begin{array}{l}\text { Since the fall of 2009, have you participated in any of the following activities outside of } \\
\text { school?* }\end{array}$ & Music or dance: Yes & 0.84 \\
\hline $\begin{array}{l}\text { During a typical weekday during the school year how many hours do you spend chatting or } \\
\text { surfing online? }\end{array}$ & 5 or more hours & 0.84 \\
\hline Not including lunch or study periods, what is your favorite school subject?* & Physical education or gym & 1.19 \\
\hline $\begin{array}{l}\text { As things stand now, what is the job or occupation that you expect or plan to have at age } \\
30 ?\end{array}$ & Veterinarians & 0.84 \\
\hline Which of the following activities do you expect to be doing in the fall of $2013^{*}$ & Serving in the military: Don't Know & 1.19 \\
\hline $\begin{array}{l}\text { As things stand now, what is the job or occupation that you expect or plan to have at age } \\
30 \text { ? }\end{array}$ & Vehicle/mobile equipment installers & 1.18 \\
\hline Not including lunch or study periods, what is your least favorite school subject? & English & 1.17 \\
\hline In general, how would you compare males and females in Science?* & Males are much better & 1.17 \\
\hline In general, how would you compare males and females in Math? & Males are much better & 1.17 \\
\hline $\begin{array}{l}\text { As things stand now, what is the job or occupation that you expect or plan to have at age } \\
30 ?\end{array}$ & Pediatricians & 0.86 \\
\hline Not including lunch or study periods, what is your favorite school subject?* & $\begin{array}{l}\text { Social studies, history, government, or } \\
\text { civics }\end{array}$ & 1.15 \\
\hline $\begin{array}{l}\text { During a typical weekday during the school year how many hours do you spend playing } \\
\text { video games? }\end{array}$ & 5 or more hours & 1.15 \\
\hline Not including lunch or study periods, what is your favorite school subject?* & Art & 0.87 \\
\hline $\begin{array}{l}\text { As things stand now, what is the job or occupation that you expect or plan to have at age } \\
30 ?^{*}\end{array}$ & Diagnostic medical sonographers & 0.87 \\
\hline What is your birth year? & 1995 & 0.87 \\
\hline
\end{tabular}

(Continued on next page) 
Appendix Table 1: Gender Predictability: Top 50 Answer Choices Most Predictive of Being Male in HSLS

Question

Answer Choice

Odds Ratio

Since the fall of 2009, have you participated in any of the following activities outside of school?*

Organized sports supervised by an adult: Yes

Since the beginning of the last school year (2008-2009), which of the following people have you talked with about personal problems?

Have you ever done any of the following activities to prepare for life after high school?*

As things stand now, what is the job or occupation that you expect or plan to have at age 30 ?

How many times did you attend class without pencil and paper, computer or other device for taking notes happen during the last 6 months?*

In general, how would you compare males and females in English or language arts

Not including lunch or study periods, what is your favorite school subject?

In general, how would you compare males and females in English or language arts*

Have you ever participated in any of the following programs?*

Not including lunch or study periods, what is your favorite school subject?*

How much do you agree or disagree with the following statements about your [fall 2009 science] course?

Your father or male guardian: No

Searched the Internet for college options or read college guides: No

Forensic science technicians

Never

0.88

Males are much better

1.13

English

0.88

Males are much better

1.13

Talent Search: Don't know what this is

1.13

English

0.89

You are confident that you can do an

excellent job on tests in this course:

As things stand now, what is the job or occupation that you expect or plan to have at age $30 ?^{*}$

Strongly agree

Veterinarians

Since the beginning of the last school year (2008-2009), how often have you accessed web sites for computer technology information?

Not including lunch or study periods, what is your favorite school subject?

As things stand now, what is the job or occupation that you expect or plan to have at age 30 ?*

Often

Art

0.89

Psychologists

0.90

How many times were absent from school during the last 6 months?*

Never

1.11

(Continued on next page) 
Appendix Table 1: Gender Predictability: Top 50 Answer Choices Most Predictive of Being Male in HSLS

Question

Answer Choice

Odds Ratio

How important to you [will/would] each of the following characteristics be when choosing a school or college to attend after high school?*

Far away from home: Not at all important

As things stand now, what is the job or occupation that you expect or plan to have at age 30 ?

Primary/secondary/special ed teacher

During a typical weekday during the school year how many hours do you spend playing video games?

3 to 4 hours

As things stand now, what is the job or occupation that you expect or plan to have at age $30 ?^{*}$

Vehicle/mobile equipment installers

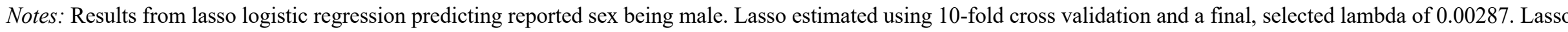

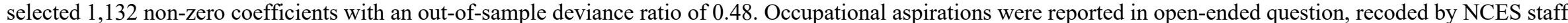

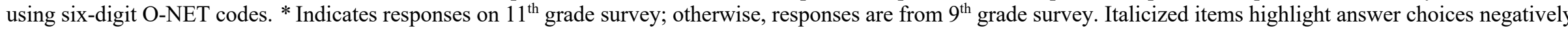
associated with reported male. 


\section{SENSITIVITY ANALYSES ON SELECTIVE REPORTING OF LGB IDENTITIES}

As discussed in the body of the text, I conducted two sets of sensitivity analyses assessing the likelihood that my primary results reflect something about who reports an LGB identity, rather than something about sexuality itself. Here, I describe these analyses more fully and present their results.

\section{Results by Sexual Attraction}

First, I assess whether my results are sensitive to my using an identity measure of sexuality, as opposed to an attraction or behavior measure. In the NSDUH, immediately before the sexual identity question, all respondents were asked "People are different in their sexual attraction to other people. Which statement best describes your feelings?" and given the following five options: "I am only attracted to females, " "I am mostly attracted to females," "I am equally attracted to females and males, "I am mostly attracted to males" and "I am only attracted to males." In Online Figure 6, I present the full set of responses, separately by sex.

As a reflection of the demography of American sexuality, the results in Online Figure 6 are interesting in and of themselves. They reveal, for example, that — in a large, nationallyrepresentative sample of American adults $(N=149,152)$ —about 4\% of straight-identified men and $8 \%$ of straight-identified women report feeling at least somewhat attracted to the members of the same sex. Within the gay and lesbian population, there is an even greater spread across attraction categories, particularly among women: $27 \%$ of gay-identified men and $45 \%$ of lesbian-identified women report at least some attraction to the other sex. Given the large sample size available in these data, further analyses could continue to uncover informative patterns by race/ethnicity, birth cohort or other dimensions of identity. 
Next, I explore how this attraction measure stratifies BA attainment. Online Figure 7 presented regression-adjusted BA attainment rates across the full, five category measure. These results broadly replicate the identity results presented in the main text. Among both men and women, those equally attracted to both sexes have the lowest rates of BA attainments of all groups and those mostly/only attracted to the same sex have significantly higher BA attainment rates than those who report being only attracted to the other sex. There is one intriguing result among women, however, which is that women who are mostly—but not exclusively—attracted to men actually have BA rates equivalent to those who are mostly/only attracted to women. Future analyses of these and other attraction data should further explore this group.

Finally, to more closely replicate the key results presented in the main text, I collapse this five-category attraction measure into three groups: those only/mostly attracted to the same sex, equally attracted to both sexes and only/mostly attracted to the other sex. Using this three-group measure, I re-estimate the regression models that produced Figure 2, Figure 3 and Figure 4 within the main text. I present these results together in Online Figure 8. For each set of resultsoverall, by race/ethnicity and birth cohort-the results in Online Figure 8 closely replicate those produced using the identity measure.

Taken together, these attraction analyses reinforce the fact the sexual attraction and sexual identity are closely connected but empirically distinct aspects of sexuality. Within any given sexual identity category, a full range of sexual attraction types are reported (and vice versa). Nevertheless, I find that sexual attraction stratifies BA attainment in much the same way that sexual identity does: not just overall, but also by race/ethnicity and birth cohort. Future analyses should explore if and how these results might change using a sexual behavior measure, which is unfortunately not available in any of my data. 
Online Figure 6: Sexual Attraction by Sex and Sexual Identity, American Adults, 25+
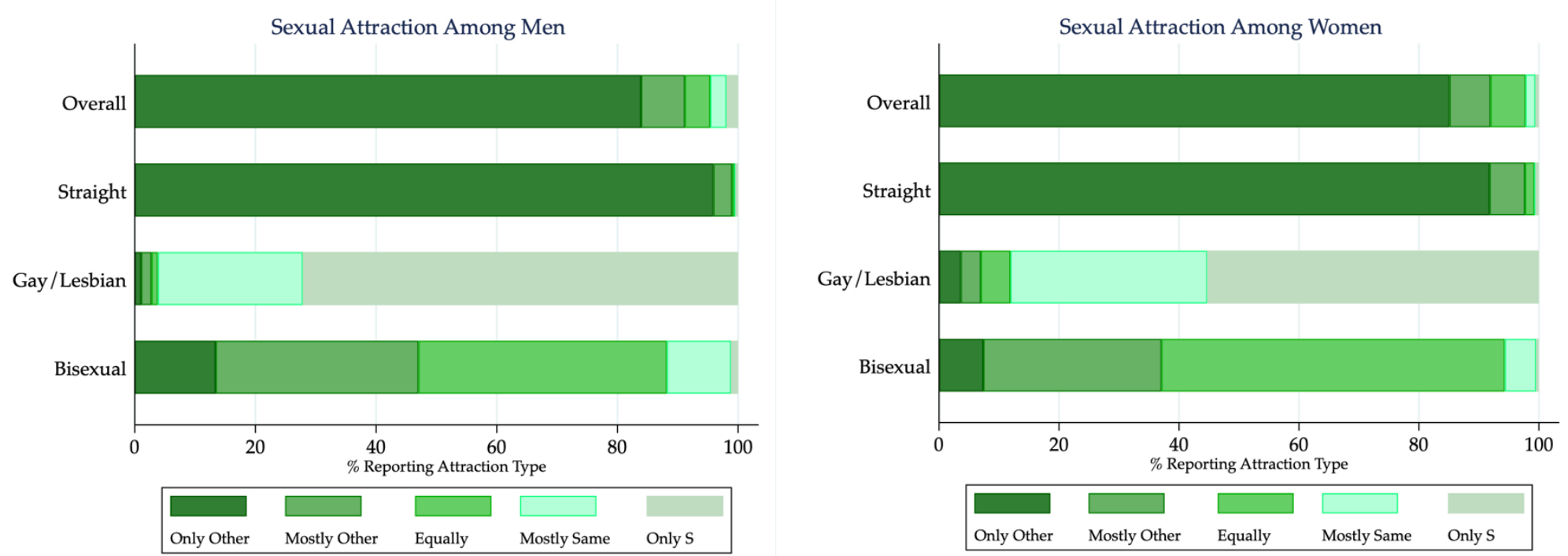

Notes: Data are from the National Study of Drug Use and Health, 2015-2019 $(N=149,152)$. Data are weighted to reflect complex sampling procedures and representative of the civilian, non-institutionalized adult $(25+)$ population of the United States. 
Online Figure 7: BA Attainment Rates Across Spectrum of Sexual Attraction, American Adults, 25+

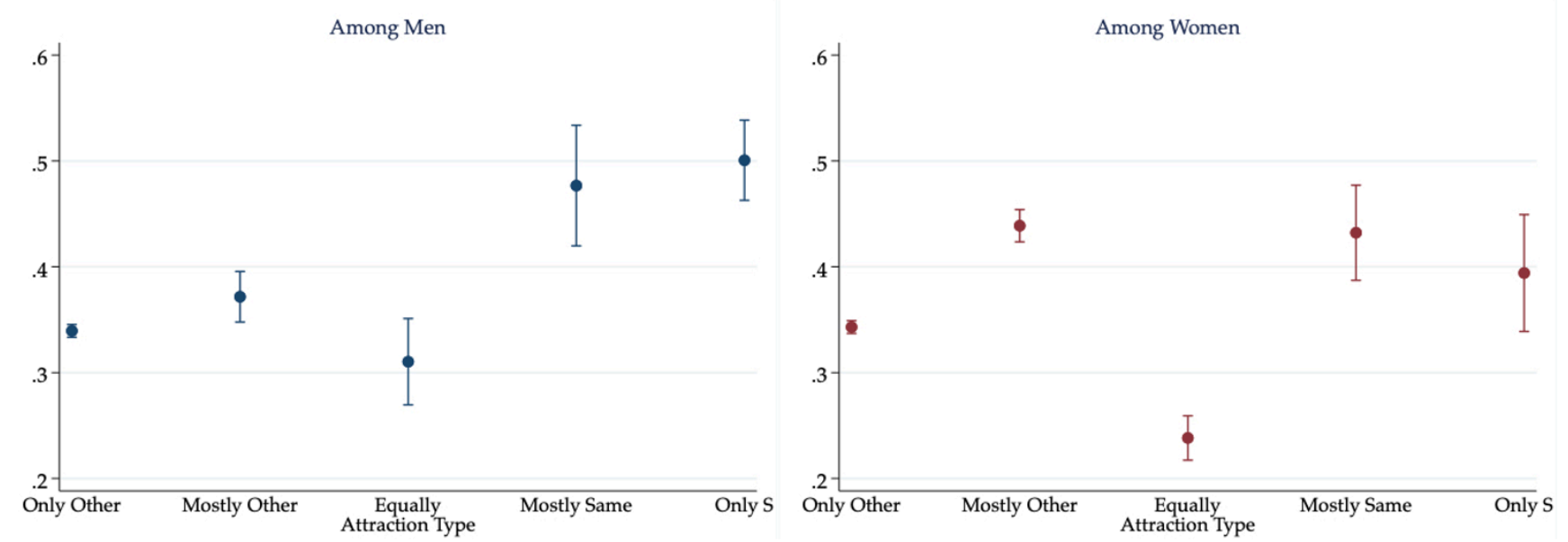

Notes: Data are from the National Study of Drug Use and Health, 2015-2019 $(N=149,152)$. Estimates are the average adjusted predictions calculated from the two-way interaction of sexual attraction-by-sex in a survey-weighted logistic regression. Regression models also controlled for: birth cohort, race/ethnicity and nativity. 
Online Figure 8: Replicating Identity Results Using Attraction: Overall, by Race/Ethnicity and Birth Cohort

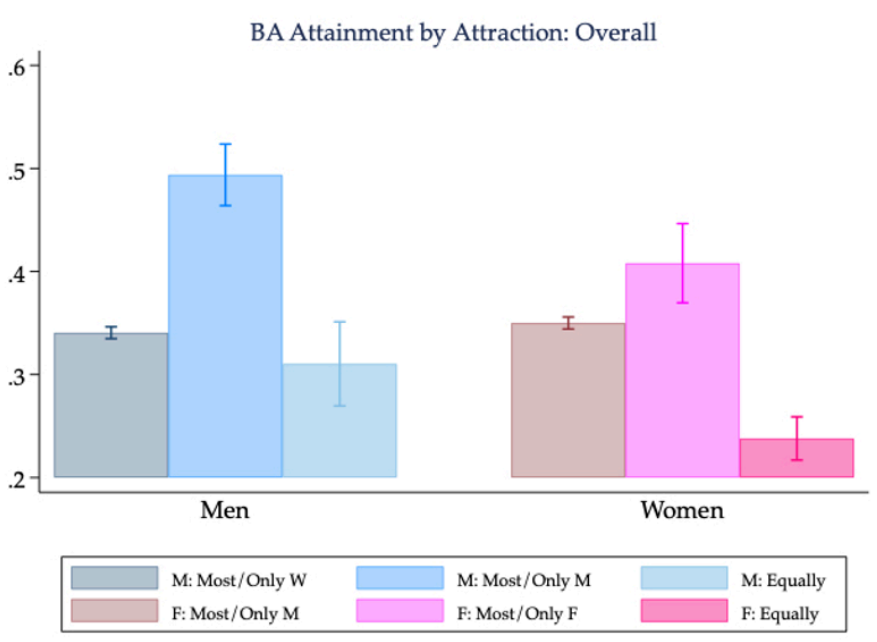

BA Disparities by Attraction: By Race/Ethnicity

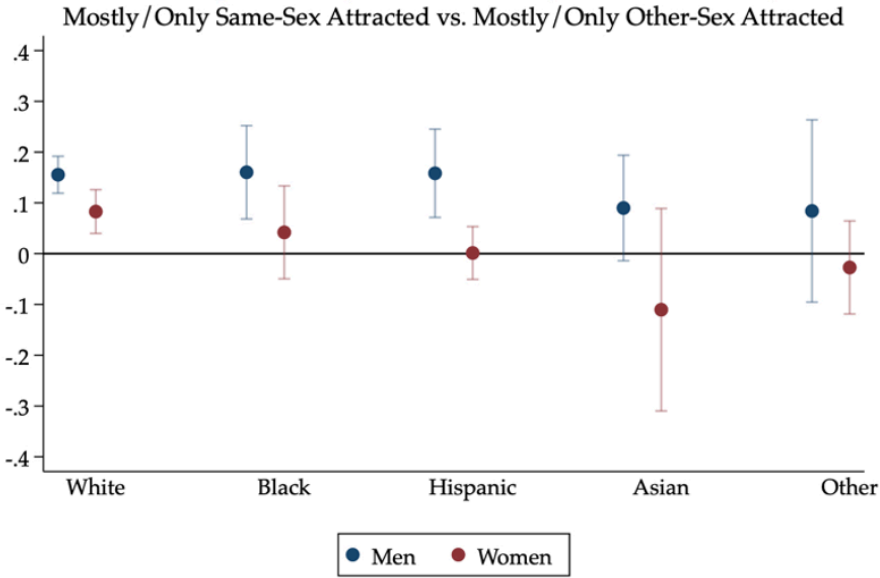

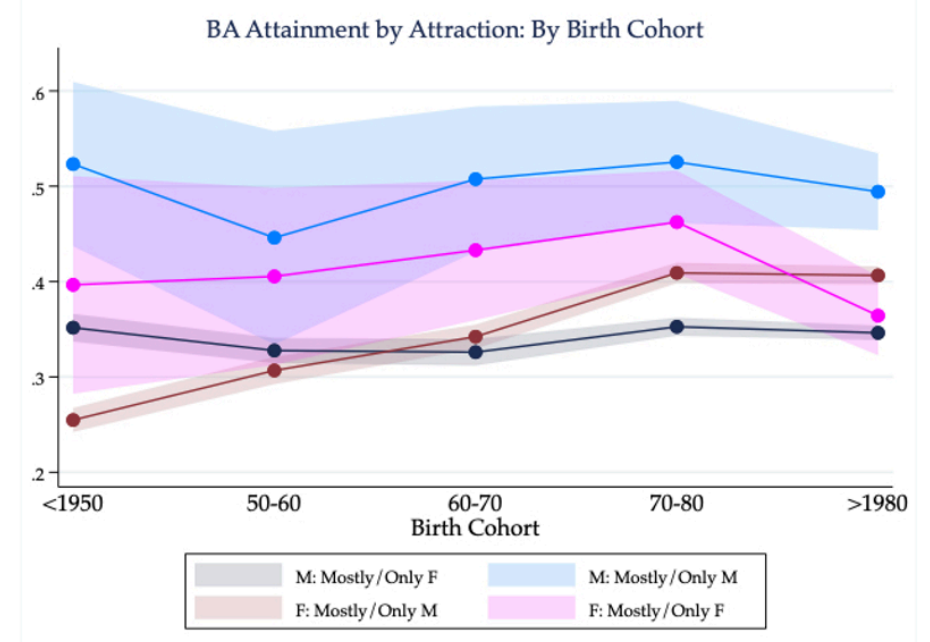

BA Disparities by Attraction: By Race/Ethnicity Equally Attracted Both Sexes vs. Mostly/Only Other-Sex Attracted

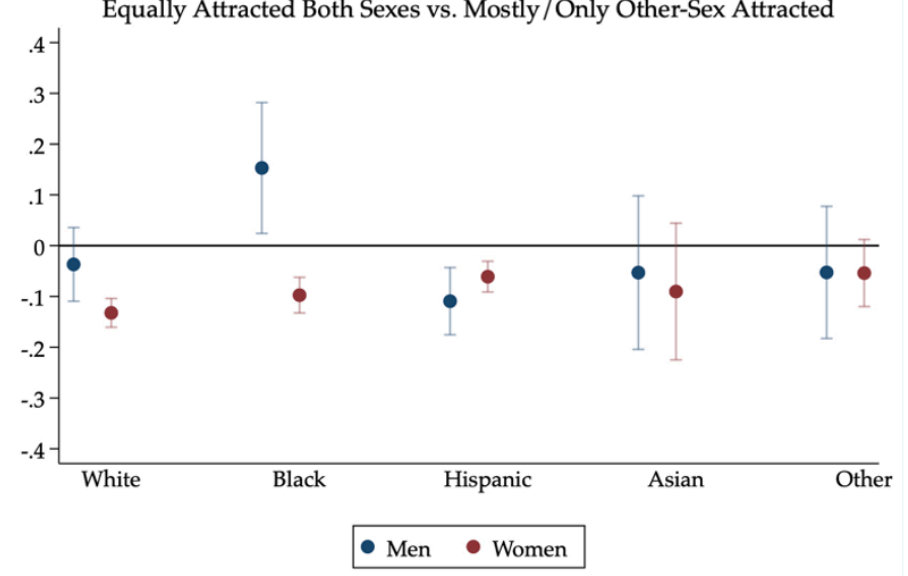

Notes: Data are from the National Study of Drug Use and Health, 2015-2019 $(N=149,152)$. Five-response sexual attraction measure collapsed into three categories: only/mostly attracted to same-sex, equally attracted to both sexes, mostly/only attracted to other sex. Results are average adjusted predictions or average marginal effects from survey-weighted logistic regressions with same specifications as in Figure 2, Figure 3 and Figure 4 of the main text. 
Assessing Selection Bias Underlying Gay Men's Advantages

Next, I more fully examine gay men's strikingly high levels of academic success, addressing a more traditional concern about selection bias. As mentioned in the text, one might imagine that reaching higher education affords gay men a freedom that makes them more willing to report their sexual identity. Or, more fundamentally, the college experience may reshape some men's sense of sexual possibility, affecting their sexual identity itself. In either case, I would be "selecting on the dependent variable" of academic success from a larger population. I address this concern in two ways.

First, I take advantage of a unique feature of the HSLS data: the fact that sexual identity was not reported until the college-aged survey. This allows me to test, more or less directly, the possibility that I am "selecting on the dependent variable" of higher education. If gay men's apparent successes in high school was only the result of the differential "coming out" of those who made it to college, then gay boys who never ended up enrolling in college should show no such advantages. As such, I reanalyze gay boys' academic outcomes within two distinct groups: those who did make it to college by the latest survey and those who did not. Online Figure 8 presents these results.

The results in Online Figure 8 demonstrate that, even among those didn't make it to college, gay boys still outperformed straight boys. Moreover, restricted only to those relatively strong students who did make it to college, gay boys still maintained an advantage in high school. These results indicate that, within the HSLS, gay boys' performance advantages are truly widespread and do not rely on selection by eventual college enrollment.

As one final check, I also analyze new data from the 2016/17 Baccalaureate and Beyond Longitudinal Study (B\&B:16/17). The fourth such study in NCES' longstanding Baccalaureate 
and Beyond Longitudinal Study series, the B\&B:16/17 is designed to analyze the undergraduate experience and post-college transitions of America's bachelor degree recipients. The B\&B:16/17 sample $(N \approx 19,490)$ is representative of the approximately 2.0 million students who completed the requirements for a bachelor's degree between July 1, 2015, and June 30, 2016. To my knowledge, the B\&B:16/17 is the first B\&B cohort in which students were able to report their sexuality.

Using these data, I analyze graduating students' cumulative undergraduate GPAs, as reported on the official transcripts provided by their colleges and universities. Specifically, I estimate a survey-weighted ordinary least squares regression, interacting students' reported sexuality and sex, controlling for race/ethnicity, nativity and whether they have at least one college-educated parent. Online Figure 9 presents these results in terms of the sex-specific average marginal effect of a gay/lesbian or bisexual identity.

The results in Online Figure 9 demonstrate that - even within this highly selective sample constituted only by students who enrolled in and successfully completed a bachelor's degree - gay men still substantially outperform straight men. As noted in the main text, the magnitude of this advantage $(0.15$ points, $\mathrm{p}<0.001)$ is more than double that associated with having at least one college-educated parent (0.06 points). Notably, these results also show that, even within this selective sample, lesbian women continue to be academically disadvantaged compared to straight women (-.09 points, $\mathrm{p} \approx 0.11)$. Bisexual men and women are precisely at parity with their straight counterparts.

Across datasets and selectively-defined subgroups, gay men persistently outperform straight men. I cannot definitively rule out the possibility these performance advantages reflect some unmeasurable selection into who reports a gay identity. However, given the magnitude of 
gay men's advantages across all analyses, I argue that any unmeasured "closeted" population may decrease gay men's advantages but would be highly unlikely to eliminate them entirely. 
Online Figure 8: Gay Boys' High School Performance Advantages, Stratified by Eventual College Enrollment

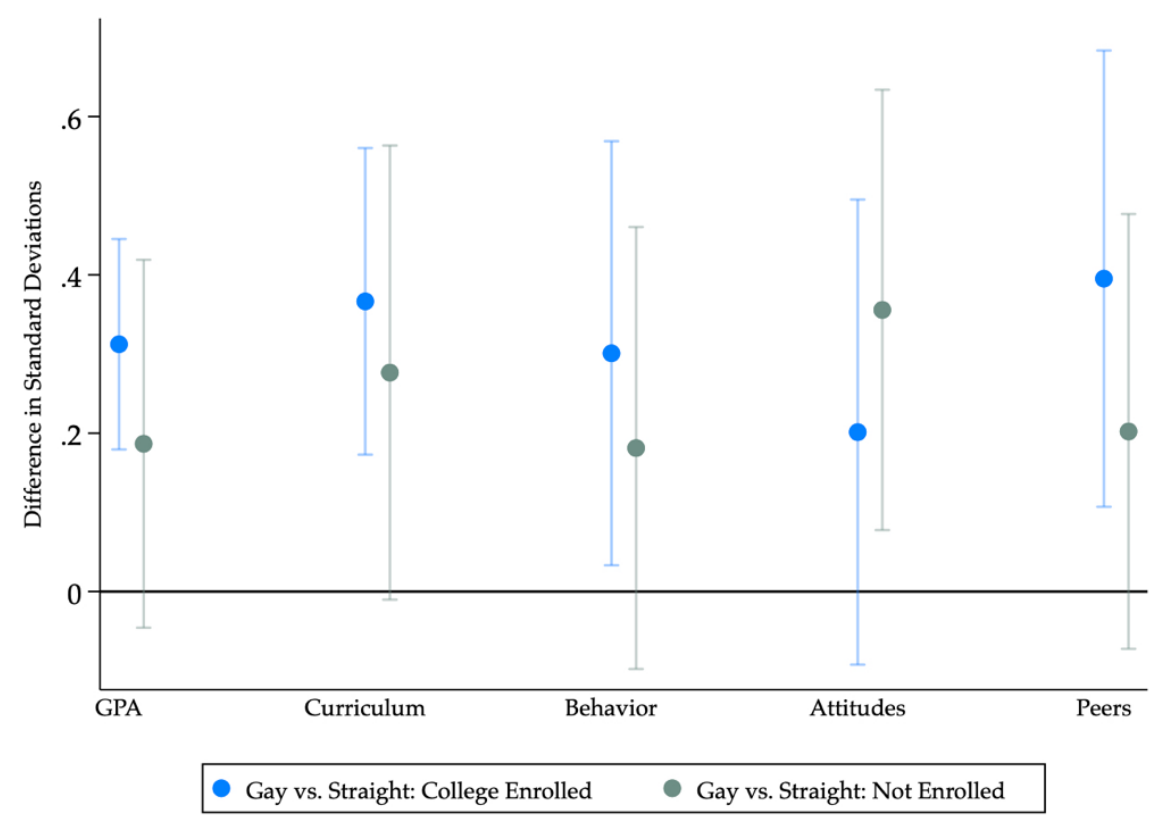

Note: Presented estimates are the average marginal effect of a gay identity, calculated from the two-way interaction of sexual identity-bysex in survey-weighted fixed effects regressions, controlling for students' race/ethnicity, native English speaking, parents' socioeconomic status and sample high school fixed effects. Regression samples were stratified between those were and were enrolled for BA at the time of the 2016 survey. 
Online Figure 9: Undergraduate GPA Disparities by Sex and Sexual Identity: B\&B 16/17

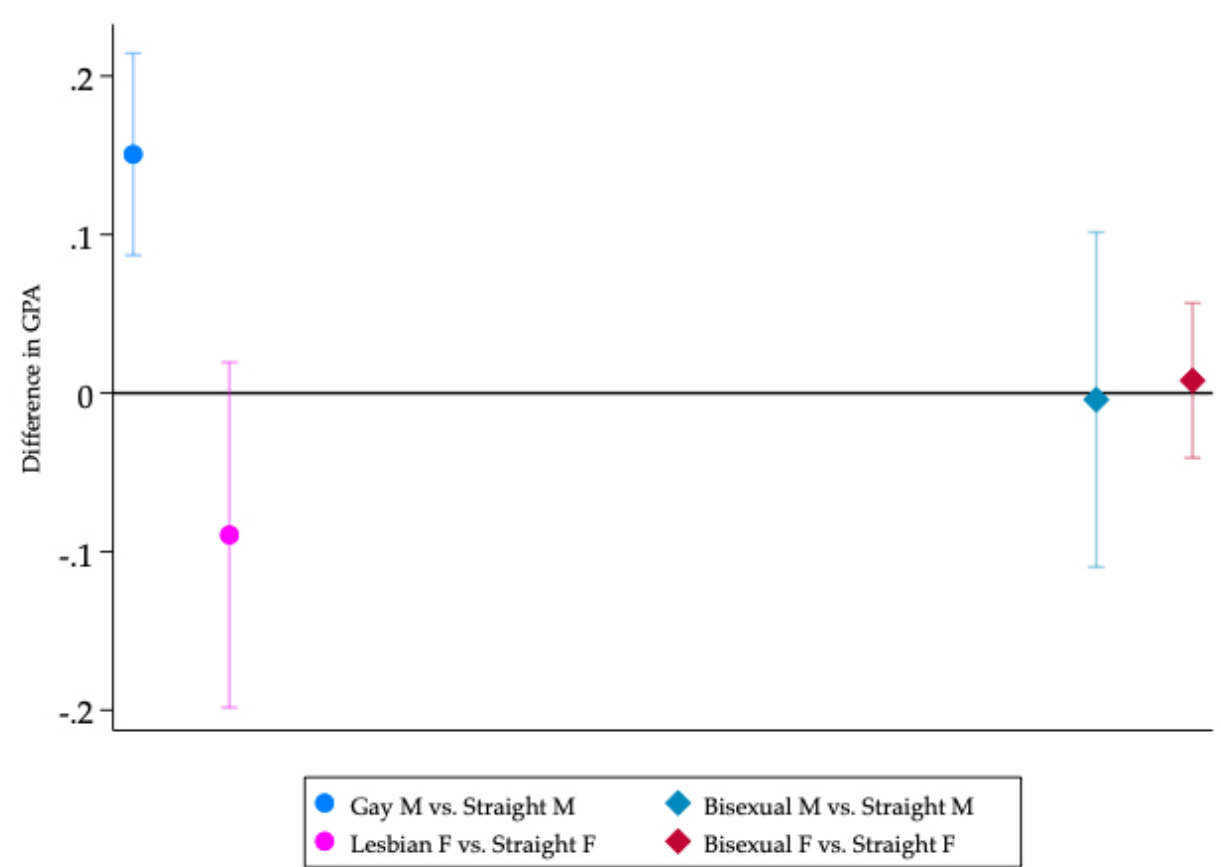

Note: Data are from 2016/17 Baccalaureate and Beyond Longitudinal Study $(N \approx 19,490)$. Presented estimates are the average marginal effect of an L/G/B identity, calculated from the two-way interaction of sexual identity-by-sex in a survey-weighted regression controlling for students' race/ethnicity, nativity and parents' education. 
Regression Results for Figure 2: Bachelor's Degree Attainment by Sex and Sexuality

\begin{tabular}{|c|c|c|c|}
\hline & NHIS & NSDUH & NCVS \\
\hline \multirow[t]{2}{*}{ Female } & 0.02 & $0.04 *$ & $-0.06 * * *$ \\
\hline & $(0.01)$ & $(0.02)$ & $(0.01)$ \\
\hline \multirow[t]{2}{*}{ Gay/Lesbian (Ref: Straight) } & $0.80 * * *$ & $0.74 * * *$ & $0.68 * * *$ \\
\hline & $(0.06)$ & $(0.08)$ & $(0.07)$ \\
\hline \multirow[t]{2}{*}{$\mathrm{Bi}$} & 0.12 & 0.13 & 0.14 \\
\hline & $(0.12)$ & $(0.09)$ & $(0.19)$ \\
\hline \multirow[t]{2}{*}{ Female X Gay/Lesbian } & $-0.38 * * *$ & $-0.47 * * *$ & $-0.27^{*}$ \\
\hline & $(0.10)$ & $(0.12)$ & $(0.11)$ \\
\hline \multirow[t]{2}{*}{ Female X Bi } & -0.20 & $-0.37 * * *$ & -0.27 \\
\hline & $(0.14)$ & $(0.11)$ & $(0.22)$ \\
\hline \multirow[t]{2}{*}{ Don't Know Sexual Identity } & $-0.52 * * *$ & $-0.82 * * *$ & $-0.48^{* * *}$ \\
\hline & $(0.13)$ & $(0.22)$ & $(0.13)$ \\
\hline \multirow[t]{2}{*}{ Refused Sexual Identity } & $0.27 * *$ & $-0.89 * * *$ & $0.17 * * *$ \\
\hline & $(0.08)$ & $(0.16)$ & $(0.04)$ \\
\hline \multirow[t]{2}{*}{ Other Sexual Identity } & -0.18 & & $0.30^{*}$ \\
\hline & $(0.11)$ & & $(0.15)$ \\
\hline \multirow[t]{2}{*}{ Black (Ref: White) } & $-0.73 * * *$ & $-0.82 * * *$ & $-0.73 * * *$ \\
\hline & $(0.03)$ & $(0.03)$ & $(0.02)$ \\
\hline \multirow[t]{2}{*}{ Hispanic } & $-1.24 * * *$ & $-0.71 * * *$ & $-1.13 * * *$ \\
\hline & $(0.04)$ & $(0.03)$ & $(0.03)$ \\
\hline \multirow[t]{2}{*}{ Asian } & $0.67 * * *$ & $1.33 * * *$ & $0.91 * * *$ \\
\hline & $(0.04)$ & $(0.05)$ & $(0.04)$ \\
\hline \multirow[t]{2}{*}{ Other } & $-1.30 * * *$ & $-0.85 * * *$ & $-0.60 * * *$ \\
\hline & $(0.08)$ & $(0.05)$ & $(0.05)$ \\
\hline \multirow[t]{2}{*}{ Born Outside USA } & $-0.22 * * *$ & $-1.38 * * *$ & $-0.11 * * *$ \\
\hline & $(0.03)$ & $(0.11)$ & $(0.02)$ \\
\hline \multirow[t]{2}{*}{ 50-59 (Ref: Born Before 1950) } & $0.26^{* * *}$ & 0.04 & $0.21 * * *$ \\
\hline & $(0.02)$ & $(0.03)$ & $(0.02)$ \\
\hline \multirow[t]{2}{*}{$60-69$} & $0.35 * * *$ & $0.14 * * *$ & $0.29 * * *$ \\
\hline & $(0.02)$ & $(0.03)$ & $(0.02)$ \\
\hline \multirow[t]{2}{*}{$70-79$} & $0.65 * * *$ & $0.35 * * *$ & $0.60 * * *$ \\
\hline & $(0.02)$ & $(0.03)$ & $(0.02)$ \\
\hline$>1980$ & $\begin{array}{c}0.71 * * * \\
(0.02)\end{array}$ & $\begin{array}{c}0.33 * * * \\
(0.03)\end{array}$ & $\begin{array}{c}0.64 * * * \\
(0.02)\end{array}$ \\
\hline Constant & $\begin{array}{c}-0.72 * * * \\
(0.03)\end{array}$ & $\begin{array}{c}-0.68 * * * \\
(0.03)\end{array}$ & $\begin{array}{c}-0.64 * * * \\
(0.03)\end{array}$ \\
\hline Observations & 197,277 & 149,189 & 141,567 \\
\hline
\end{tabular}


Regression Results for Figure 3: Differences in Bachelor's Degree Attainment, by Sex, Sexuality and Race/Ethnicity, American Adults 25+

\begin{tabular}{|c|c|c|c|}
\hline & NHIS & NSDUH & NCVS \\
\hline \multirow[t]{2}{*}{ Female } & 0.01 & -0.01 & $-0.07 * * *$ \\
\hline & $(0.02)$ & $(0.02)$ & $(0.02)$ \\
\hline \multirow[t]{2}{*}{ Gay/Lesbian } & $0.77 * * *$ & $0.70 * * *$ & $0.68 * * *$ \\
\hline & $(0.07)$ & $(0.09)$ & $(0.08)$ \\
\hline \multirow[t]{2}{*}{$\mathrm{Bi}$} & 0.05 & 0.05 & 0.01 \\
\hline & $(0.14)$ & $(0.12)$ & $(0.22)$ \\
\hline \multirow[t]{2}{*}{ Female X Gay/Lesbian } & -0.21 & $-0.29 *$ & -0.16 \\
\hline & $(0.11)$ & $(0.13)$ & $(0.13)$ \\
\hline \multirow[t]{2}{*}{ Female X Bi } & -0.03 & $-0.34^{*}$ & -0.09 \\
\hline & $(0.16)$ & $(0.13)$ & $(0.25)$ \\
\hline \multirow[t]{2}{*}{ Black } & $-0.77 * * *$ & $-1.00 * * *$ & $-0.78 * * *$ \\
\hline & $(0.04)$ & $(0.04)$ & $(0.03)$ \\
\hline \multirow[t]{2}{*}{ Hispanic } & $-1.32 * * *$ & $-0.80 * * *$ & $-1.13 * * *$ \\
\hline & $(0.05)$ & $(0.05)$ & $(0.04)$ \\
\hline \multirow[t]{2}{*}{ Asian } & $0.74 * * *$ & $1.41 * * *$ & $1.01 * * *$ \\
\hline & $(0.06)$ & $(0.07)$ & $(0.05)$ \\
\hline \multirow[t]{2}{*}{ Other } & $-1.22 * * *$ & $-0.97 * * *$ & $-0.64 * * *$ \\
\hline & $(0.11)$ & $(0.07)$ & $(0.07)$ \\
\hline \multirow[t]{2}{*}{ Female X Black } & $0.10^{*}$ & $0.31 * * *$ & $0.12 * *$ \\
\hline & $(0.05)$ & $(0.05)$ & $(0.04)$ \\
\hline \multirow[t]{2}{*}{ Female X Hispanic } & $0.12 *$ & $0.18^{* *}$ & 0.01 \\
\hline & $(0.05)$ & $(0.05)$ & $(0.05)$ \\
\hline \multirow[t]{2}{*}{ Female X Asian } & $-0.12 *$ & -0.14 & $-0.22 * * *$ \\
\hline & $(0.06)$ & $(0.08)$ & $(0.06)$ \\
\hline \multirow[t]{2}{*}{ Female X Other } & -0.14 & $0.19^{*}$ & 0.06 \\
\hline & $(0.14)$ & $(0.09)$ & $(0.10)$ \\
\hline \multirow[t]{2}{*}{ Gay/Lesbian X Black } & -0.36 & 0.13 & -0.12 \\
\hline & $(0.24)$ & $(0.26)$ & $(0.26)$ \\
\hline \multirow[t]{2}{*}{ Gay/Lesbian X Hispanic } & $0.55^{* *}$ & 0.28 & 0.14 \\
\hline & $(0.19)$ & $(0.25)$ & $(0.21)$ \\
\hline \multirow[t]{2}{*}{ Gay/Lesbian X Asian } & -0.20 & -0.06 & 0.20 \\
\hline & $(0.50)$ & $(0.42)$ & $(0.55)$ \\
\hline \multirow[t]{2}{*}{ Gay/Lesbian X Other } & -0.72 & -0.17 & -0.35 \\
\hline & $(0.60)$ & $(0.52)$ & $(0.50)$ \\
\hline \multirow[t]{2}{*}{ Bi X Black } & -0.14 & $0.78^{* *}$ & 0.11 \\
\hline & $(0.44)$ & $(0.29)$ & $(0.61)$ \\
\hline
\end{tabular}


Regression Results for Figure 3: Differences in Bachelor's Degree Attainment, by Sex, Sexuality and Race/Ethnicity, American Adults 25+

\begin{tabular}{|c|c|c|c|}
\hline & NHIS & NSDUH & NCVS \\
\hline \multirow[t]{2}{*}{ Bi X Hispanic } & 0.29 & -0.16 & 0.73 \\
\hline & $(0.39)$ & $(0.41)$ & $(0.57)$ \\
\hline \multirow[t]{2}{*}{ Bi X Asian } & $1.21 * *$ & 0.25 & 0.58 \\
\hline & $(0.47)$ & $(0.61)$ & $(0.78)$ \\
\hline \multirow[t]{2}{*}{ Bi X Other } & -0.33 & 0.27 & 0.08 \\
\hline & $(0.79)$ & $(0.41)$ & $(0.76)$ \\
\hline \multirow[t]{2}{*}{ Female X Gay/Lesbian X Black } & -0.52 & -0.59 & -0.46 \\
\hline & $(0.34)$ & $(0.30)$ & $(0.37)$ \\
\hline \multicolumn{4}{|l|}{ Female X Gay/Lesbian X } \\
\hline \multirow[t]{2}{*}{ Hispanic } & -0.38 & -0.55 & -0.34 \\
\hline & $(0.32)$ & $(0.31)$ & $(0.35)$ \\
\hline \multirow[t]{2}{*}{ Female X Gay/Lesbian X Asian } & -0.65 & $-1.54 * *$ & -0.59 \\
\hline & $(0.82)$ & $(0.51)$ & $(0.77)$ \\
\hline \multirow[t]{2}{*}{ Female X Gay/Lesbian X Other } & 0.37 & -0.53 & 0.25 \\
\hline & $(0.89)$ & $(0.62)$ & $(0.66)$ \\
\hline \multirow[t]{2}{*}{ Female X Bi X Black } & -0.96 & $-0.87 * *$ & -0.52 \\
\hline & $(0.57)$ & $(0.33)$ & $(0.73)$ \\
\hline \multirow[t]{2}{*}{ Female X Bi X Hispanic } & -0.54 & 0.33 & -1.05 \\
\hline & $(0.51)$ & $(0.42)$ & $(0.71)$ \\
\hline \multirow[t]{2}{*}{ Female X Bi X Asian } & -1.21 & -0.34 & -0.37 \\
\hline & $(0.70)$ & $(0.72)$ & $(1.04)$ \\
\hline \multirow[t]{2}{*}{ Female X Bi X Other } & 0.93 & 0.52 & 0.75 \\
\hline & $(0.98)$ & $(0.47)$ & $(0.93)$ \\
\hline \multirow[t]{2}{*}{ Don't Know Sexual Identity } & $-0.52 * * *$ & $-0.82 * * *$ & $-0.48 * * *$ \\
\hline & $(0.13)$ & $(0.22)$ & $(0.13)$ \\
\hline \multirow[t]{2}{*}{ Refused Sexual Identity } & $0.27 * *$ & $-0.89 * * *$ & $0.17 * * *$ \\
\hline & $(0.08)$ & $(0.16)$ & $(0.04)$ \\
\hline \multirow[t]{2}{*}{ Other Sexual Identity } & -0.18 & & $0.30^{*}$ \\
\hline & $(0.11)$ & & $(0.15)$ \\
\hline \multirow[t]{2}{*}{ Born Outside USA } & $-0.22 * * *$ & $-1.38 * * *$ & $-0.11 * * *$ \\
\hline & $(0.03)$ & $(0.11)$ & $(0.02)$ \\
\hline \multirow[t]{2}{*}{ 50-59 (Ref: Born Before 1950) } & $0.26^{* * *}$ & 0.04 & $0.21 * * *$ \\
\hline & $(0.02)$ & $(0.03)$ & $(0.02)$ \\
\hline \multirow[t]{2}{*}{$60-69$} & $0.35 * * *$ & $0.14 * * *$ & $0.29 * * *$ \\
\hline & $(0.02)$ & $(0.03)$ & $(0.02)$ \\
\hline \multirow[t]{2}{*}{$70-79$} & $0.65 * * *$ & $0.35 * * *$ & $0.60 * * *$ \\
\hline & $(0.02)$ & $(0.03)$ & $(0.02)$ \\
\hline
\end{tabular}


Regression Results for Figure 3: Differences in Bachelor's Degree Attainment, by Sex, Sexuality and Race/Ethnicity, American Adults 25+

\begin{tabular}{lccc}
\hline & NHIS & NSDUH & NCVS \\
\hline$>1980$ & $0.71^{* * *}$ & $0.33^{* * *}$ & $0.64^{* * *}$ \\
& $(0.02)$ & $(0.03)$ & $(0.02)$ \\
Constant & $-0.71^{* * *}$ & $-0.65^{* * *}$ & $-0.64 * * *$ \\
& $(0.03)$ & $(0.03)$ & $(0.03)$ \\
\hline Observations & 197,277 & 149,189 & 141,567 \\
\hline
\end{tabular}

Note: ${ }^{*} \mathrm{p}<0.05,{ }^{* *} \mathrm{p}<0.01,{ }^{* * *} \mathrm{p}<0.001$. Results from three separate, survey-weighted logistic regressions. 
Regression Results for Figure 4: Reconstructing the "Rise of Women:" Bachelor's Degree Attainment by Sex, Sexuality and Birth Cohort

\begin{tabular}{|c|c|c|c|}
\hline & NHIS & NSDUH & NCVS \\
\hline \multirow[t]{2}{*}{ 50-59 (Ref: Born Before 1950) } & -0.00 & $-0.19 * * *$ & -0.06 \\
\hline & $(0.03)$ & $(0.04)$ & $(0.03)$ \\
\hline \multirow[t]{2}{*}{$60-69$} & -0.00 & $-0.15 * * *$ & -0.05 \\
\hline & $(0.03)$ & $(0.04)$ & $(0.03)$ \\
\hline \multirow[t]{2}{*}{$70-79$} & $0.28 * * *$ & -0.03 & $0.24 * * *$ \\
\hline & $(0.03)$ & $(0.03)$ & $(0.03)$ \\
\hline \multirow[t]{2}{*}{$>1980$} & $0.30 * * *$ & -0.05 & $0.29 * * *$ \\
\hline & $(0.03)$ & $(0.03)$ & $(0.03)$ \\
\hline \multirow[t]{2}{*}{ Female } & $-0.52 * * *$ & $-0.50 * * *$ & $-0.62 * * *$ \\
\hline & $(0.03)$ & $(0.04)$ & $(0.03)$ \\
\hline \multirow[t]{2}{*}{ 50-59 X Female } & $0.48 * * *$ & $0.44 * * *$ & $0.50 * * *$ \\
\hline & $(0.04)$ & $(0.06)$ & $(0.04)$ \\
\hline \multirow[t]{2}{*}{ 60-69 X Female } & $0.65^{* * *}$ & $0.58 * * *$ & $0.67 * * *$ \\
\hline & $(0.04)$ & $(0.06)$ & $(0.04)$ \\
\hline \multirow[t]{2}{*}{ 70-79 X Female } & $0.68 * * *$ & $0.76^{* * *}$ & $0.72 * * *$ \\
\hline & $(0.04)$ & $(0.05)$ & $(0.04)$ \\
\hline \multirow[t]{2}{*}{$>1980$ X Female } & $0.80 * * *$ & $0.78 * * *$ & $0.70 * * *$ \\
\hline & $(0.04)$ & $(0.05)$ & $(0.04)$ \\
\hline \multirow[t]{2}{*}{ Gay/Lesbian (Ref: Straight) } & $0.94 * * *$ & $1.20 * * *$ & $0.79 * *$ \\
\hline & $(0.18)$ & $(0.30)$ & $(0.25)$ \\
\hline \multirow[t]{2}{*}{ 50-59 X Gay/Lesbian } & 0.08 & -0.65 & 0.17 \\
\hline & $(0.23)$ & $(0.35)$ & $(0.31)$ \\
\hline \multirow[t]{2}{*}{ 60-69 X Gay/Lesbian } & -0.11 & -0.35 & -0.02 \\
\hline & $(0.21)$ & $(0.30)$ & $(0.29)$ \\
\hline \multirow[t]{2}{*}{ 70-79 X Gay/Lesbian } & -0.18 & -0.56 & -0.30 \\
\hline & $(0.24)$ & $(0.34)$ & $(0.30)$ \\
\hline \multirow[t]{2}{*}{ >1980 X Gay/Lesbian } & -0.21 & -0.40 & -0.11 \\
\hline & $(0.22)$ & $(0.31)$ & $(0.28)$ \\
\hline \multirow[t]{2}{*}{ Female X Gay/Lesbian } & 0.19 & -0.36 & 0.21 \\
\hline & $(0.26)$ & $(0.47)$ & $(0.42)$ \\
\hline \multirow[t]{2}{*}{ 50-59 X Female X Gay/Lesbian } & -0.33 & 0.15 & -0.40 \\
\hline & $(0.32)$ & $(0.51)$ & $(0.51)$ \\
\hline \multirow[t]{2}{*}{ 60-69 X Female X Gay/Lesbian } & -0.35 & 0.05 & -0.32 \\
\hline & $(0.33)$ & $(0.50)$ & $(0.48)$ \\
\hline \multirow[t]{2}{*}{ 70-79 X Female X Gay/Lesbian } & $-0.73 *$ & -0.08 & -0.39 \\
\hline & $(0.34)$ & $(0.54)$ & $(0.49)$ \\
\hline \multirow[t]{2}{*}{ >1980 X Female X Gay/Lesbian } & $-1.11 * *$ & -0.58 & -0.84 \\
\hline & $(0.34)$ & $(0.48)$ & $(0.46)$ \\
\hline \multirow[t]{2}{*}{$\mathrm{Bi}$} & $0.62 *$ & $0.59 *$ & 1.30 \\
\hline & $(0.27)$ & $(0.28)$ & $(0.71)$ \\
\hline
\end{tabular}


Regression Results for Figure 4: Reconstructing the "Rise of Women:" Bachelor's Degree Attainment by Sex, Sexuality and Birth Cohort (Continued)

\begin{tabular}{|c|c|c|c|}
\hline 50-59 X Bi & $\begin{array}{l}-0.36 \\
(0.42)\end{array}$ & $\begin{array}{l}0.28 \\
(0.35)\end{array}$ & $\begin{array}{l}-0.18 \\
(0.88)\end{array}$ \\
\hline \multirow[t]{2}{*}{$60-69 \times \mathrm{Bi}$} & -0.26 & -0.68 & -1.01 \\
\hline & $(0.39)$ & $(0.51)$ & $(0.81)$ \\
\hline \multirow[t]{2}{*}{ 70-79 X Bi } & -0.23 & -0.33 & $-1.93 *$ \\
\hline & $(0.44)$ & $(0.35)$ & $(0.93)$ \\
\hline \multirow[t]{2}{*}{$>1980$ X Bi } & $-0.79 *$ & $-0.87 * *$ & -1.25 \\
\hline & $(0.34)$ & $(0.31)$ & $(0.76)$ \\
\hline \multirow[t]{2}{*}{ Female X Bi } & -0.01 & -0.01 & -0.34 \\
\hline & $(0.44)$ & $(0.70)$ & $(0.87)$ \\
\hline \multirow[t]{2}{*}{ 50-59 X Female X Bi } & -0.05 & -0.38 & -0.32 \\
\hline & $(0.62)$ & $(0.71)$ & $(1.08)$ \\
\hline \multirow[t]{2}{*}{ 60-69 X Female X Bi } & -0.25 & 0.06 & 0.02 \\
\hline & $(0.55)$ & $(0.80)$ & $(1.01)$ \\
\hline \multirow[t]{2}{*}{ 70-79 X Female X Bi } & -0.40 & -0.54 & 0.79 \\
\hline & $(0.59)$ & $(0.69)$ & $(1.08)$ \\
\hline \multirow[t]{2}{*}{ >1980 X Female X Bi } & -0.17 & -0.25 & -0.04 \\
\hline & $(0.50)$ & $(0.75)$ & $(0.91)$ \\
\hline \multirow[t]{2}{*}{ Don't Know Sexual Identity } & $-0.53 * * *$ & $-0.86 * * *$ & $-0.49 * * *$ \\
\hline & $(0.13)$ & $(0.22)$ & $(0.13)$ \\
\hline \multirow[t]{2}{*}{ Refused Sexual Identity } & $0.28 * * *$ & $-0.90 * * *$ & $0.18 * * *$ \\
\hline & $(0.08)$ & $(0.17)$ & $(0.04)$ \\
\hline \multirow[t]{2}{*}{ Other Sexual Identity } & -0.20 & & $0.29 *$ \\
\hline & $(0.11)$ & & $(0.15)$ \\
\hline \multirow[t]{2}{*}{ Black (Ref: White) } & $-0.73 * * *$ & $-0.82 * * *$ & $-0.73 * * *$ \\
\hline & $(0.03)$ & $(0.03)$ & $(0.02)$ \\
\hline \multirow[t]{2}{*}{ Hispanic } & $-1.25 * * *$ & $-0.71 * * *$ & $-1.13 * * *$ \\
\hline & $(0.04)$ & $(0.03)$ & $(0.03)$ \\
\hline \multirow[t]{2}{*}{ Asian } & $0.67 * * *$ & $1.33 * * *$ & $0.91 * * *$ \\
\hline & $(0.04)$ & $(0.05)$ & $(0.04)$ \\
\hline \multirow[t]{2}{*}{ Other } & $-1.31 * * *$ & $-0.85 * * *$ & $-0.61 * * *$ \\
\hline & $(0.08)$ & $(0.05)$ & $(0.05)$ \\
\hline \multirow[t]{2}{*}{ Born Outside USA } & $-0.22 * * *$ & $-1.38 * * *$ & $-0.10 * * *$ \\
\hline & $(0.03)$ & $(0.11)$ & $(0.02)$ \\
\hline \multirow[t]{2}{*}{ Constant } & $-0.42 * * *$ & $-0.41 * * *$ & $-0.36 * * *$ \\
\hline & $(0.03)$ & $(0.03)$ & $(0.03)$ \\
\hline Observations & 197,277 & 149,189 & 141,567 \\
\hline
\end{tabular}


Regression Results for Figure 5: Bachelor's Degree Attainment or Enrollment, by Sex and Sexuality, Among Contemporary Cohorts: Adult Datasets

\begin{tabular}{|c|c|c|c|}
\hline & NHIS & NSDUH & NCVS \\
\hline \multirow[t]{2}{*}{ Female } & $0.28 * * *$ & $0.29 * * *$ & $0.10 * * *$ \\
\hline & $(0.03)$ & $(0.02)$ & $(0.03)$ \\
\hline \multirow[t]{2}{*}{ Gay/Lesbian (Ref: Straight) } & $0.75^{* * *}$ & $0.84 * * *$ & $0.71 * * *$ \\
\hline & $(0.13)$ & $(0.10)$ & $(0.12)$ \\
\hline \multirow[t]{2}{*}{$\mathrm{Bi}$} & -0.15 & $-0.26^{*}$ & 0.06 \\
\hline & $(0.20)$ & $(0.11)$ & $(0.27)$ \\
\hline \multirow[t]{2}{*}{ Female X Gay/Lesbian } & $-0.94 * * *$ & $-0.95 * * *$ & $-0.64 * * *$ \\
\hline & $(0.20)$ & $(0.13)$ & $(0.18)$ \\
\hline \multirow[t]{2}{*}{ Female X Bi } & -0.19 & $-0.26^{*}$ & -0.37 \\
\hline & $(0.23)$ & $(0.13)$ & $(0.31)$ \\
\hline \multirow[t]{2}{*}{ Don't Know Sexual Identity } & -0.53 & -0.51 & -0.37 \\
\hline & $(0.34)$ & $(0.27)$ & $(0.25)$ \\
\hline \multirow[t]{2}{*}{ Refused Sexual Identity } & 0.16 & $-0.55 * *$ & $0.18^{*}$ \\
\hline & $(0.21)$ & $(0.20)$ & $(0.08)$ \\
\hline \multirow[t]{2}{*}{ Other Sexual Identity } & -0.32 & & 0.35 \\
\hline & $(0.18)$ & & $(0.22)$ \\
\hline \multirow[t]{2}{*}{ Black (Ref: White) } & $-0.80 * * *$ & $-0.93 * * *$ & $-0.81 * * *$ \\
\hline & $(0.05)$ & $(0.04)$ & $(0.04)$ \\
\hline \multirow[t]{2}{*}{ Hispanic } & $-1.25 * * *$ & $-0.88 * * *$ & $-1.22 * * *$ \\
\hline & $(0.06)$ & $(0.04)$ & $(0.04)$ \\
\hline \multirow[t]{2}{*}{ Asian } & $0.98 * * *$ & $1.42 * * *$ & $1.25^{* * *}$ \\
\hline & $(0.09)$ & $(0.06)$ & $(0.06)$ \\
\hline \multirow[t]{2}{*}{ Other } & $-1.39 * * *$ & $-0.86 * * *$ & $-0.60 * * *$ \\
\hline & $(0.12)$ & $(0.06)$ & $(0.08)$ \\
\hline \multirow[t]{2}{*}{ Born Outside USA } & $-0.18 * * *$ & $-1.23 * * *$ & $-0.14 * * *$ \\
\hline & $(0.05)$ & $(0.11)$ & $(0.04)$ \\
\hline \multirow[t]{2}{*}{ Age } & $0.01 * *$ & $0.02 * * *$ & $0.01 *$ \\
\hline & $(0.00)$ & $(0.00)$ & $(0.00)$ \\
\hline \multirow[t]{2}{*}{ Constant } & $-0.55 * * *$ & $-0.95 * * *$ & $-0.27 *$ \\
\hline & $(0.14)$ & $(0.09)$ & $(0.11)$ \\
\hline Observations & 40,709 & 62,607 & 36,057 \\
\hline
\end{tabular}


Regression Results for Figure 6: HSLS Attainment Results

\begin{tabular}{|c|c|c|c|}
\hline & BA Enrollment & HS Diploma & Ever "Dropped Out" HS \\
\hline \multirow[t]{2}{*}{ Gay/Lesbian (Ref: Straight) } & $0.17 * * *$ & -0.00 & -0.06 \\
\hline & $(0.04)$ & $(0.04)$ & $(0.03)$ \\
\hline \multirow[t]{2}{*}{$\mathrm{Bi}$} & $-0.10 * *$ & -0.03 & 0.04 \\
\hline & $(0.04)$ & $(0.03)$ & $(0.04)$ \\
\hline \multirow[t]{2}{*}{ Female } & $0.09 * * *$ & $0.03 * * *$ & $-0.04 * * *$ \\
\hline & $(0.01)$ & $(0.01)$ & $(0.01)$ \\
\hline \multirow[t]{2}{*}{ Gay/Lesbian X Female } & $-0.16^{*}$ & -0.05 & $0.17 * *$ \\
\hline & $(0.07)$ & $(0.05)$ & $(0.06)$ \\
\hline \multirow[t]{2}{*}{ Bi X Female } & -0.03 & -0.04 & 0.08 \\
\hline & $(0.05)$ & $(0.04)$ & $(0.05)$ \\
\hline \multirow[t]{2}{*}{ Another Sexual Identity } & 0.00 & -0.01 & 0.08 \\
\hline & $(0.04)$ & $(0.03)$ & $(0.04)$ \\
\hline \multirow[t]{2}{*}{ Don't Know Sexual Identity } & -0.06 & -0.06 & $0.10^{*}$ \\
\hline & $(0.03)$ & $(0.04)$ & $(0.04)$ \\
\hline \multirow[t]{2}{*}{ Black (Ref: White) } & 0.04 & 0.02 & $-0.06^{*}$ \\
\hline & $(0.02)$ & $(0.01)$ & $(0.02)$ \\
\hline \multirow[t]{2}{*}{ Hispanic } & $-0.05 *$ & -0.00 & 0.03 \\
\hline & $(0.02)$ & $(0.01)$ & $(0.02)$ \\
\hline \multirow[t]{2}{*}{ Asian } & $-0.09 * * *$ & -0.00 & 0.04 \\
\hline & $(0.02)$ & $(0.01)$ & $(0.02)$ \\
\hline \multirow[t]{2}{*}{ Native Am } & $0.08 * *$ & 0.02 & -0.02 \\
\hline & $(0.03)$ & $(0.01)$ & $(0.02)$ \\
\hline \multirow[t]{2}{*}{ Other } & 0.00 & -0.11 & 0.11 \\
\hline & $(0.06)$ & $(0.06)$ & $(0.06)$ \\
\hline \multirow[t]{2}{*}{ Native Language Not English } & $-0.07 * * *$ & 0.01 & -0.00 \\
\hline & $(0.02)$ & $(0.01)$ & $(0.02)$ \\
\hline \multirow[t]{2}{*}{ Parent SES Composite } & $0.18 * * *$ & $0.04 * * *$ & $-0.07 * * *$ \\
\hline & $(0.01)$ & $(0.01)$ & $(0.01)$ \\
\hline \multirow[t]{2}{*}{ Constant } & $0.31 * *$ & $0.94 * * *$ & $0.05^{*}$ \\
\hline & $(0.11)$ & $(0.01)$ & $(0.02)$ \\
\hline Observations & $\sim 15,270$ & $\sim 15,270$ & $\sim 15,270$ \\
\hline
\end{tabular}

Note: ${ }^{*} \mathrm{p}<0.05,{ }^{* *} \mathrm{p}<0.01,{ }^{* * *} \mathrm{p}<0.001$. Results from survey-weighted ordinary least squares school fixed effects model. 
Regression Results for Figure 6: HSLS Achievement and Course Taking Results

\begin{tabular}{|c|c|c|c|}
\hline & HS GPA & $\begin{array}{c}\text { Post-Secondary } \\
\text { GPA }\end{array}$ & $\begin{array}{c}\text { HS Curricular } \\
\text { Intensity } \\
\end{array}$ \\
\hline \multirow[t]{2}{*}{ Gay/Lesbian (Ref: Straight) } & $0.39 * * *$ & $0.48 * * *$ & $0.45^{* * *}$ \\
\hline & $(0.08)$ & $(0.09)$ & $(0.09)$ \\
\hline \multirow[t]{2}{*}{$\mathrm{Bi}$} & -0.09 & -0.24 & -0.04 \\
\hline & $(0.09)$ & $(0.14)$ & $(0.12)$ \\
\hline \multirow[t]{2}{*}{ Female } & $0.34 * * *$ & $0.29 * * *$ & $0.23 * * *$ \\
\hline & $(0.02)$ & $(0.03)$ & $(0.02)$ \\
\hline \multirow[t]{2}{*}{ Gay/Lesbian X Female } & $-0.58 * * *$ & $-0.43 * *$ & $-0.54 * * *$ \\
\hline & $(0.13)$ & $(0.16)$ & $(0.16)$ \\
\hline \multirow[t]{2}{*}{ Bi X Female } & $-0.22 *$ & -0.04 & -0.16 \\
\hline & $(0.11)$ & $(0.16)$ & $(0.14)$ \\
\hline \multirow[t]{2}{*}{ Another Sexual Identity } & -0.02 & -0.04 & 0.12 \\
\hline & $(0.08)$ & $(0.10)$ & $(0.10)$ \\
\hline \multirow[t]{2}{*}{ Don't Know Sexual Identity } & -0.14 & -0.01 & -0.19 \\
\hline & $(0.09)$ & $(0.12)$ & $(0.12)$ \\
\hline \multirow[t]{2}{*}{ Black (Ref: White) } & $0.18 * * *$ & $0.15^{*}$ & $0.21 * * *$ \\
\hline & $(0.04)$ & $(0.07)$ & $(0.05)$ \\
\hline \multirow[t]{2}{*}{ Hispanic } & $-0.37 * * *$ & $-0.59 * * *$ & $-0.19 * * *$ \\
\hline & $(0.04)$ & $(0.06)$ & $(0.05)$ \\
\hline \multirow[t]{2}{*}{ Asian } & $-0.28 * * *$ & $-0.26 * * *$ & $-0.20 * * *$ \\
\hline & $(0.04)$ & $(0.06)$ & $(0.05)$ \\
\hline \multirow[t]{2}{*}{ Native Am } & $0.22 * * *$ & 0.03 & $0.35 * * *$ \\
\hline & $(0.05)$ & $(0.07)$ & $(0.06)$ \\
\hline \multirow[t]{2}{*}{ Other } & $-0.55 * * *$ & -0.25 & $-0.34 *$ \\
\hline & $(0.14)$ & $(0.15)$ & $(0.15)$ \\
\hline \multirow[t]{2}{*}{ Native Language Not English } & $-0.23 * * *$ & $-0.26 * * *$ & $-0.11 * *$ \\
\hline & $(0.04)$ & $(0.06)$ & $(0.04)$ \\
\hline \multirow[t]{2}{*}{ Parent SES Composite } & $0.34 * * *$ & $0.21 * * *$ & $0.34 * * *$ \\
\hline & $(0.02)$ & $(0.02)$ & $(0.02)$ \\
\hline \multirow[t]{2}{*}{ Constant } & 0.09 & $-0.72 *$ & $-0.35^{*}$ \\
\hline & $(0.16)$ & $(0.28)$ & $(0.14)$ \\
\hline Observations & $\sim 15,270$ & $\sim 9,580$ & $\sim 15,270$ \\
\hline
\end{tabular}


Regression Results for Figure 6: HSLS Attitudes and Behaviors

\begin{tabular}{|c|c|c|c|}
\hline & Effort and Behavior & Pro-School Attitudes & $\begin{array}{c}\text { Peer Academic } \\
\text { Orientation }\end{array}$ \\
\hline \multirow[t]{2}{*}{ Gay/Lesbian (Ref: Straight) } & $0.29 * *$ & $0.38^{* * *}$ & $0.36 * * *$ \\
\hline & $(0.10)$ & $(0.10)$ & $(0.10)$ \\
\hline \multirow[t]{2}{*}{$\mathrm{Bi}$} & 0.08 & -0.13 & 0.11 \\
\hline & $(0.11)$ & $(0.10)$ & $(0.11)$ \\
\hline \multirow[t]{2}{*}{ Female } & $0.34 * * *$ & $0.23 * * *$ & $0.23 * * *$ \\
\hline & $(0.03)$ & $(0.03)$ & $(0.03)$ \\
\hline \multirow{2}{*}{ Gay/Lesbian X Female } & $-0.40 * *$ & $-0.68 * * *$ & $-0.57 * * *$ \\
\hline & $(0.15)$ & $(0.17)$ & $(0.15)$ \\
\hline \multirow[t]{2}{*}{ Bi X Female } & $-0.28 *$ & -0.15 & $-0.37 * *$ \\
\hline & $(0.13)$ & $(0.13)$ & $(0.13)$ \\
\hline \multirow[t]{2}{*}{ Another Sexual Identity } & -0.10 & -0.13 & $-0.21 *$ \\
\hline & $(0.08)$ & $(0.11)$ & $(0.09)$ \\
\hline \multirow[t]{2}{*}{ Don't Know Sexual Identity } & -0.09 & $-0.24 *$ & -0.17 \\
\hline & $(0.13)$ & $(0.11)$ & $(0.09)$ \\
\hline \multirow[t]{2}{*}{ Black (Ref: White) } & -0.03 & -0.07 & 0.08 \\
\hline & $(0.06)$ & $(0.06)$ & $(0.05)$ \\
\hline \multirow[t]{2}{*}{ Hispanic } & -0.11 & -0.09 & -0.06 \\
\hline & $(0.06)$ & $(0.05)$ & $(0.05)$ \\
\hline \multirow[t]{2}{*}{ Asian } & -0.09 & -0.00 & $-0.23 * * *$ \\
\hline & $(0.06)$ & $(0.06)$ & $(0.05)$ \\
\hline \multirow[t]{2}{*}{ Native Am } & $0.27 * * *$ & $0.18^{*}$ & $0.21 * * *$ \\
\hline & $(0.08)$ & $(0.08)$ & $(0.06)$ \\
\hline \multirow[t]{2}{*}{ Other } & $-0.37 *$ & 0.05 & $-0.27 *$ \\
\hline & $(0.17)$ & $(0.14)$ & $(0.13)$ \\
\hline \multirow[t]{2}{*}{ Native Language Not English } & -0.04 & $-0.14 * *$ & $-0.12^{*}$ \\
\hline & $(0.05)$ & $(0.05)$ & $(0.05)$ \\
\hline \multirow[t]{2}{*}{ Parent SES Composite } & $0.11 * * *$ & $0.16^{* * *}$ & $0.30 * * *$ \\
\hline & $(0.02)$ & $(0.02)$ & $(0.02)$ \\
\hline \multirow[t]{2}{*}{ Constant } & 0.50 & -0.29 & -0.02 \\
\hline & $(0.27)$ & $(0.40)$ & $(0.22)$ \\
\hline Observations & $\sim 15,270$ & $\sim 15,270$ & $\sim 15,270$ \\
\hline
\end{tabular}

Note: ${ }^{*} \mathrm{p}<0.05,{ }^{* *} \mathrm{p}<0.01,{ }^{* * *} \mathrm{p}<0.001$. Results from survey-weighted ordinary least squares school fixed effects model. 
Regression Results for Figure 6: HSLS Discrimination and Minority Stress

\begin{tabular}{|c|c|c|c|}
\hline & $\begin{array}{l}\text { Feel Unsafe in } \\
\text { School }\end{array}$ & $\begin{array}{l}\text { Discriminatio } \\
\text { Limited } \\
\text { Education }\end{array}$ & $\begin{array}{c}\text { Trouble Concentrating B/C } \\
\text { Mental Health }\end{array}$ \\
\hline \multirow[t]{2}{*}{ Gay/Lesbian (Ref: Straight) } & $0.09 *$ & $0.11 *$ & $0.09 *$ \\
\hline & $(0.04)$ & $(0.04)$ & $(0.04)$ \\
\hline \multirow[t]{2}{*}{$\mathrm{Bi}$} & 0.07 & 0.05 & $0.20 * * *$ \\
\hline & $(0.04)$ & $(0.04)$ & $(0.05)$ \\
\hline \multirow[t]{2}{*}{ Female } & $-0.02 * *$ & -0.01 & $0.04 * * *$ \\
\hline & $(0.01)$ & $(0.01)$ & $(0.01)$ \\
\hline \multirow[t]{2}{*}{ Gay/Lesbian X Female } & -0.08 & -0.05 & 0.04 \\
\hline & $(0.05)$ & $(0.06)$ & $(0.07)$ \\
\hline \multirow[t]{2}{*}{ Bi X Female } & 0.02 & -0.00 & -0.04 \\
\hline & $(0.06)$ & $(0.05)$ & $(0.06)$ \\
\hline \multirow[t]{2}{*}{ Another Sexual Identity } & 0.08 & 0.03 & $0.17 * * *$ \\
\hline & $(0.04)$ & $(0.04)$ & $(0.04)$ \\
\hline \multirow[t]{2}{*}{ Don't Know Sexual Identity } & 0.01 & 0.05 & $0.12 * *$ \\
\hline & $(0.04)$ & $(0.04)$ & $(0.05)$ \\
\hline \multirow[t]{2}{*}{ Black (Ref: White) } & 0.01 & 0.02 & -0.03 \\
\hline & $(0.02)$ & $(0.02)$ & $(0.02)$ \\
\hline \multirow[t]{2}{*}{ Hispanic } & 0.00 & $0.08 * * *$ & $-0.04 * *$ \\
\hline & $(0.02)$ & $(0.02)$ & $(0.01)$ \\
\hline \multirow[t]{2}{*}{ Asian } & 0.01 & $0.06 * *$ & 0.02 \\
\hline & $(0.01)$ & $(0.02)$ & $(0.02)$ \\
\hline \multirow[t]{2}{*}{ Native Am } & 0.01 & $0.09 * * *$ & -0.01 \\
\hline & $(0.02)$ & $(0.03)$ & $(0.02)$ \\
\hline \multirow[t]{2}{*}{ Other } & -0.01 & 0.05 & 0.02 \\
\hline & $(0.07)$ & $(0.06)$ & $(0.06)$ \\
\hline \multirow[t]{2}{*}{ Native Language Not English } & $0.05 *$ & $0.04 *$ & 0.01 \\
\hline & $(0.02)$ & $(0.02)$ & $(0.02)$ \\
\hline \multirow[t]{2}{*}{ Parent SES Composite } & -0.01 & $-0.03 * * *$ & 0.00 \\
\hline & $(0.01)$ & $(0.01)$ & $(0.01)$ \\
\hline \multirow[t]{2}{*}{ Constant } & 0.07 & 0.18 & 0.11 \\
\hline & $(0.07)$ & $(0.12)$ & $(0.10)$ \\
\hline Observations & $\sim 15,270$ & $\sim 15,270$ & $\sim 15,270$ \\
\hline
\end{tabular}

Note: $* \mathrm{p}<0.05,{ }^{* *} \mathrm{p}<0.01,{ }^{* * *} \mathrm{p}<0.001$. Results from survey-weighted ordinary least squares school fixed effects model. 